\title{
Le site du Petit Parc à Ménil-Froger (Orne) de la Préhistoire à la villa gallo-romaine
}

The site of Petit Parc at Ménil-Froger (Orne) from Pehistory to Gallo-Roman villa

\section{Romuald Ferrette et Laure Simon}

Traducteur : Sandra Sicard et Boris Kerampran

\section{OpenEdition} Journals

Édition électronique

URL : http://journals.openedition.org/rao/1338

DOI : $10.4000 /$ rao. 1338

ISSN : $1775-3732$

Éditeur

Presses universitaires de Rennes

\section{Édition imprimée}

Date de publication : 31 décembre 2010

Pagination : 85-127

ISBN : 978-2-7535-1383-9

ISSN : 0767-709X

Référence électronique

Romuald Ferrette et Laure Simon, « Le site du Petit Parc à Ménil-Froger (Orne) de la Préhistoire à la villa gallo-romaine », Revue archéologique de l'Ouest [En ligne], 27 | 2010, mis en ligne le 25 février 2012, consulté le 04 décembre 2020. URL : http://journals.openedition.org/rao/1338 ; DOI : https://doi.org/ 10.4000/rao.1338

Ce document a été généré automatiquement le 4 décembre 2020.

Tous droits réservés 


\title{
Le site du Petit Parc à Ménil-Froger (Orne) de la Préhistoire à la villa gallo-romaine
}

The site of Petit Parc at Ménil-Froger (Orne) from Pehistory to Gallo-Roman villa

\author{
Romuald Ferrette et Laure Simon
}

Traduction : Sandra Sicard et Boris Kerampran

L'établissement gallo-romain du Petit Parc sur la commune de Ménil-Froger (Orne) est implanté à une douzaine de kilomètres au nord-est de la ville antique et actuelle de Sées, à proximité de la frontière présumée entre les cités des Esuviens/Sagiens et des Lexoviens (fig. 1 $)^{2}$. Sa découverte s'inscrit dans le cadre de l'investigation réalisée sur le tracé de l'autoroute A 28 nord, qui relie désormais Alençon à Rouen. Des sondages mécaniques avaient démontré, au niveau de l'intersection entre le chemin rural 28 et la future autoroute, l'existence de vestiges antiques associant une villa et une partie de son terroir. Le bâtiment d'habitation était intégralement conservé dans l'emprise foncière concernée par les travaux autoroutiers, tandis que des installations annexes se développaient à l'est et au sud (Cousyn, 2003) ${ }^{3}$. 


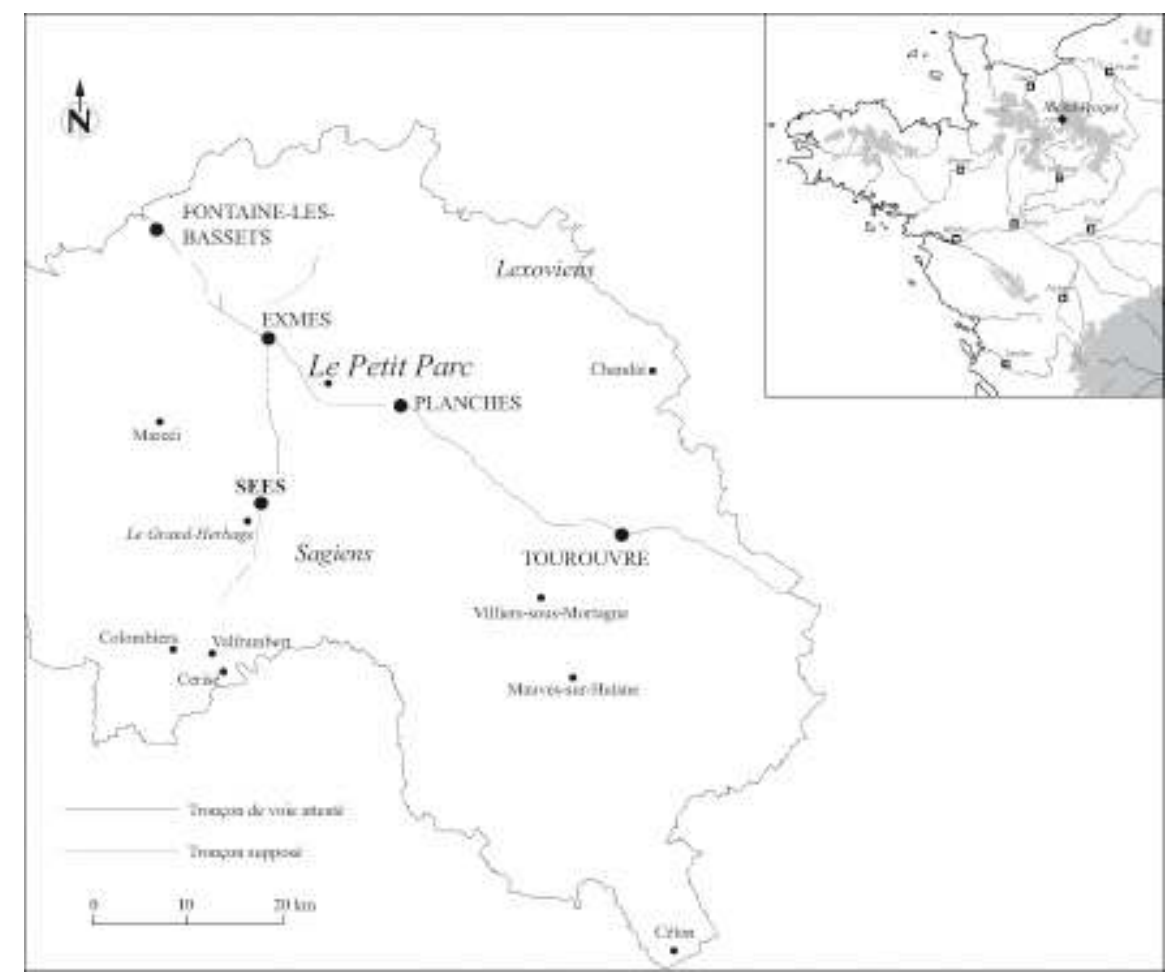

Figure 1 : Localisation du Petit Parc (en Ménil-Froger) et des lieux mentionnés dans le texte (DAO R. Ferrette/L. Simon, d'après Delrieu et Desloges, 2007).

Figure 1: Location of Petit Parc (commune of Ménil Froger) and of placenames mentionned in text.

2 L'occupation humaine s'est établie à la limite des plaines centrales limoneuses de l'Orne, plus précisément sur la retombée orientale d'un relief surplombant la vallée de la Dieuze et dont le point culminant $(221 \mathrm{~m})$ se situe plus à l'ouest, au lieu-dit le Ménil. Sur l'emprise de l'opération, l'altitude oscille d'ouest en est entre 214 et $210 \mathrm{~m}$, la villa étant installée dans la partie supérieure du versant. Le substrat, constitué d'une argile marno-sableuse entrecoupée parfois de filons de calcaire à fossiles, se rattache aux assises crétacées du Bassin Parisien. L'épaisseur de l'humus, peu importante, est en moyenne d'une vingtaine de centimètres. Cette terre, assez pauvre et peu propice à une agriculture intensive, est souvent opposée à la plaine fertile de Sées. Aujourd'hui, l'essentiel du paysage environnant est bocager et tourné vers l'élevage.

Parmi les sites remarquables qui environnent l'établissement du Petit Parc, mentionnons la ville actuelle de Sées qui recouvre l'ancienne capitale administrative de la cité des Esuviens/Sagiens. Créée à l'époque augutéenne, elle connaît une phase d'essor à partir du règne de Tibère, époque à laquelle l'oppidum d'Exmes, distant d'une dizaine de kilomètres de l'intervention, semble voir sa population diminuer (Marcigny et al., 2007, p. 77 ; Fichet de Clairfontaine et Leclerc, 2007, p. 98 ; Fichet de Clairfontaine, 1992, p. 99). L'établissement du Petit Parc est aussi localisé à proximité de deux axes de communication, dont la voie Le Mans/Lisieux qui traverse Exmes et Sées. Le second, le "Chemin Haussé», relie Vieux à Chartres en passant par les agglomérations secondaires de Fontaine-les-Bassets, Exmes, Planches et Tourouvre (Desloges, 2000). Il traverserait le village actuel de Saint-Germain-de-Clairfeuille, situé plus au sud, à moins de $2 \mathrm{~km}$ de l'intervention. 
Les vestiges découverts concernent principalement la période postérieure à la Conquête, mais la fouille a aussi mis en exergue des occupations beaucoup plus anciennes, dont la mieux renseignée intéresse la Préhistoire (fig. 2).

\section{Les occupations antérieures à l'époque gallo- romaine}

\section{La Préhistoire}

La fréquentation du secteur dès le Néolithique ancien ou moyen est attestée par sept creusements reconnus dans la partie est de l'intervention et par un corpus lithique et macrolithique constitué de 125 pièces (fig. 3 ; tab. 1 et 2).

Cinq des sept fosses de cette période appartiennent à un probable monument orienté est-ouest (F 9, 13, 22, 4 et 29). Ces creusements sont installés dans une cuvette profonde d'une dizaine de centimètres, F 5 , dont l'origine anthropique n'est pas assurée. Ses contours irréguliers sont matérialisés au sol par une couche cendreuse, qui correspond à la destruction d'un bâtiment gallo-romain sur poteaux plantés. Les fosses F 4, 13 et 22 renferment des blocs de calcaire, plus rarement de grès, noyés dans un sédiment argileux orangé à brun, qui correspond aux matériaux extraits lors de leur creusement. À l'origine, ces blocs devaient soutenir une dalle, à l'image de celle de la fosse F 9. Cette dernière accueille en effet un monolithe en grès, d'un diamètre proche de $1,5 \mathrm{~m}$, stabilisé grâce à une dizaine de pierres calcaires. Deux autres monolithes ne disposant d'aucun calage ont aussi été découverts dans la fosse F 29.

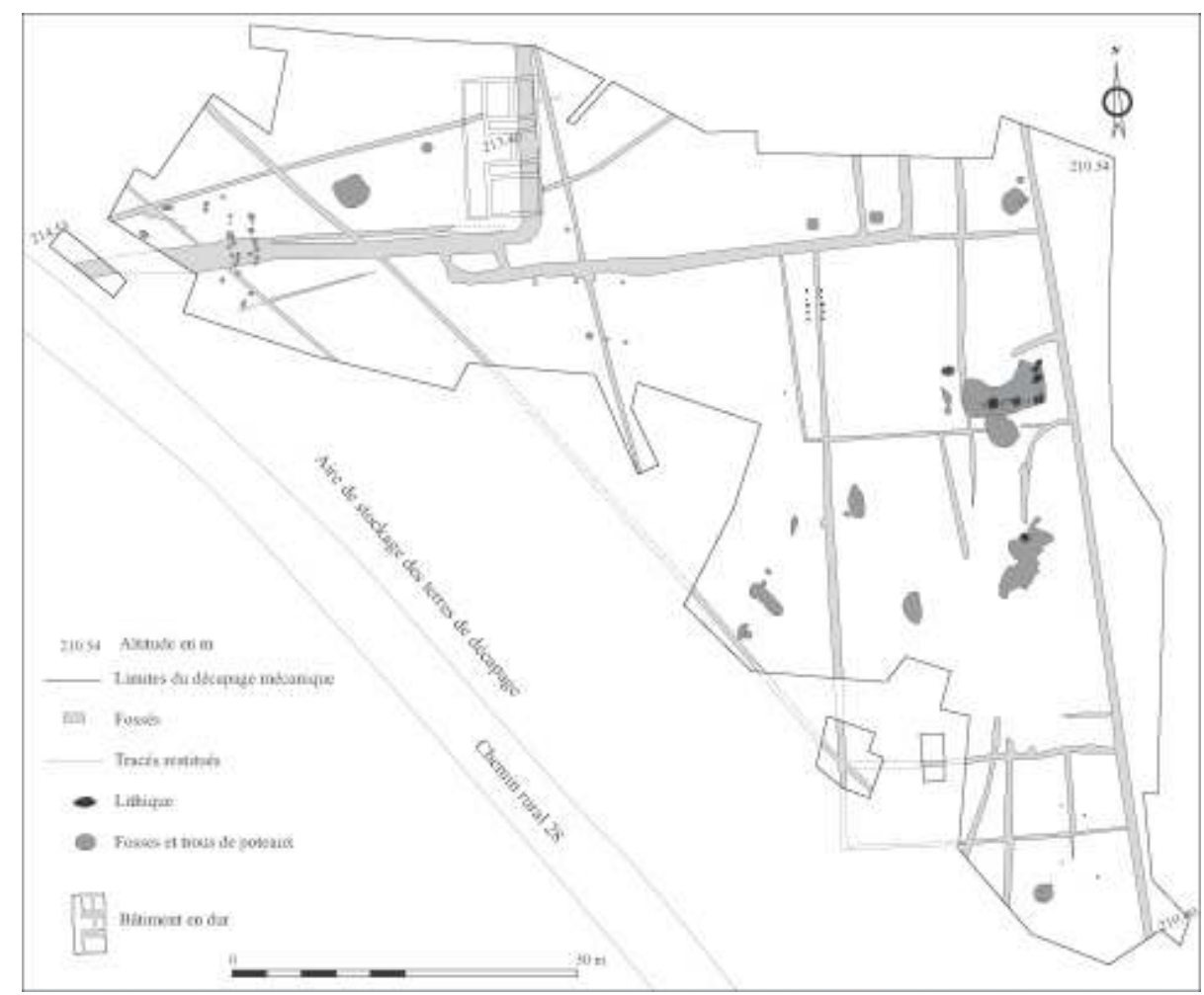

Figure 2 : Plan général du site du Petit Parc (DAO B. Kerampran/R. Ferrette).

Figure 2: General plan of Petit Parc site. 


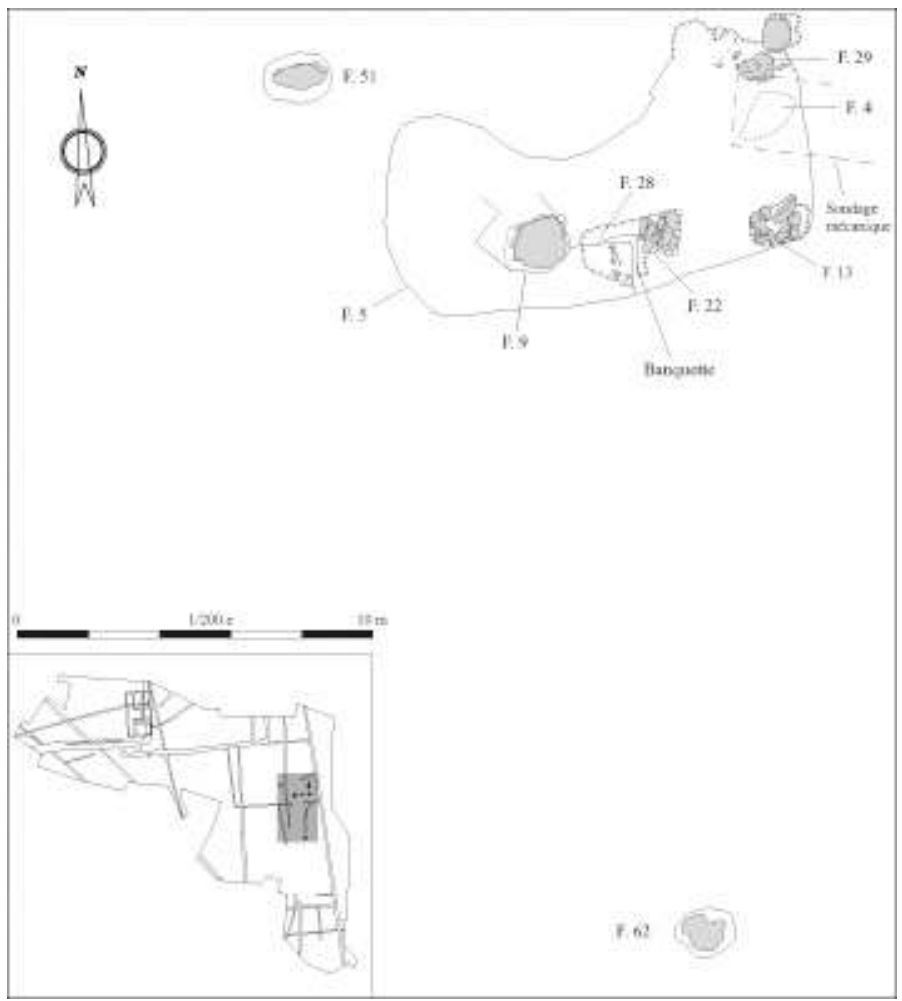

Figure 3 : Plan et localisation des aménagements attribués à la préhistoire (DAO B. Kerampran/ R. Ferrette).

Figure 3: Plan and location of features ascribed to Prehistory.

\begin{tabular}{|l|l|l|l|}
\hline Nature & Diagnostic & Fouille & Total \\
\hline Éclat brut & 19 & 16 & 35 \\
\hline Éclat laminaire & 2 & & 2 \\
\hline Lame brute & 4 & & 4 \\
\hline Cassons & 3 & 19 & 22 \\
\hline Nucléus à éclat & 1 & & 1 \\
\hline Nucléus lamellaire & 1 & 1 & 2 \\
\hline Eclat retouché & 5 & 11 & 16 \\
\hline Couteau à dos & 1 & 2 & 3 \\
\hline Lame retouchée & 1 & 2 & 3 \\
\hline Perçoir & 1 & 1 & 2 \\
\hline Troncature & 1 & 2 & 3 \\
\hline Burin & 2 & 1 & 3 \\
\hline Hache & & 2 & 2 \\
\hline Racloir & 2 & 3 & 5 \\
\hline Grattoir & 2 & 2 & 4 \\
\hline Coche & 2 & & \\
\hline
\end{tabular}




\begin{tabular}{|l|l|l|l|}
\hline Armature perçante & & 1 & 1 \\
\hline Pointe & & 2 & 2 \\
\hline Tranchet & 1 & 1 & 2 \\
\hline Ciseau & 1 & & 1 \\
\hline Total & 49 & 66 & 115 \\
\hline
\end{tabular}

Tableau 1 : Eventail typologique et chronologique du corpus lithique du Petit Parc (identification S. Sicard).

Table 1: Typological and chronological range of Petit Parc lithic assemblage.

7 Les deux dernières structures, $\mathrm{F} 51$ et $\mathrm{F}$ 62, sont isolées des précédentes. La première renferme un monolithe couché en grès ferrugineux d'une longueur de 1,6 $\mathrm{m}$, qui a été partiellement débité puis enterré à une époque indéterminée. Nous ignorons sa fonction d'origine et sa position. Ni système de calage ni mobilier n'ont été rencontrés dans le comblement de F 51. Un constat similaire concerne F 62 qui contient un bloc de nature identique.

\begin{tabular}{|l|l|l|l|}
\hline Nature & Diagnostic & Fouille & Total \\
\hline Percuteur & 2 & 1 & 3 \\
\hline Meule & & 1 & 1 \\
\hline Broyeur & & 1 & 1 \\
\hline Lissoir & 1 & 1 & 2 \\
\hline Pendeloque & 2 & & 2 \\
\hline Bracelet & & 1 & 1 \\
\hline Total & 5 & 5 & $\mathbf{1 0}$ \\
\hline
\end{tabular}

Tableau 2 : Eventail fonctionnel des éléments macrolithiques du Petit Parc (identification S. Sicard). Table 2: Functional range of macrolithic elements from Petit Parc assemblage.

8 Aucun mobilier ne permet de situer précisément la réalisation de ces aménagements. L'hypothèse d'une création au cours de la période néolithique peut néanmoins être argumentée par un corpus lithique et macrolithique assez abondant (tab. 1 et 2). 71 pièces ont en effet été recueillies, dont une partie non négligeable lors du décapage (36 éléments). On signalera une armature perçante de forme losangique à un bord retouché et une base aménagée par retouches inversées. Deux couteaux à dos et deux lames retouchées constituent les éléments remarquables de l'outillage commun. Une pièce brûlée, difficile à déterminer, pourrait correspondre à une ébauche de tranchet ou ciseau. Deux haches en roche dure sont en outre présentes. L'outillage macrolithique est constitué par une meule en plaquette de grès avec une face supérieure concave et lustrée, deux broyeurs en quartz, dont l'un a servi de lissoir. À ces objets, s'ajoutent 54 pièces trouvées lors du diagnostic préalable. Ce lot, malgré les conditions de découverte et sa dispersion au sol, offre un outillage varié mais homogène, qui trouve des similitudes avec les ensembles de la fin du Néolithique ancien et du Néolithique moyen mis au jour en Normandie (Watté, 1990). L'armature perçante, un fragment de bracelet 
en schiste et le nucleus lamellaire sont les indices les plus caractéristiques de ces périodes.

Ce matériel trouve aussi un écho dans l'environnement du Petit Parc. La carte archéologique du SRA de Basse-Normandie référencie en effet un gisement néolithique au lieu-dit La Vallée, au pied du village actuel de Ménil-Froger. Un polissoir en grès lustré, localisé sur la commune voisine de Saint-Germain-de-Clairfeuille, témoigne aussi de la fréquentation de ce secteur au cours de la Préhistoire (Marcigny et al., 2006).

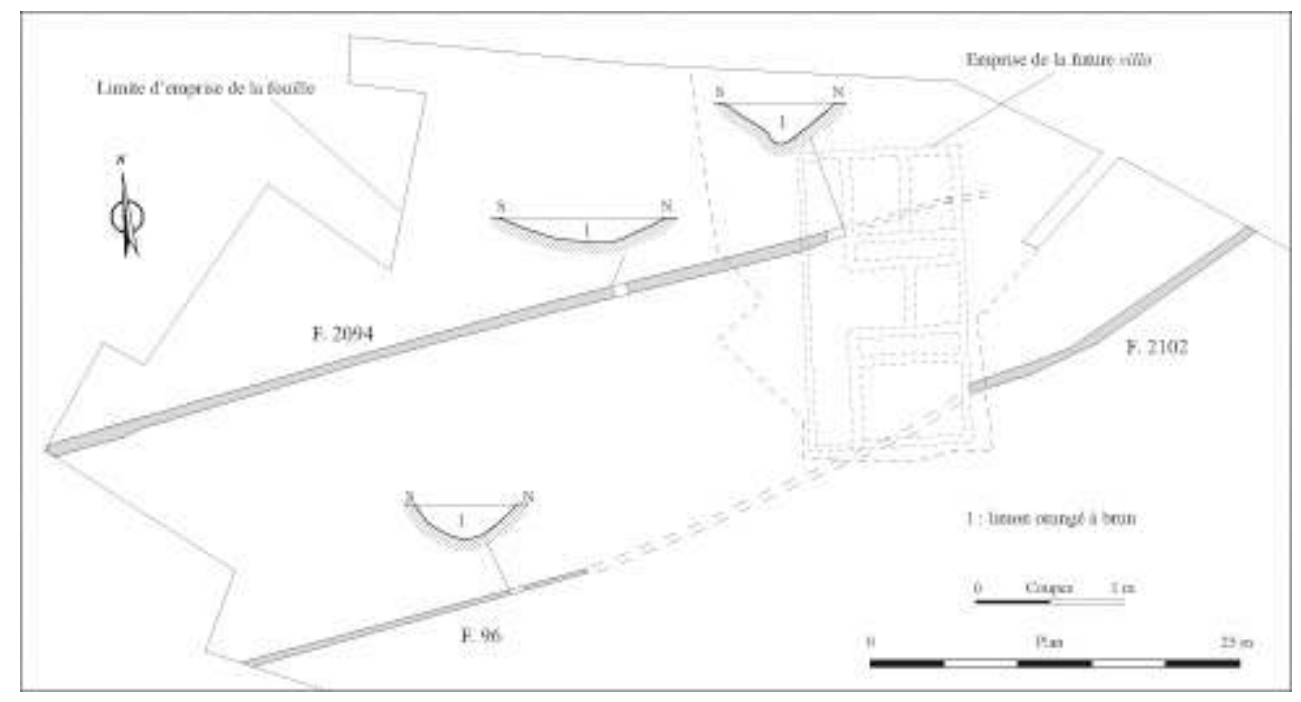

Figure 4 : Plan et coupes des structures attribuées à la protohistoire (DAO B. Kerampran/R. Ferrette). Figure 4: Plan and sections of features ascribed to Protohistory.

\section{La période protohistorique}

Les vestiges correspondants sont peu nombreux et se limitent à trois fossés érodés et recoupés par les aménagements antiques : F 2094, 2102 et 96 (fig. 4). Ils ont été observés dans la partie ouest de l'intervention et se prolongent hors de son emprise. De rares tessons ramassés dans des creusements plus récents tendent à confirmer leur appartenance à une occupation laténienne.

L'orientation nord-est/sud-ouest de ces fossés diffère très nettement du réseau parcellaire postérieur et, malgré l'absence de relation directe entre eux, F 96 et F 2102 semblent correspondre à un unique creusement. Ces tracés se développent de façon sensiblement parallèle et leur écartement maximal est de $17 \mathrm{~m}$ environ. Dans les limites du décapage, l'absence de toute autre structure associée n'autorise aucune interprétation assurée.

Les quelques tessons recueillis dans le comblement du fossé $\mathrm{F} 2094$ sont comparables au mobilier découvert sur le site de "La Corvée», localisé sur la commune proche de Coulmer et daté de La Tène ancienne/Tène moyenne (Ferrette et Cherel, 2004). Les pâtes sont riches en glauconie et un bord comportant un décor d'impressions digitées mérite d'être signalé. Une panse décorée au peigne, datable du second âge du Fer, a aussi été mise au jour dans l'un des sondages effectués dans le fossé $\mathrm{F} 61$, structure dont l'appartenance au parcellaire antique ne peut toutefois être remise en cause. 


\section{La période gallo-romaine}

13 La période postérieure à la Conquête est marquée par l'apparition d'un système fossoyé qui, malgré des évolutions, gardera durant toute la durée de l'occupation la même orientation axée sur les points cardinaux. L'analyse des relations stratigraphiques entre les creusements, combinée à l'étude du mobilier, a conduit à distinguer trois phases principales aboutissant à la création d'une villa.

\section{La genèse de l'établissement}

\section{Un système d'enclos fossoyés?}

14 L'occupation la plus ancienne se résume à deux enclos sans relations physiques avérées (fig. 5 ; enclos A et B). Un seul est conservé en plan dans son intégralité, le second se prolongeant en dehors de l'emprise étudiée. Certaines des limites fossoyées de cette période initiale ont conditionné les aménagements ultérieurs, la villa s'installant par exemple en partie au-dessus de l'enclos A (fig. 5 : F 2046, sondages 5 et 6). Quelques fosses appartiennent aussi à cette première période, mais aucun plan de bâtiment n'a été mis en évidence.

15 L'enclos A, a priori quadrangulaire, est constitué du fossé F 2046, qui s'étire du nord au sud sur près de $28 \mathrm{~m}$ avant d'obliquer vers l'ouest. Des creusements plus récents rendent hasardeux le suivi de son tracé, mais sa continuation hors de l'emprise décapée est manifeste car aucun retour nord-sud n'a été mis en évidence. Son ouverture maximale, observée à l'emplacement de la future villa, est de $2,60 \mathrm{~m}$ pour une profondeur voisine de $1,70 \mathrm{~m}$ (fig. 5). Son profil s'évase régulièrement et son fond est plat ou affecte un profil en $U$.

16 Le remplissage dénote deux étapes de comblement distinctes. Une première séquence comprend des niveaux d'argile plus ou moins plastique qui témoignent de phénomènes d'érosion et de dépôts naturels, indiquant un fonctionnement ouvert (sondage 2, us 4 ; sondage 5 , us 10 à 13 ; sondage 6 , us 6 à 8 ). Ces couches sont surmontées d'un niveau grisâtre et charbonneux, qui traduit une stagnation d'eau et des rejets domestiques ponctuels durant la période de fonctionnement de F 2046 (sondage 2, us 3 ; sondage 5, us 7 ; sondage 6 , us 3 et 4). La dernière grande séquence, illustrée par un niveau d'argile compacte renfermant de nombreuses poches de marne verte, témoigne du démantèlement du talus interne du fossé F 2046 (sondage 2, us 2 ; sondage 5, us 5 et 6 ; sondage 6 , us 3 ).

17 Au sud, cet enclos est doublé sur sa face interne par un petit fossé (F 109), recoupé par des creusements postérieurs et qui n'a pas été observé à l'emplacement de la future villa (fig. 5). Profond d'une quarantaine de centimètres, il peut correspondre, d'après son profil irrégulier et son comblement, proche du substrat, à une palissade à poteaux jointifs, qui succéderait, à la fin de cette phase initiale, à l'enclos A. Le petit fossé F 109 peut aussi signifier que l'enclos $\mathrm{F} 2046$ fonctionnait dès son origine, au moins en partie, avec un talus palissadé.

18 L'enclos $B$, beaucoup plus modeste, est restituable en plan dans son intégralité (fig. 5). Il est de forme rectangulaire et ses dimensions internes sont estimées à $28 \mathrm{~m}$ du nord au sud et à $37 \mathrm{~m}$ d'est en ouest. Son entrée, localisée au sud, se signale par un arrêt du fossé F 18 et le développement de deux autres fossés, F 17 et F 24, formant des 
antennes. Cet enclos semble aussi disposer d'une partition interne, comme pourrait en témoigner le fossé F 16. Tous ces creusements sont relativement mal conservés et offrent au maximum une ouverture de $0,60 \mathrm{~m}$ pour une profondeur ne dépassant guère $0,40 \mathrm{~m}$ dans le cas de $\mathrm{F} 40$. Leur remplissage est formé d'un sédiment orangé et compact, contenant parfois des charbons de bois.

Hormis ces deux enclos, l'unique fossé se rattachant à cette première période est $\mathrm{F} 33$, dégagé au sud de la fouille sur une vingtaine de mètres. Son profil, assez irrégulier, présente une ouverture de 0,60 à $0,70 \mathrm{~m}$ pour une profondeur conservée de $0,40 \mathrm{~m}$ au maximum. Son remplissage est similaire à celui des fossés de l'enclos B.

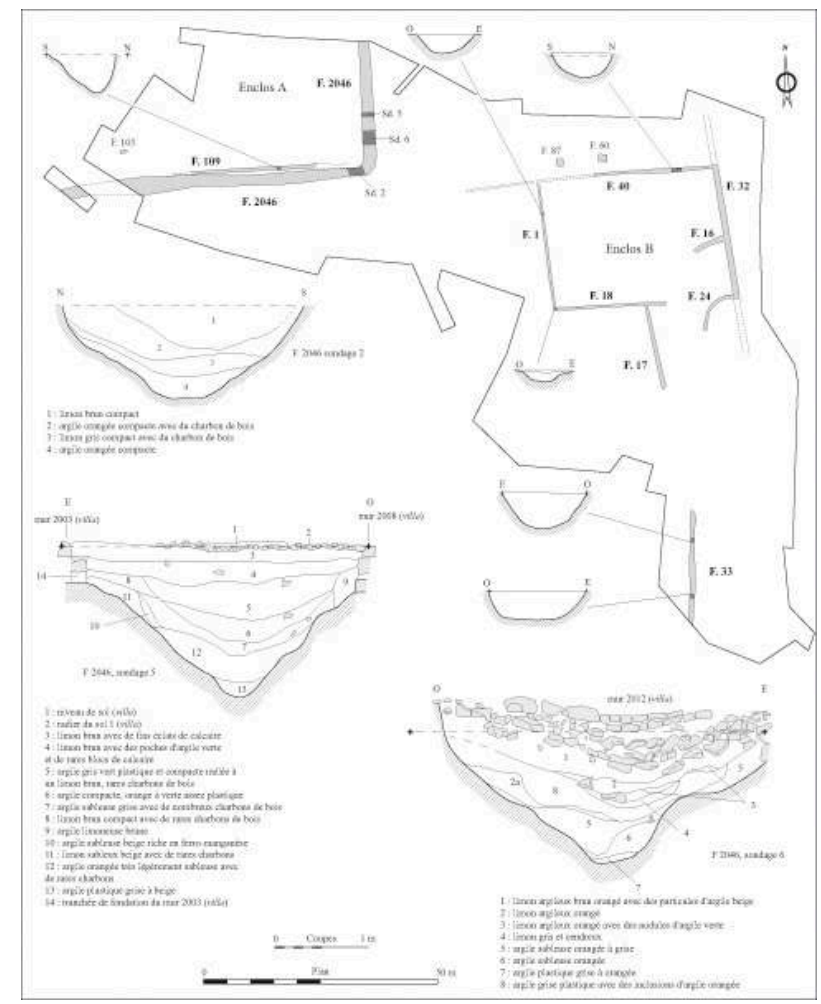

Figure 5 : Plan des aménagements de la première phase gallo-romaine et coupes des fossés (DAO B. Kerampran/R. Ferrette).

Figure 5: First Gallo-Roman phase: plan of features and sections of ditches.

Trois fosses se rattachent également à cette période. La première (F 103) est localisée à l'intérieur de l'enclos A (fig. 5 et 6). L'essentiel de son remplissage est formé de deux niveaux cendreux qui soulignent une condamnation rapide. Sa fonction demeure inconnue. F 87 et $\mathrm{F} 60$ se trouvent, quant à elles, au nord de l'enclos B (fig. 5). De plans similaires, elles présentent une ouverture de $1,50 \mathrm{~m}$ environ au niveau du décapage et comportent des parois régulières et droites, profondes d'une cinquantaine de centimètres. Ces caractéristiques ne sont pas sans évoquer des silos enterrés ou semi enterrés très arasés. Les dynamiques de comblement sont identiques et dénotent trois étapes principales. La première est illustrée par un sédiment argileux qui traduit des effondrements de parois (fig. 6, us 4 et 8). La deuxième, une succession de niveaux plus ou moins riches en charbons de bois et en mobilier, témoigne d'une condamnation rapide à l'aide de rejets domestiques (us 2, 3, 6 et 9). Un niveau brun, consécutif au tassement des couches précédentes, scelle enfin ces deux creusements (us 1 et 5 ). 


\section{Éléments de datation de l'occupation initiale}

21 Le matériel, d'une manière générale assez rare, provient essentiellement des trois fosses F 103, 87 et 60 . Un petit lot de mobilier a aussi été recueilli dans le remplissage de l'enclos A (fossé F 2046). La confrontation de ces informations invite à placer la création de l'établissement du Petit Parc dans le courant de la seconde moitié du i ${ }^{\text {er }}$ siècle av. J.C., tandis que les éléments les plus récents, découverts dans le fossé F 2046 ou le silo F 60 , situent la fin de cette première phase aux alentours du changement d'ère au plus tard.

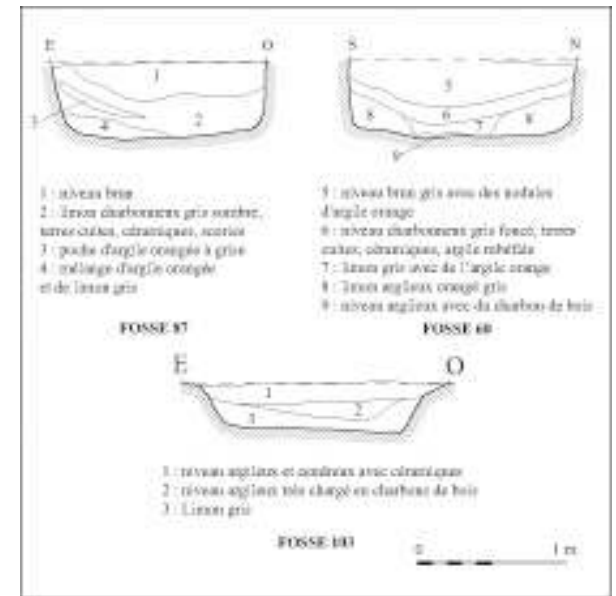

Figure 6 : Coupes des fosses de la première phase gallo-romaine (DAO B. Kerampran/R. Ferrette). Figure 6: Sections of pits from first Gallo-Roman phase.

\section{Le mobilier de la fosse 103 (fig. 7)}

Cet ensemble, une douzaine de fragments de céramique représentant 5 vases, est à situer dans le courant de la deuxième moitié du Ier s. av. J.-C. Il est bien difficile de proposer une datation plus précise du fait de la faiblesse de l'échantillon. Un seul individu semble avoir été façonné au tour : il s'agit d'un grand vase à pied évidé, en céramique à pâte glauconieuse mi-fine noire à brun-noir, dont n'est conservé que le fond $\left(n^{\circ} 1\right)$. On distingue par ailleurs trois vases de «type Besançon » importés, à lèvre caractérisée par deux moulures $\left(n^{\circ} 2\right.$, sans traces de revêtement de surface; $n^{\circ} 3$, à engobe micacé en haut de panse externe ainsi que sur le bord) ou, exceptionnellement, par une moulure unique (non illustré, à lèvre courte sans traces de revêtement de surface). Un autre vase modelé doit être signalé; il s'agit d'un grand récipient très ouvert, confectionné dans une argile chargée en grains de glauconie $\left(n^{\circ} 4\right.$, de teinte noire à brun-noir). 


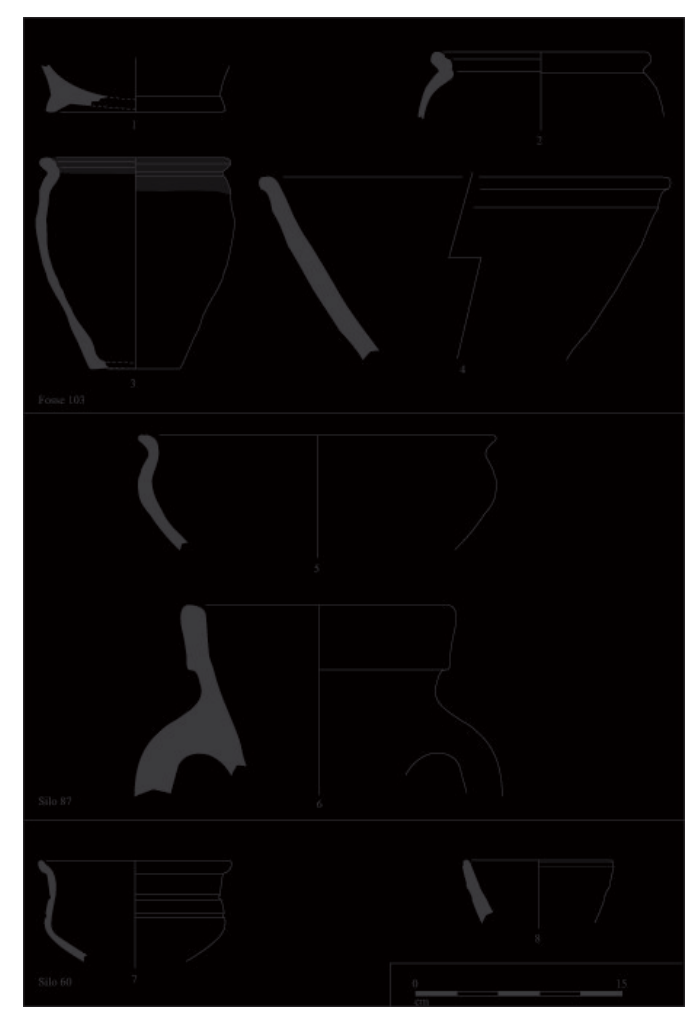

Figure 7 : Mobilier de la fosse 103 et des silos 87 et 60 (relevés et DAO L. Simon).

Figure 7: Finds from pit 103 and silos 87 and 60.

\section{Le mobilier du silo F 87 (fig. 7)}

Les éléments céramiques recueillis sont peu nombreux : 45 fragments équivalant à 6 individus. Ils se rapportent majoritairement à La Tène finale. On observe en effet la présence d'un vase à profil en $\mathrm{S}$, modelé et aux surfaces très érodées, datable des $\mathrm{II}^{\mathrm{e}}$ $\mathrm{I}^{\mathrm{er}}$ siècle av. J.-C. ( $\mathrm{n}^{\circ} 5$; pâte à gros grains de quartz et mica fin abondant). Un lot de 43 fragments d'amphores à vin caractéristiques de la péninsule italique, et correspondant à 4 individus d'après les différences de pâtes, est également attesté. L'un d'eux est de type Dressel 1B $\left(n^{\circ} 6\right)$, importé en Gaule interne au cours de La Tène D2 essentiellement, et même jusqu'à la période augustéenne dans certaines régions comme l'est parisien (Séguier et Mallet, 2005, p. 555-556). Par ailleurs, la présence d'un fragment d'amphore à vin espagnol de Tarraconaise (Pascual 1 ou Dressel 2/4) tend à indiquer qu'il ne convient pas de placer le comblement définitif de ce silo avant les années 40-30 av. J.-C. au plus tôt.

\section{Le mobilier du silo F 60 (fig. 7)}

Les artefacts recueillis dans le comblement de ce silo se limitent à 15 fragments de céramique représentant 7 vases. Les plus caractéristiques permettent de poser l'hypothèse d'une datation augustéenne, aux alentours du changement d'ère au plus tard.

On note la présence de deux coupes carénées en terra nigra à lèvre en gouttière, de type Menez 103, toutes deux à pâte gris clair micacée et aux surfaces gris foncé. La plus complète comporte des rainures horizontales sur la panse au-dessus de la carène $\left(n^{\circ} 7\right)$. 
Sont également attestés des fragments d'un vase à pâte claire et siliceuse, dont la forme d'origine ne peut être restituée.

La catégorie des vases modelés comprend un vase à paroi oblique avec bord aminci régularisé et rainuré, tandis que la paroi externe semble avoir subi un traitement de surface vertical ( $\mathrm{n}^{\circ} 8$; pâte à quartz, noire à brun-noir).

Les amphores sont représentées par deux types: d'une part une amphore à vin de la péninsule italique, de forme Dressel 1 ou Dressel 2/4 (6 fragments), datable de La Tène finale au Ier s. de notre ère et d'autre part un récipient ayant servi au transport de l'huile de Bétique, de type Dressel 20.

\section{Le mobilier de l'enclos A (fossé F 2046 ; fig. 8)}

L'étude du comblement de ce fossé est essentielle pour définir la période d'abandon de la phase la plus ancienne de l'établissement. Malheureusement, la faiblesse quantitative du lot céramique (seulement 28 fragments), associée à la rareté des marqueurs chronologiques, n'autorise pas une datation très fine au sein de la période "galloromaine précoce ". À titre d'hypothèse, nous proposons de situer cet ensemble aux alentours du changement d'ère.

Peu de formes peuvent être déterminées au sein de la vaisselle de table. Dans la catégorie terra nigra (3 fragments), nous pouvons tout juste mentionner une coupe présentant une carène moulurée (Menez 103 ?), à pâte micacée gris clair et surfaces gris foncé, tandis que la terra rubra comprend une seule assiette, vraisemblablement de type Menez 22/27 (engobe rouge foncé, pâte rougeâtre à cœur gris, finement micacée). Des formes aux caractéristiques techniques similaires sont connues à Orléans, Blois et Chartres, tant au cours de la période augustéenne que pendant la période tibérienne (Couvin, 2005, p. 125-126, fig. 32, n 5 ; Sellès, 2001, p. 30-31, n 101).

30 La céramique à engobe blanc est, quant à elle, représentée par 11 fragments de panses de cruches, à pâte brune ou rougeâtre mais, dans tous les cas, finement sableuse et micacée. Notons encore un petit pot trapu, sans col, à lèvre simple oblique, classé en " céramique fine indéterminée » et peut-être inspiré des vases de Type Beuvray $\left(\mathrm{n}^{\circ} 1\right.$; pâte mi-fine orangée sombre à cœur gris moyen, finement micacée, surface engobée et noire).

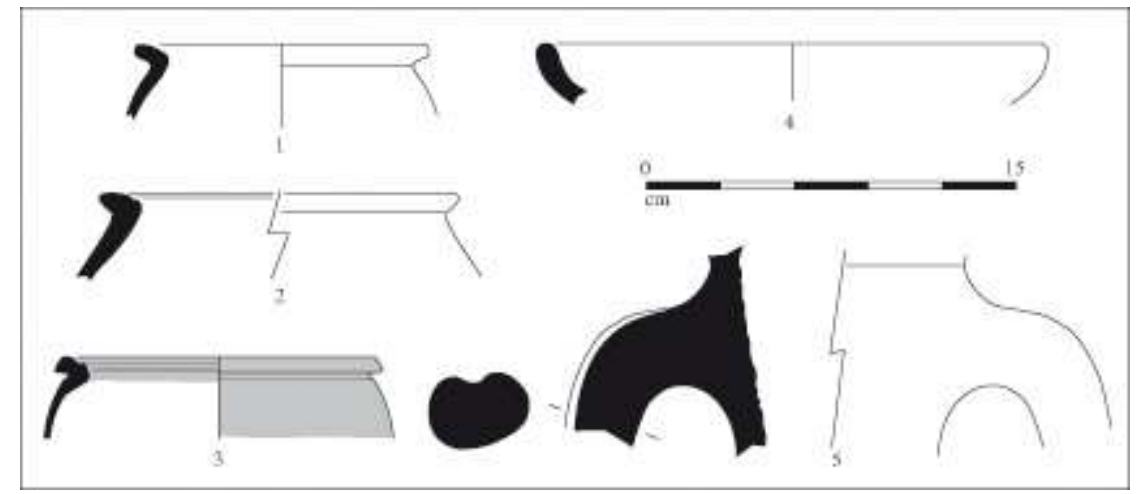

Figure 8 : Mobilier du fossé 2046 (relevés et DAO L. Simon).

Figure 8: Finds from ditch 2046.

Les céramiques communes sont à peine mieux représentées: en commune claire, notons le fond d'un petit pot/gobelet à pâte brune micacée (base apode) et, en 
commune sombre, un pot globulaire sans col à bord massif incisé $\left(n^{\circ} 2 ;\right.$ pâte à cœur noir, franges brunes et surfaces noires, finement sableuse, micacée, contenant de rares inclusions de feldspath de grande taille).

La céramique non tournée de «type Besançon » comprend un individu de petit module, présentant les spécificités morphologiques propres aux horizons "gallo-romains précoces ». La présence de mica jaune peut être observée sur sa lèvre et le haut de la panse $\left(n^{\circ} 3\right)$. Les autres éléments en céramique modelée ( 7 fragments) se limitent à des tessons de panse, un fond de pot et une écuelle à bord rentrant $\left(n^{\circ} 4 ;\right.$ pâte à quartz brun-noir, finement micacée).

Enfin, la catégorie des amphores est représentée par deux fragments de récipients vinaires à pâte beige provenant de la péninsule ibérique, plus précisément de la province de Tarraconaise, dont une Pascual $1\left(n^{\circ} 5\right)$.

\section{Le mobilier de l'enclos B et du fossé F 33}

Associé à un fragment de cruche à engobe blanc, un pot de "type Besançon " a été découvert dans le remplissage du fossé $\mathrm{F} 40$. Quant au fossé $\mathrm{F} 1$, il a livré comme élément remarquable une assiette en terra nigra Menez 39. Couramment rencontrée durant les premières décennies de notre ère en Basse-Normandie, cette forme apparaît cependant dès l'Horizon 2 (début de l'époque augustéenne) sur le site de Touffreville dans le Calvados (Simon et al., 2002, p. 24). Enfin, un fragment d'amphore à vin en provenance d'Espagne (Pascual 1 ou Dressel 2/4) a été ramassé lors du décapage de F 33. S'ils n'apportent pas de précisions significatives, ces éléments chronologiques ne sont pas en désaccord avec ceux recueillis dans le fossé F 2046 de l'enclos A.

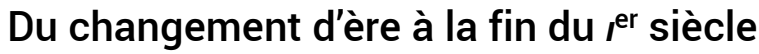

\section{Une première transformation de l'établissement}

Cette période assez longue, dont nous pouvons seulement restituer les évolutions principales, débute par la destruction des enclos A et B. Certaines de leurs limites subsistent néanmoins et vont conditionner le développement d'un nouveau réseau fossoyé. Cette phase marque en effet l'apparition d'un réseau parcellaire, parfois complexe, à l'image des découvertes de la partie sud-est de la fouille. L'existence d'un bâtiment sur poteaux, localisé également au sud-est de l'intervention, peut être envisagée à partir des découvertes mobilières (fig. 9).

La pérennisation de l'ancienne limite sud de l'enclos A est illustrée par le fossé $\mathrm{F} 98$, dont le tracé conserve partiellement celui de l'ancien fossé 2046. Il a été reconnu ponctuellement en raison de sa reprise postérieure par le fossé F 61. D'ouest en est, F 98 se développerait sur une distance voisine de $52 \mathrm{~m}$, aucun retour n'ayant été identifié. Il forme ensuite un coude avant de se poursuivre vers l'est. Son retour est alors constitué du fossé $\mathrm{F} 59$, recoupé par $\mathrm{F} 61$ lors de la phase suivante. F 98 s'étirerait par conséquent sur une longueur supérieure à $110 \mathrm{~m}$.

Son ouverture varie de $2,20 \mathrm{~m}$ (sondage 1) à plus de $3 \mathrm{~m}$ (sondage 3 ), pour une profondeur conservée supérieure à $1 \mathrm{~m}$. Son fond est tapissé d'une argile orangée et sablonneuse qui correspond au comblement initial de F 2046 (fig. 9, sondage 1, us 2; sondage 2 , us 4 et sondage 3 , us 8 à 10). L'essentiel du remplissage est toutefois 
constitué d'une succession de couches à dominante brune, plus ou moins riches en matériaux détritiques, ce qui souligne une condamnation rapide et volontaire. La présence dans ces niveaux de très nombreuses tuiles brûlées et de pierres semble aussi témoigner du démantèlement d'un bâtiment proche. La vaisselle exhumée placerait la destruction de cet édifice dans le courant du règne de Tibère d'après l'association entre des sigillées italiques et les premières productions gauloises du pôle de Millau-La Graufesenque (cf. infra - «Les éléments de datation »). Cette proposition implique dès lors des transformations assez rapides puisque l'enclos A est remblayé partiellement aux alentours $d u$ changement d'ère. On ignore en outre les motivations du remblaiement du fossé $\mathrm{F} 98$ et surtout si cette condamnation a concerné seulement une portion ou l'intégralité de son tracé. Dans le second cas, la question de la permanence de cette limite sous une autre forme mérite d'être posée (haie, fossé plus modeste), puisqu'elle sera reprise bien plus tard par le fossé $\mathrm{F} 61$.

Dans le secteur est de la fouille, la permanence de certaines des limites de l'enclos B est aussi manifeste. Sa bordure orientale est ainsi pérennisée par un nouveau fossé qui se poursuit bien au-delà de l'emprise initiale de l'ancien enclos (fig. 9, F 32a). En outre, le développement des fossés 98 et 59 implique aussi une réutilisation partielle de la limite nord de l'enclos B.

La concrétisation de ces deux limites nord-sud et est-ouest (F 98 et $\mathrm{F}$ 32a) est complétée par l'apparition de nouvelles structures linéaires (fig. 9). Le fossé $F 15$ vient ainsi frôler le côté ouest de l'ancienne entrée de l'enclos B. Il se développe sur une distance minimale de $50 \mathrm{~m}$ et présente un profil en cuvette ou trapézoïdal à fond plat, ce qui témoigne sans doute de curages. Les dimensions de F 15, fortement érodé dans sa portion sud, sont relativement modestes: l'ouverture est inférieure à $1 \mathrm{~m}$ et la profondeur va de 15 à $40 \mathrm{~cm}$. Il fonctionne avec les fossés 27 et 24, qui encadrent une entrée dont la largeur exacte ne peut être restituée car la terminaison de F 24 a été détruite par une fosse plus récente. Quoi qu'il en soit, ce nouvel accès se positionne au même emplacement que celui de l'enclos B. Cette nouvelle entrée est elle-même précédée d'un petit creusement (F 25) qui pourrait matérialiser l'emplacement d'une haie. 


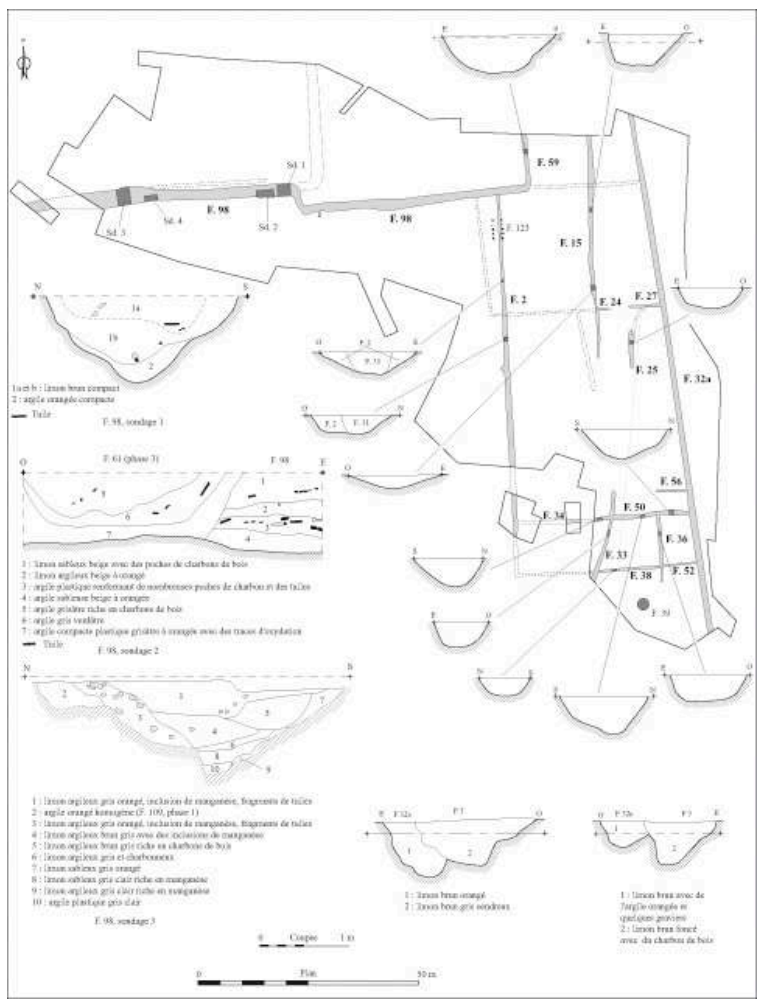

Figure 9 : Plan des aménagements de la deuxième phase gallo-romaine et coupes des fossés (DAO B. Kerampran/R. Ferrette)K/F.

Figure 9: Second Gallo-Roman phase: plan of features and sections of ditches.

D'orientation similaire à $\mathrm{F} 15$, le fossé $\mathrm{F} 2$ a été dégagé sur près de $80 \mathrm{~m}$. Relativement érodé et à fond plat et large, il constitue une limite secondaire non négligeable puisque son tracé a perduré lors de l'ultime phase sous une autre forme (cf. infra, fig. 17, F 31). La principale originalité de $\mathrm{F} 2$ réside dans un aménagement composé de 10 plots en calcaire espacés de $1 \mathrm{~m}$ (fig. 10, F 123). Plusieurs blocs de nature similaire et appartenant à ces supports ont été retrouvés dans le remplissage de $\mathrm{F} 2$, attestant d'un aménagement spécifique au-dessus de ce dernier. Une interprétation plausible consiste à considérer ces vestiges comme les soubassements d'une passerelle autorisant le franchissement du fossé. Ce passage aurait été d'une largeur voisine de $5 \mathrm{~m}$, ce qui pose la question de l'existence d'un chemin, dont ne subsisterait aucune autre trace. 


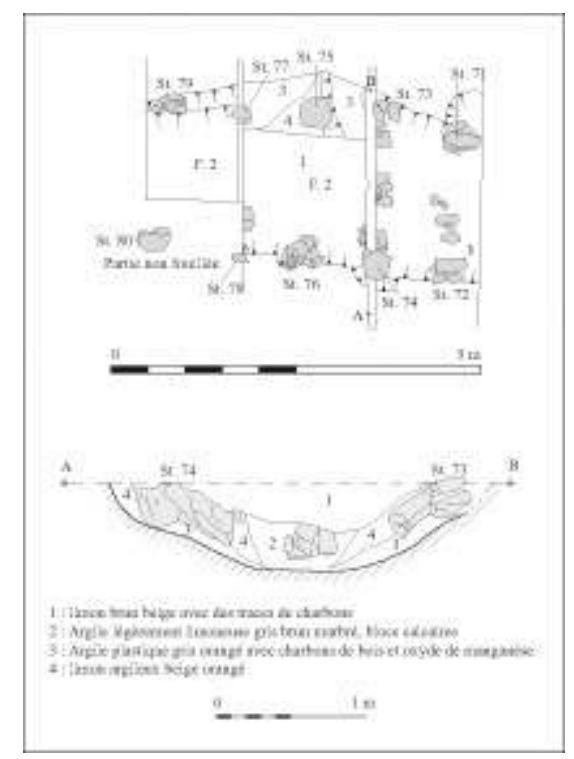

Figure 10 : Plan et coupe de la construction sur plots calcaires F 123 au-dessus du fossé F 2 (DAO B. Kerampran / R. Ferrette).

Figure 10: Plan and section of building F 123 supported by limestone blocks, above ditch F 2 .

Cette deuxième période inaugure aussi une densification du réseau fossoyé au sud-est de l'intervention (fig. 9). Malheureusement, l'état de conservation et les remplissages identiques des creusements n'autorisent aucune appréciation fine des évolutions qui se sont produites et seules quelques hypothèses peuvent être proposées. La synchronie des fossés $\mathrm{F} 34 / 50$ et $\mathrm{F} 38 / 52$ n'est pas évidente mais aucun argument n'autorise à définir l'antériorité de l'un par rapport à l'autre, ni même à affirmer que leur tracé a toujours été continu. Le seul point avéré est que le premier ne semble pas se prolonger à l'ouest de $\mathrm{F} 2^{1}$. Le fossé 36 entretient également une relation avec le tracé $\mathrm{F} 34 / \mathrm{F} 50$ puisqu'il ne se poursuit pas au-delà de ce dernier. On observe aussi qu'il se développe dans l'axe de la terminaison de F 56. Enfin, la terminaison de $\mathrm{F} 33$ se place à la hauteur $\mathrm{du}$ fossé 56 . Les creusements $\mathrm{F} 56,36$ et 33 pourraient alors marquer des points de passage (fig. 11). Cette hypothèse implique que le fossé $\mathrm{F} 34 / 50$ n'a pas toujours été continu. Une première entrée, d'une largeur de $5 \mathrm{~m}$ environ, aurait été établie à la hauteur de F 32a, tandis qu'une seconde aurait permis de se diriger au nord ou au sud, sans doute, dans ce second cas, afin d'accéder à un possible bâtiment situé en dehors de l'emprise décapée ${ }^{2}$. L'existence de cette construction peut être défendue grâce au mobilier découvert dans la fosse F 39, localisée au sud de ces passages (fig. 11). Outre de la céramique, 45 éléments en fer, principalement des clous et plusieurs fragments de torchis brûlés, ont été recueillis dans son comblement.

\section{Les éléments de datation}

\section{Le mobilier du fossé F 98 (tabl. 3 ; fig. 12-14)}

Cette étude rassemble le mobilier de trois sondages réalisés dans le fossé 98 (fig. 9 , sondages 1, 3 et 4), ainsi qu'à l'intersection entre F 98 et $F 61$ (sondage 2). L'observation de la dynamique des remplissages, confrontée à l'analyse du mobilier, a permis de mettre clairement en évidence l'antériorité de F 98, puisqu'il est recoupé par F 61 à la phase 3 (recreusement), ainsi que l'absence du fossé 61 à l'emplacement des sondages 3 et 4. Enfin, l'ensemble du mobilier recueilli à la hauteur de l'intersection entre F 61 et 
F 98 appartient uniquement au comblement de F 98. Il apparaît ainsi que l'ensemble de ces sondages concerne en propre ce dernier fossé. L'étude du mobilier montre que le scellement de ces différentes sections a dû s'opérer au même moment, aux alentours des années 10 à 30/40 au plus tard.

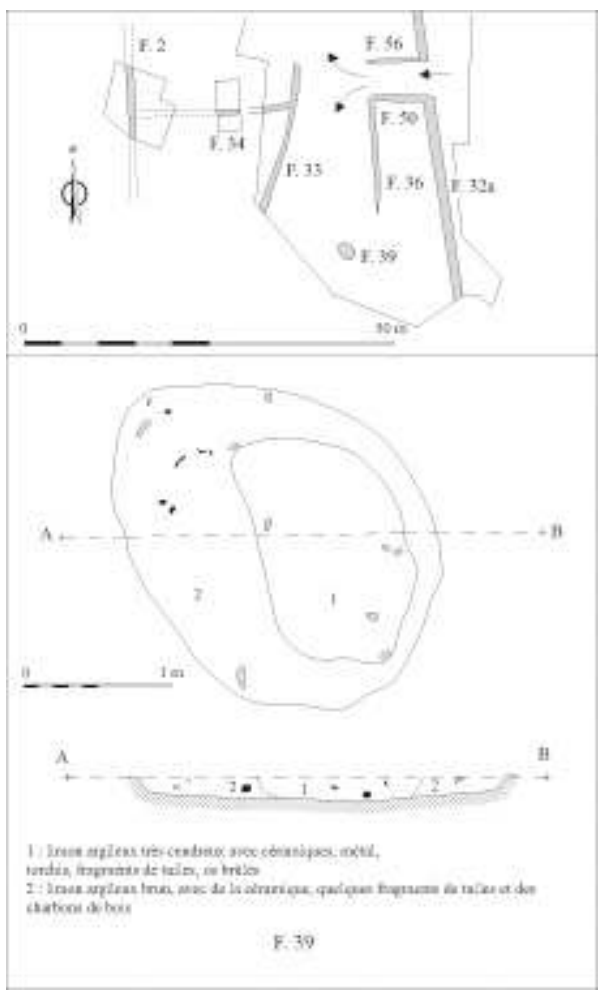

Figure 11 : Fosse 39 : localisation au sud des fossés de la zone sud-est; plan et coupes (DAO B. Kerampran/R. Ferrette).

Figure 11: Pit 39: Location south of ditches of south-eastern area; plan and sections.

Le lot se compose de 398 fragments, représentant un minimum de 56 individus répartis en 12 catégories techniques. Cette variété est particulièrement intéressante pour la connaissance $\mathrm{du}$ faciès régional de cette période. Elle témoigne de la richesse du répertoire, tout autant que de la multiplicité des sources d'approvisionnement: péninsules italique et ibérique, sud et centre de la Gaule, mais aussi productions du Grand-Ouest/Centre-Ouest de la Gaule. Par ailleurs, la présence de vases confectionnés dans une argile à glauconie atteste l'activité d'ateliers régionaux, orientés alors autant vers la fabrication de vaisselle de table que de récipients à usage culinaire.

\begin{tabular}{|l|l|l|l|l|}
\hline F. 98 & Nb Frag. & \%Nb Frag. & NMI & \%NMI \\
\hline sigillée & 42 & $10,6 \%$ & 11 & $19,6 \%$ \\
\hline type Beuvray & 1 & $0,3 \%$ & 1 & $1,8 \%$ \\
\hline terra rubra & 3 & $0,8 \%$ & 2 & $3,6 \%$ \\
\hline terra nigra & 107 & $26,9 \%$ & 13 & $23,2 \%$ \\
\hline engobe blanc & 8 & $2,0 \%$ & 3 & $5,4 \%$ \\
\hline engobe orangé & 2 & $0,5 \%$ & 1 & $1,8 \%$ \\
\hline engobe micacé & 93 & $23,4 \%$ & 6 & $10,7 \%$ \\
\hline
\end{tabular}




\begin{tabular}{|l|l|l|l|l|}
\hline cér. commune claire & 51 & $12,8 \%$ & 5 & $8,9 \%$ \\
\hline cér. commune sombre & 22 & $5,5 \%$ & 3 & $5,4 \%$ \\
\hline CNT type Besançon & 31 & $7,8 \%$ & 3 & $5,4 \%$ \\
\hline cér. non tournée & 33 & $8,3 \%$ & 3 & $5,4 \%$ \\
\hline amphore & 5 & $1,3 \%$ & 5 & $8,9 \%$ \\
\hline TOTAL & 398 & $100,0 \%$ & 56 & $100,0 \%$ \\
\hline
\end{tabular}

Tableau 3 : Dénombrement des céramiques du fossé $F 98$.

Table 3: Summary of ceramics from ditch $F 98$.

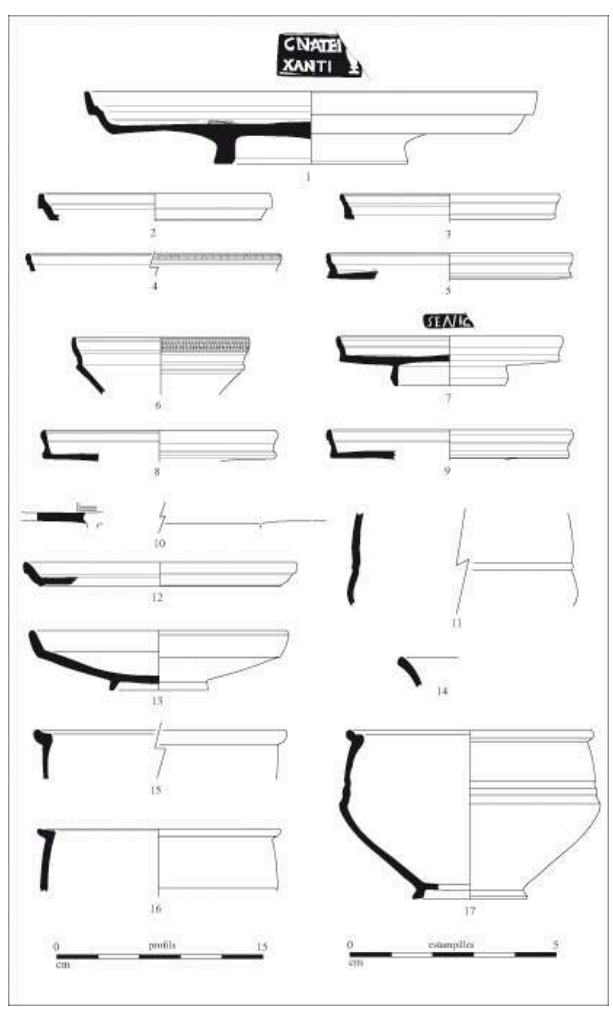

Figure 12 : Mobilier du fossé 98 : 1-9, sigillées ; 10-11, terra rubra ; 12-17, terra nigra (relevés et DAO L. Simon).

Figure 12: Finds from ditch 98: 1-9, terra sigillata; 10-17, terra rubra; 12-17, terra nigra. 


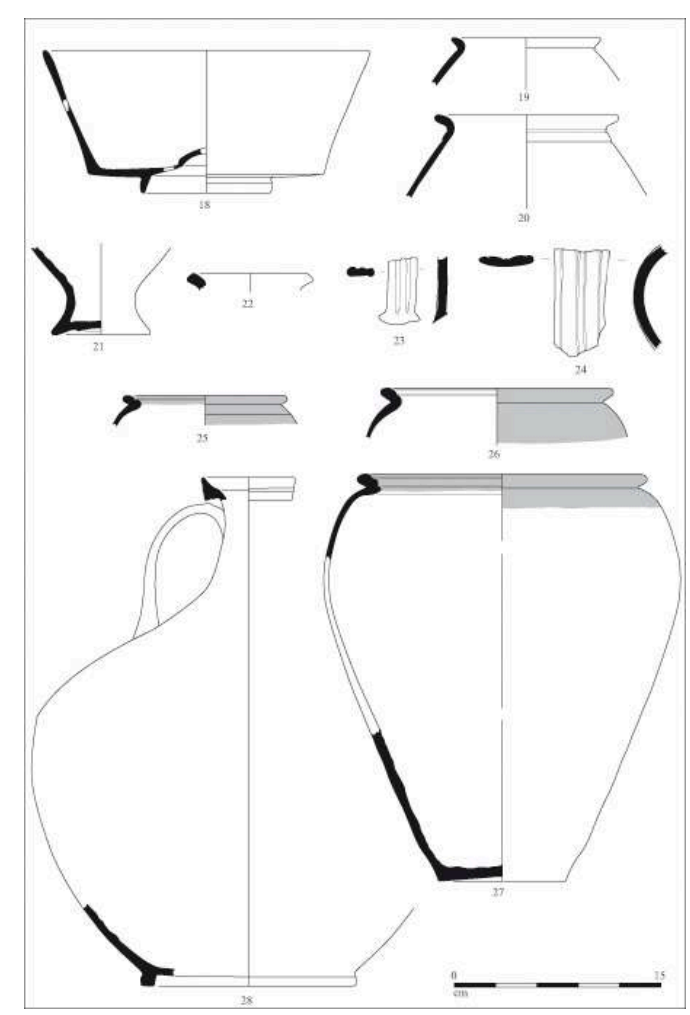

Figure 13 : Mobilier du fossé 98 (suite) : 18-21, terra nigra ; 22-23, céramique à engobe blanc ; 24 , engobe orangé ; $25-27$, engobe micacé ; 28 , commune claire (relevés et DAO L. Simon).

Figure 13: Finds from ditch 98 (continued): 18-21, terra nigra; 22-23, white slipped ware; 24, orange slipped; 25-27, micaceous slipped; 28, pale domestic ware.

Des analogies de répertoire peuvent être constatées à l'échelle régionale, notamment avec l'Horizon 4 proposé pour la région de la Plaine de Caen (Simon et al., 2002, p. 29-34), vers les années 10/15 à 30/40. Au-delà, le lot présente des points communs avec de nombreux sites du grand quart nord-ouest de la France. En région Centre, citons Sellès (1998) pour les phases 9-16 de Chartres en Eure-et-Loir, Chambon (2001) avec l'ensemble 1 d'Orléans dans le Loiret, Couvin (2005) pour l'horizon 2 du Val de Loire, notamment Orléans, Blois, Tours. En Île-de-France, notons Guyard (1998) : états 2, 3 de Paris, site de la rue Saint-Martin. En Pays de la Loire, on citera Guitton et Thébaud (2001) avec le site de Rezé en Loire-Atlantique et, pour la Bretagne, Ferrette (2003) avec l'horizon I récent de Corseul dans les Côtes-d'Armor.

Dans le matériel de $\mathrm{F} 98$, la sigillée (11 individus) se répartit à peu près à parts égales entre des vases de type italique et les premières sigillées de mode $C$ du sud de la Gaule (pôle de La Graufesenque). Les vases de type italique correspondent tous à des formes basses destinées à la présentation, avec quatre assiettes et un plat. Il s'agit de représentants des services Ic (fig. 12, $\left.n^{\circ} 1-2\right)$ et II ( $\left.n^{\circ} 3-5\right)$, dont l'association n'est pas rare, en Gaule de l'ouest, depuis la période augustéenne récente jusque dans le courant de l'ère tibérienne, par exemple à Corseul (Ferrette, 2003, Horizon 1 récent). Une mention particulière doit être accordée au plat du service Ic qui comporte une estampille attribuable aux productions de Pise, datable des années 5 av. J.-C. à 20 apr. J.C. $\left(n^{\circ} 1\right)$. Cette marque appartient à une série comportant plusieurs variantes encore mal identifiées (Oxé et al., 2000, $n^{\circ}$ 316.1). Une estampille de la même série est recensée à Rezé (Guitton, 2001, p. 327, fig. 3, n 21). Une autre vient d'être signalée à Fréjus (Var), 
malheureusement en situation résiduelle (niveau de voie, III $^{\mathrm{e}}$ siècle); elle vient s'ajouter à six occurrences similaires précédemment répertoriées (Rivet, 2005, p. 716, 719, n 13 ).

La sigillée sud-gauloise est assortie aux vases italiques du service II puisqu'elle est représentée principalement par de la vaisselle adoptant le même profil bipartite, avec une coupelle Ritt. $5\left(n^{\circ} 6\right)$ et quatre assiettes Drag. $17\left(n^{\circ} 7-9\right.$, plus une autre dont l'attribution typologique n'est pas assurée. Les caractéristiques techniques de ces vases sont typiques des productions tibériennes du pôle de Millau-La Graufesenque. Le récipient $\mathrm{n}^{\circ} 7$ porte une estampille incomplète, SENIC [...] pour SENICIO. Ce nom de potier est attesté du règne de Tibère à celui de Vespasien (Polak, 2000, p. 328-329, pl. 22). Elle figure notamment sur le site de production dans un contexte daté des années 15/30 de notre ère (fosse de FRONTO ; Genin et al., 2002, p. 69).

La vaisselle de table de type Beuvray figure ici sous la forme d'un fragment de paroi (gobelet cylindrique ou ovoïde ?) à pâte beige finement micacée et surface externe brun foncé, caractéristique des productions originaires de la vallée de la Loire. On les rencontre habituellement dans les horizons augustéens et tibériens du Grand Ouest de la France notamment.

La terra rubra comprend 2 individus, aux caractéristiques fort différentes. Ces vases ( $n^{\circ} 10$ et 11) comportent un engobe, respectivement orangé et rouge foncé. Le premier présente une pâte beige, tandis que l'autre a une pâte brune à cœur gris, finement micacée. On distingue un plat, probablement caréné $\left(n^{\circ} 10\right)$, avec des traces d'engobe sur les faces interne et externe. Le second individu est une coupe à carène douce dont la paroi est revêtue d'un engobe uniquement sur sa face externe. De telles productions sont bien attestées en cité carnute, dans la région de Blois et surtout d'Orléans (Couvin, 2005, p. 125-127). 


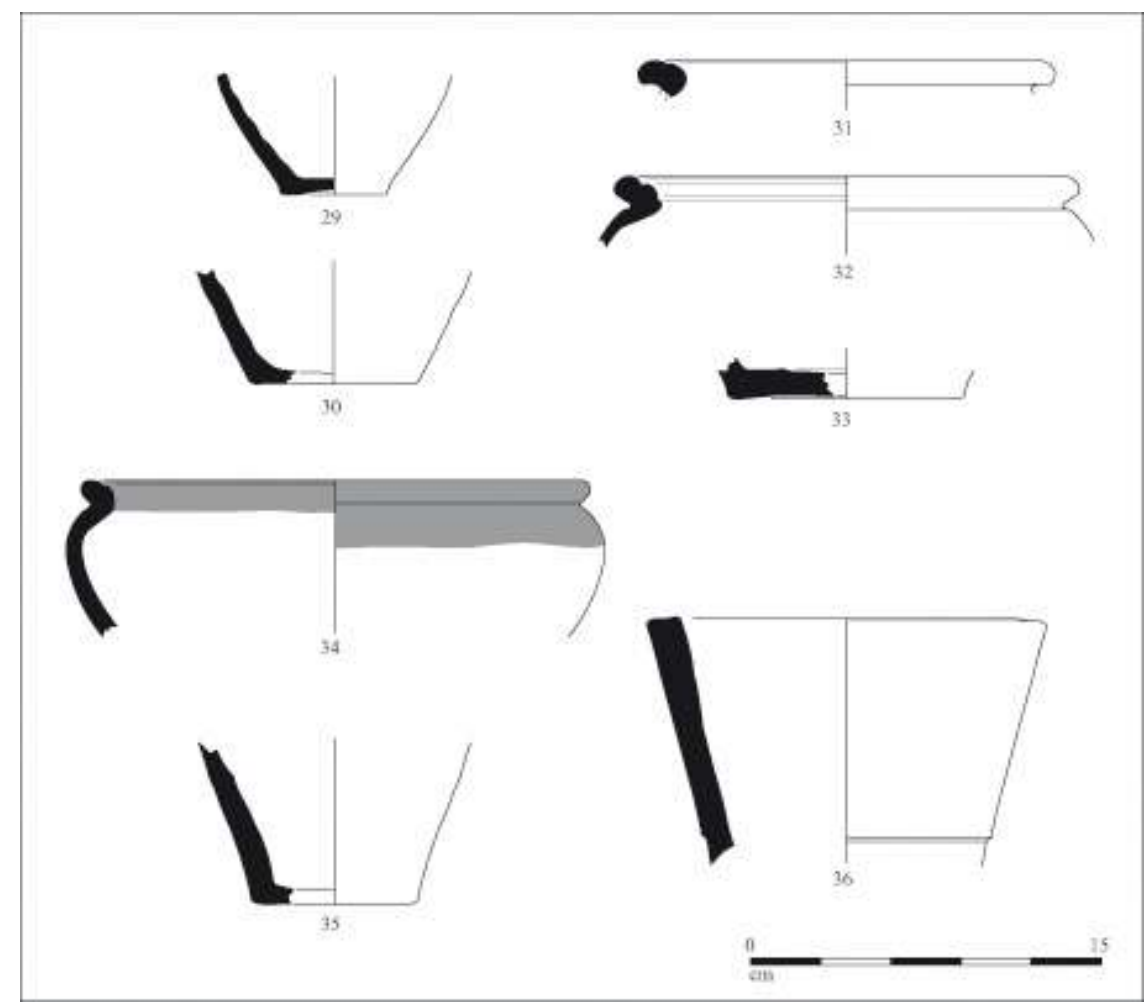

Figure 14 : Mobilier du fossé 98 (suite) : 29-30, commune sombre tournée ; 31-33, « type Besançon » ; 34-35, commune sombre non tournée ; 36, amphore (relevés et DAO L. Simon).

Figure 14: Finds from ditch 98 (continued): 29-30, wheel-turned dark domestic ware; 37-33, "Besançon type"; 34-35, hand-made dark domestic ware; 36, amphora.

La catégorie de vaisselle la plus importante numériquement, mais aussi la plus variée, est la terra nigra (107 fragments, 13 individus) ${ }^{3}$. Figurent dans ce lot plusieurs types d'assiettes, notamment un exemplaire Menez 33, imitant les productions sigillées de type italique du service Ic ( $n^{\circ} 12$, à pâte de type Centre, de teinte gris clair à surface gris foncé à noir, comprenant de très fines paillettes de mica en abondance). Un individu à bord oblique de type Menez 22/27 se caractérise par une pâte régionale à tendance « rugueuse », de teinte gris moyen et surfaces gris foncé ( $\left.n^{\circ} 13\right)$. On compte encore une assiette profonde ou coupe carénée ( $\mathrm{n}^{\circ} 14$, à pâte beige non micacée, surfaces noires), ainsi qu'une hypothétique assiette Menez 7/11 (pâte gris clair à surfaces gris foncé, finement micacée). Les coupes répondent principalement au type à lèvre en gouttière Menez 103, avec au moins trois exemplaires. Deux individus ( $\left.n^{\circ} 16-17\right)$, de teinte gris moyen mais dont la surface est brun-gris pour l'un $\left(n^{\circ} 17\right)$, ont été réalisés dans une pâte régionale à glauconie ; ce n'est pas le cas de la coupe $n^{\circ} 15$, à pâte « sèche » brungris, qui comporte de très fines paillettes de mica en quantité moyenne et des oxydes métalliques noirâtres. Notons encore la présence d'une coupe carénée à paroi oblique et fond ombiliqué, dont le type ne paraît pas avoir été répertorié (fig. $13, \mathrm{n}^{\circ} 18$; pâte glauconieuse à cœur brun, franges brun foncé et surface noire), ainsi qu'une possible coupe à flancs concaves Menez 125/126 ("vase-bobine" à pâte beige-rosée non micacée à surfaces noires). Les vases fermés sont représentés par des pots globulaires (ou «bouteilles») de type Menez 94 (Menez, 1989) : deux individus à lèvre oblique ( $n^{\circ}$ 19-20), l'un avec une moulure à la jonction col/bord, dont le type est connu avec un pied balustre $\left(\mathrm{n}^{\circ} 21\right)$. Tous comportent une pâte rougeâtre à brun et des surfaces noires, avec de très fines paillettes de mica en quantité. Détails formels et qualités techniques 
de ces formes hautes plaident pour des productions du Val de Loire, telles qu'on en trouve dans le secteur voisin des Carnutes au cours de la première moitié du $\mathrm{I}^{\mathrm{er}}$ siècle (Couvin, 2005, p. 109-119; Sellès, 1992, p. 169, fig. 4, forme 5.1; Sellès, 2001, p. 110-111, $\mathrm{n}^{\circ} 1111$; à comparer également avec la forme NPR 37 à pâte fine dans Jobelot et Vermeersch, 1991). Un exemplaire similaire est signalé parmi les formes de céramiques communes d'un fossé augustéen dans la région d'Evreux (Adrian, 2001, p. 101, fig. 3, $\mathrm{n}^{\circ}$ 105-7).

La céramique à engobe blanc constitue une autre catégorie susceptible d'être employée à table (service des liquides). Elle est faiblement attestée dans ce lot, avec un minimum de 3 individus et des éléments formels très lacunaires, issus manifestement de cruches. Tout au plus distingue-t-on un bord à extrémité équarrie éversée ( $n^{\circ} 22$, à pâte orangérouge, sableuse, finement micacée) et une anse plate de profil rectiligne à double rainure ( $n^{\circ} 23$; pâte beige, fine, finement micacée).

51 La céramique à engobe orangé est représentée par un seul individu, une cruche à large anse moulurée $\left(n^{\circ} 24\right.$; engobe orangé clair, pâte beige à cœur beige foncé, finement micacée).

Les céramiques à engobe micacé ont répondu au moins pour partie à un usage culinaire, ainsi que l'indiquent des restes de dépôt noirâtre (suie) sur l'extérieur de la panse. Elles totalisent 93 tessons qui équivalent à un minimum de six vases. Ce sont des formes hautes et fermées ( $\left.n^{\circ} 25-27\right)$, dont on trouve des attestations essentiellement dans les horizons augustéens et tibériens. Elles présentent un profil trapu, dépourvu de col marquant la liaison bord-panse, avec une lèvre disposée à l'oblique, marquée d'un ou deux sillons. Un engobe micacé revêt la partie supérieure de la panse, ainsi que partiellement la lèvre. Ces productions, réalisées au tour, ont une pâte de teinte homogène, brune ou orangé-brun, et se différencient clairement des productions modelées de «type Besançon » dont elles s'inspirent.

53 La céramique commune claire est représentée par cinq individus issus de 51 tessons, majoritairement des fragments de panse de cruche. Les seuls éléments morphologiques attestés sont le bord et le fond d'une grande cruche à pâte finement micacée, de teinte beige clair avec un cœur beige-rosé $\left(n^{\circ} 28\right)$. Ce type, à bord mouluré et pied annulaire, est habituel dans les niveaux "gallo-romains précoces » en Gaule de l'Ouest. À l'image des cruches à engobe blanc, il s'agit d'ustensiles destinés au service des liquides. La céramique commune sombre comprend 22 fragments qui équivalent à 3 individus. Leur caractère lacunaire ne permet pas d'apprécier leur morphologie puisque seulement deux fonds de récipients hauts et fermés, de petite taille, ont été recueillis (fig. $14, n^{\circ} 29$ et 30 , tournés respectivement dans une argile à quartz et dans une argile à grains de glauconie).

55 La céramique de "type Besançon" stricto sensu est attestée dans cet horizon par 3 individus ( $\mathrm{n}^{\circ}$ 31-33) qui présentent des caractéristiques formelles typiques des dernières productions de cette catégorie modelée de tradition gauloise (Lallemand et Tuffreau-Libre, 2005). Les lèvres, rectilignes, sont courtes, épaisses et marquées d'un ou deux sillons. L'altération des surfaces ne permet pas d'observer la présence de revêtement.

La céramique non tournée est, elle aussi, attestée par un nombre minimum de 3 individus (33 fragments). Tous ont été confectionnés dans une argile glauconieuse : 
une jatte à courte lèvre marquée d'une cannelure très superficielle $\left(n^{\circ} 34\right)$, ainsi que la partie inférieure de deux pots à fond plat, de faible gabarit $\left(\mathrm{n}^{\circ} 35\right)$.

La catégorie des amphores, avec seulement cinq fragments, montre des origines variées. Certaines sont caractéristiques des productions de la péninsule ibérique, notamment de Bétique (amphore à huile Dressel 20 et à saumure Dressel 7/11) ou de Tarraconaise (1 fragment à pâte beige d'amphore à vin Pascual 1 ou Dressel 2/4). Des fragments d'une autre amphore vinaire témoignent aussi d'échanges avec la péninsule italique (Dressel 2/4 voire Dressel 1, en ce cas résiduelle dans ce contexte). Notons encore la présence d'une amphore Pascual 1 de fabrication gauloise $\left(n^{\circ} 36\right.$, pâte brune à revêtement blanchâtre). De telles productions sont attestées en Gaule de l'Ouest et du Centre-Ouest dès le début du $\mathrm{I}^{\mathrm{er}}$ siècle, mais surtout à partir de l'époque tibérienne (Laubenheimer et al., 2005).

\section{Le mobilier de la fosse 39 (tabl. 4 ; fig. 15 et 16)}

Le comblement de cette fosse s'est révélé riche en céramique (598 tessons, 57 individus), avec un lot qui se caractérise toutefois par une fragmentation forte, notamment au sein de la céramique commune claire. On soulignera également qu'une partie du mobilier a subi l'action d'un feu qui a non seulement fragilisé les fragments mais parfois modifié leur aspect.

Les éléments datants, très cohérents, permettent d'obtenir une fourchette chronologique vers 50-70 apr. J.-C. Cet ensemble apparaît par conséquent contemporain de celui de la rue Amesland à Sées (Fichet de Clairfontaine et Gros, 1995). On observera notamment entre ces deux sites une communauté de répertoire concernant la vaisselle de table. D'autres points de comparaison peuvent être proposés avec une fosse et deux fossés de la région d'Evreux, à Guichainville (similitude dans le répertoire des sigillées, terra nigra, NPR, mais aussi pour certaines céramiques communes); malheureusement, ces creusements sont moins précisément datés (deuxième moitié du $\mathrm{I}^{\mathrm{er}}$ siècle : Adrian, 2001, p. 101-111). C'est aussi le cas de niveaux de circulation attestés devant la villa de Ménil-Froger (cf. infra, phase 3, us 2028/2029/2103).

\begin{tabular}{|l|l|l|l|l|}
\hline F39 & Nb Frag. & \%N Frag. & NMI & \%NMI \\
\hline sigillée & 30 & $5,0 \%$ & 5 & $8,8 \%$ \\
\hline cér. plombifère & 20 & $3,3 \%$ & 1 & $1,8 \%$ \\
\hline terra nigra & 78 & $13,0 \%$ & 22 & $38,6 \%$ \\
\hline engobe blanc & 16 & $2,7 \%$ & 4 & $7,0 \%$ \\
\hline cér. commune claire & 271 & $45,3 \%$ & 6 & $10,5 \%$ \\
\hline NPR commune & 8 & $1,3 \%$ & 2 & $3,5 \%$ \\
\hline cér. commune sombre & 113 & $18,9 \%$ & 12 & $21,1 \%$ \\
\hline cér. non tournée & 6 & $1,0 \%$ & 2 & $3,5 \%$ \\
\hline amphore & 56 & $9,4 \%$ & 3 & $5,3 \%$ \\
\hline
\end{tabular}




\begin{tabular}{|l|l|l|l|l|}
\hline TOTAL & 598 & $100,0 \%$ & 57 & $100,0 \%$ \\
\hline
\end{tabular}

Tableau 4 : Dénombrement des céramiques de la fosse $F 39$. Table 4: Summary of ceramics from pit $F 39$.

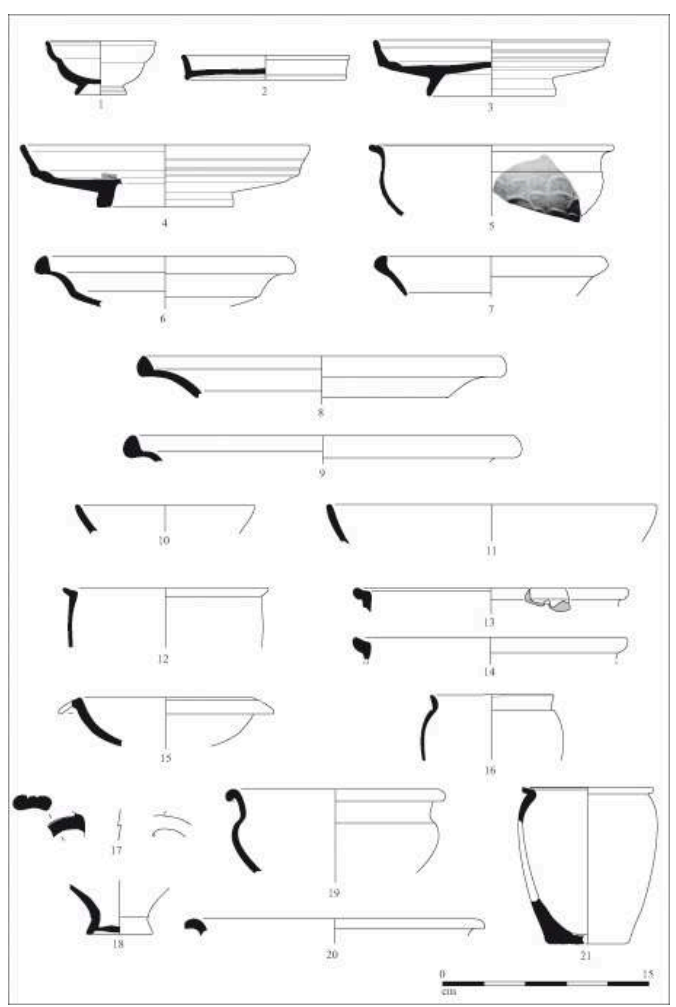

Figure 15 : Mobilier de la fosse 39 : 1-4, sigillée ; 5, céramique plombifère ; 6-16, terra nigra ; 17-18, céramique à engobe blanc ; 19-21, commune claire (relevés et DAO L. Simon).

Figure 15: Finds from pit 39: 1-4, terra sigillata; 5, lead-glazed ware; 6-16, terra nigra; 17-18, white slipped ware; 19-21, dark domestic ware. 


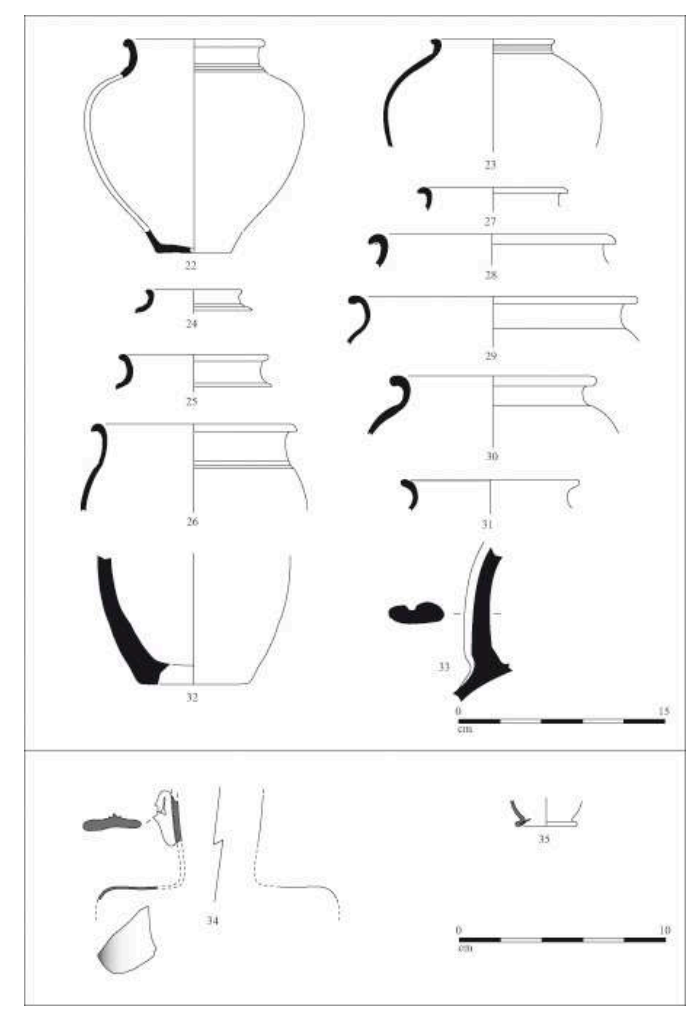

Figure 16 : Mobilier de la fosse 39 (suite) : 22-23, noire à pâte rouge ; 24-31, commune sombre tournée ; 32, commune sombre non tournée ; 33, amphore ; 34-35, verre (relevés et DAO L. Simon)

Figure 16: Finds from pit 39 (continued): 22-37, black-coated/red cored ware; 24-37, wheel-turned dark domestic ware; 32, hand-made dark domestic ware; 33, amphora; 34-35, glass.

La sigillée est représentée par 5 individus, bien conservés contrairement à certaines catégories. Ils comportent majoritairement les caractéristiques techniques du pôle méridional de Millau-La Graufesenque. C'est le cas d'une petite coupelle de forme Drag. 27 (fig. $\left.15, n^{\circ} 1\right)$, des assiettes Drag. $22\left(n^{\circ} 2\right)$ et Drag. $15 / 17\left(n^{\circ} 3\right.$, cette dernière portant une estampille fragmentaire illisible), ainsi que d'un plat Drag. 15/17 ( $\left.n^{\circ} 4\right)$. Dans ce contexte, des fragments d'un plat augustéen de type italique, du service Ic, figurent à titre résiduel.

61 La céramique à glaçure plombifère compte une coupe à pâte beige très clair finement micacée $\left(n^{\circ} 5\right)$ du centre de la Gaule, en usage majoritairement aux deuxième et troisième quarts $d u \mathrm{i}^{\mathrm{er}}$ siècle. Elle présente une lèvre en légère gouttière et un décor d'écailles imbriquées, correspondant à la forme 8 de la typologie établie par J. Corrocher (1983, pl. I, n 8 ). Le décor a été réalisé avec une argile d'aspect plus blanc que le corps du vase. La glaçure, en très grande partie disparue aujourd'hui, était probablement jaune miel. Précisons que ce type est inconnu du recensement des vases à glaçure plombifère, trouvés principalement en contexte funéraire, qu'avait établi Claude Jigan pour plusieurs départements de Haute et Basse-Normandie (Jigan, 1988).

La terra nigra est bien représentée dans ce lot, avec 78 fragments équivalant à un minimum de 22 individus. On recense quatre assiettes de type Menez 40 ( $\left.n^{\circ} 6-9\right)$, toutes à pâte glauconieuse, de teinte gris ou brun-gris, avec des surfaces brun-gris à gris foncé. Le corpus se compose également de coupes, dont deux individus à lèvre simple pouvant s'apparenter à la forme Menez 59. L'un présente une pâte glauconieuse $\left(n^{\circ} 10\right)$, à surfaces noires et cœur brun incluant des grains de chamotte ou d'oxydes métalliques rougeâtres. L'autre ( $\left.n^{\circ} 11\right)$ est caractéristique des productions de type Centre, avec une 
pâte brune à surfaces noires, du mica très fin en abondance, quelques fins nodules de chamotte ou oxydes rougeâtres. Notons encore la présence de trois coupes carénées de forme Menez 103. Celle qui possède le profil le plus effilé $\left(n^{\circ} 12\right)$ a une pâte fortement chargée en grains de glauconie, de teinte gris moyen à surfaces gris foncé. Les deux autres ( $\left.n^{\circ} 13-14\right)$ ont une pâte de type Centre, brune à surfaces noires, faiblement micacée. Signalons que le $\mathrm{n}^{\circ} 13$ a fait l'objet d'une réparation, ainsi que l'indique la perforation pratiquée juste au-dessous de la lèvre. Le répertoire des formes de taille moyenne compte également une coupe à collerette Menez 118/119 $\left(\mathrm{n}^{\circ} 15\right.$; pâte glauconieuse brune à surfaces brun foncé à noir), ainsi qu'une coupe à flancs concaves ("vase-bobine ») Menez 125 ou 126 (résiduelle), représentée par son ombilic (pâte à glauconie). Les formes hautes se limitent à un pot à lèvre effilée Menez $146\left(\mathrm{n}^{\circ} 16\right.$; pâte glauconieuse de teinte gris moyen à surfaces gris foncé).

La céramique à engobe blanc (16 fragments, 4 individus) figure sous forme de tessons de cruche, notamment une anse à pâte glauconieuse brun-rougeâtre $\left(n^{\circ} 17\right)$, ainsi qu'un fond à pied mouluré ( $n^{\circ} 18$, à pâte beige-rosé finement micacée de type Centre, avec des oxydes métalliques rougeâtres). Notons qu'une cruche à panse en toupie et pied similaire au $\mathrm{n}^{\circ} 18$, avec une pâte trahissant une même origine, est signalée dans la région d'Evreux à Guichainville, dans un fossé contenant du mobilier de la deuxième moitié du $\mathrm{I}^{\mathrm{er}}$ siècle (Adrian, 2001, p. 104, fig. 16, $\mathrm{n}^{\circ}$ 202-72). Les autres fragments de céramique à engobe blanc de la fosse 39 possèdent une pâte beige micacée identique (productions de type Centre).

64 La céramique commune claire totalise un nombre important d'éléments avec 271 fragments, mais équivalant à un minimum de seulement six individus. La fragmentation du matériel ne permet que la représentation graphique de trois vases, dont deux coupes ( $\left.n^{\circ} 19-20\right)$ de teinte brune (cœur noir pour le $\left.n^{\circ} 19\right)$ et confectionnées dans une argile glauconieuse. On notera que des jattes de profil similaire sont notamment attestées parmi les productions de La Boissière-École (Yvelines), en territoire carnute, au cours des années 40 à 70 , mais façonnées dans une argile cependant différente (Dufaÿ et al., 1997, p. 167-168, série 2-100 et notamment 2-103). Le vase $n^{\circ} 21$ est, quant à lui, un pot trapu à lèvre équarrie striée, qui se distingue bien des vases à lèvre oblique incisée de la période "augusto-tibérienne ». Il possède une pâte brune très micacée, lissée et dépourvue de tout revêtement.

La céramique noire à pâte rouge (NPR) commune, courante notamment dans les régions Île-de-France et Centre, connaît une représentativité maximale au milieu du $\mathrm{I}^{\mathrm{er}}$ siècle, bien qu'étant alors en usage depuis plusieurs décennies (Jobelot et Vermeersch, 1991 ; 1993; Jobelot, 2000). Elle possède ici deux représentants, des pots à cuire respectivement de type NPR 150 et 35 (fig. 16, $n^{\circ} 22$, à pâte rougeâtre, et 23, à pâte brune). Le premier est fréquent en territoire carnute tout au long du $\mathrm{I}^{\mathrm{er}}$ siècle et particulièrement au cours de la seconde moitié de celui-ci, notamment à Chartres (Sellès, 2001, p. 134-135, nº 1323/24). Tous deux connaissent par ailleurs des équivalents formels à Guichainville, dans un fossé comblé au tout début du II siècle mais contenant majoritairement du matériel de la seconde moitié du $\mathrm{I}^{\mathrm{er}}$ siècle (Adrian, 2001, p. 108, fig. 13, n 202-62 à 65).

Les céramiques communes sombres (113 fragments, 12 individus) se composent de pots à cuire ( $\left.n^{\circ} 24-31\right)$, à l'exception d'une faisselle (fragment de panse à perforations multiples). Certains comportent des moulures ou cannelures marquant la liaison col/ panse ( $n^{\circ}$ 24-26), à l'image des vases de type NPR présentés précédemment. Des ateliers 
de la cité carnute sont connus pour en avoir produit, par exemple ceux du Ier s. de La Boissière-École, déjà mentionnés (Dufaÿ et al., 1997, p. 167-168, série 4-100). Tous ces pots ont une lèvre simple, peu ou pas épaissie, parfois seulement allongée. Un seul exemplaire présente une lèvre incisée $\left(n^{\circ} 31\right)$, destinée vraisemblablement à recevoir un couvercle.

Plusieurs origines géologiques sont à envisager, du fait de caractéristiques techniques bien différenciées. Un groupe se démarque, confectionné dans une argile à glauconie $\left(n^{\circ} 27,28,30,31\right.$, ainsi que de nombreux fragments de panses non attribuables à un individu précis). Les vases ont une pâte brune plus ou moins foncée, parfois "sandwichée " ( $n^{\circ} 28$, cœur gris, franges brunes) et des surfaces noires. Le $n^{\circ} 30$ se distingue par son aspect plus sableux, avec de rares particules de mica très fines et des oxydes noirâtres. Sa pâte est à cœur gris clair et ses surfaces sont de teinte gris moyen. Il possède quelques points communs avec deux pots d'un autre groupe, à pâte dure incluant du mica très fin en quantité moyenne à faible et des oxydes métalliques noirâtres. Ces derniers ont un cœur gris clair $\left(n^{\circ} 29\right)$ ou gris foncé $\left(n^{\circ} 26\right)$ et des surfaces gris moyen. Un pot à col mouluré $\left(n^{\circ} 25\right)$ présente une pâte finement sableuse qui n'est pas sans rappeler celle des vases de type NPR, avec cependant un cœur gris. Enfin, un seul vase ( $\left.n^{\circ} 24\right)$ présente une pâte à grains de quartz (calibrés et de taille moyenne), de teinte gris très clair et aux surfaces gris foncé.

La céramique non tournée est, quant à elle, largement minoritaire avec deux récipients (six fragments), dont un vase de stockage à fond plat et parois épaisses ( $n^{\circ} 32$, à pâte glauconieuse).

Les amphores totalisent trois individus. Les productions importées proviennent de Bétique, avec quelques fragments d'amphore à huile Dressel 20. On recense par ailleurs un conteneur à vin de Narbonnaise, de forme Gauloise 3/5, type diffusé à partir des années 50/60 ( $n^{\circ} 33$ ). La présence d'une amphore « régionale » de type indéterminé doit être encore notée (pâte finement sableuse rougeâtre, certains fragments ayant subi l'action du feu; attache d'anse plate).

70 Le comblement de cette fosse 39 a également livré huit fragments de récipients en verre appartenant à trois individus de teintes différentes. Deux d'entre eux ont été soufflés dans un verre coloré, de teinte ambre et brune. Si la forme du premier ne peut être déterminée, le second correspond à une bouteille à panse prismatique (fig. 16, $\mathrm{n}^{\circ} 34$ ), carrée ou rectangulaire comme l'indique un fragment caréné marquant la liaison col/panse. Elle a pu être utilisée pour le service de table ou la conservation de produits. Le troisième individu est un gobelet à boire de " couleur naturelle » vert clair, représenté par son fond $\left(n^{\circ} 35\right)$. Il est à rapprocher, parmi d'autres possibilités, du type Isings 34/AR 37. Dans tous les cas, bien que le type précis de ces objets ne puisse être déterminé, leurs caractéristiques techniques et formelles les désignent comme des productions du Ier s., jusqu'à courant II $^{\mathrm{e}}$ siècle pour le gobelet.

\section{L'apogée de l'établissement gallo-romain}

71 Cette dernière période consacre l'apparition d'un bâtiment résidentiel de type villa. Deux autres constructions sur poteaux plantés font également leur apparition, tandis que le paysage environnant est de nouveau modifié (fig. 17). 


\section{Le système fossoyé}

72 Les transformations du parcellaire aboutissent à une simplification de celui-ci, mais la pérennisation de limites anciennes est réaffirmée. Ainsi, à l'est, le fossé $\mathrm{F} 3$, qui succède à $\mathrm{F} 32 \mathrm{a}$, se développe sur une distance supérieure à $120 \mathrm{~m}$. Son profil est trapézoïdal avec un fond plat d'une trentaine de centimètres environ et une ouverture de 0,80 à $1 \mathrm{~m}$ (fig. 17) ou plus évasé avec un fond arrondi et une ouverture comprise entre 1,10 et $1,60 \mathrm{~m}$. Ce creusement n'entame jamais le calcaire qui apparait à $0,80 \mathrm{~m}$ sous la surface au sud de l'intervention. Il s'agit manifestement d'un choix volontaire qui peut expliquer l'ouverture assez large du fossé au sud-est. Son comblement est homogène et constitué généralement d'une terre plus ou moins brune.

La limite décrite par le fossé $\mathrm{F} 98$ trouve une dernière concrétisation dans la réalisation de F 61. Depuis son retour à l'est, matérialisé par le fossé 58, F 61 se développe sur $67 \mathrm{~m}$ avant d'opérer un coude pour se diriger de nouveau vers l'ouest. Certains des aspects de $\mathrm{F} 98$ sont donc conservés lors de cette période : existence d'un retour à l'est et d'une chicane au sud de la villa. Environ $25 \mathrm{~m}$ à l'ouest de cette dernière, le tracé $\mathrm{F} 61$ s'interrompt à l'approche d'un bâtiment sur poteaux (bâtiment 1). Malheureusement, la largeur de ce passage, supérieure à $5 \mathrm{~m}$, ne peut être précisée ${ }^{4}$.

Le fossé $\mathrm{F} 61$ comporte un fond plat de $0,80 \mathrm{~m}$ environ, pour une profondeur conservée de 0,70 à $0,80 \mathrm{~m}$ au maximum. Son ouverture oscille de $1,4 \mathrm{~m}$ (sondage 9) à plus de $2 \mathrm{~m}$ (sondages 1 et 2) et ses bords s'évasent de façon régulière ou montrent parfois des inflexions résultant de l'effondrement des parois. Son remplissage est formé d'une seule strate, une matrice argileuse brun orangé, qui repose parfois sur un dépôt grisâtre riche en manganèse, confirmant un fonctionnent ouvert. En tout état de cause, aucun dépôt anthropique n'a été observé dans les sondages de F 61 .

Hormis ces deux creusements, l'unique limite fossoyée attribuable à cette période est constituée par le fossé $\mathrm{F} 31$, qui succède à $\mathrm{F} 2$. Ce nouveau fossé ne mesure plus qu'une soixantaine de centimètres de large pour une profondeur inférieure à $30 \mathrm{~cm}$ (cf. supra fig. 9). La passerelle 123 est alors détruite, mais un passage, figuré par une interruption du fossé 31, est maintenu au même emplacement (fig. 17).

\section{Les bâtiments sur poteaux}

Le bâtiment 2 se situe à l'écart de la villa, à l'emplacement des anciens aménagements attribués à la Préhistoire. Son plan, incomplet, est matérialisé au sol par cinq trous de poteaux (fig. 18, Tp. 10-12, 19, 20), un sixième étant plus douteux (Tp. 41). Cinq sont installés sur l'axe des anciennes fosses de calage F 9, 22, 28 et 13. Le dernier est situé entre les creusements F 13 et F 4, marquant ainsi l'amorce d'un retour. Au sud de la construction, l'espace est occupé par la fosse $\mathrm{F} 6$, large de $4 \mathrm{~m}$ et longue de plus de 5 . Son comblement cendreux a livré de nombreux morceaux de tuiles et de torchis brûlé, de la céramique, ainsi que plusieurs objets en fer dont un gros clou de charpente. Ces artefacts illustrent la destruction du bâtiment 2, au même titre peut-être qu'une grille en fer découverte dans le comblement supérieur du fossé $\mathrm{F} 3$ et qui s'apparente à une armature de fenêtre. L'ensemble de ces indices permet d'imaginer un bâtiment en matériaux périssables et couvert d'une toiture en tuiles. 


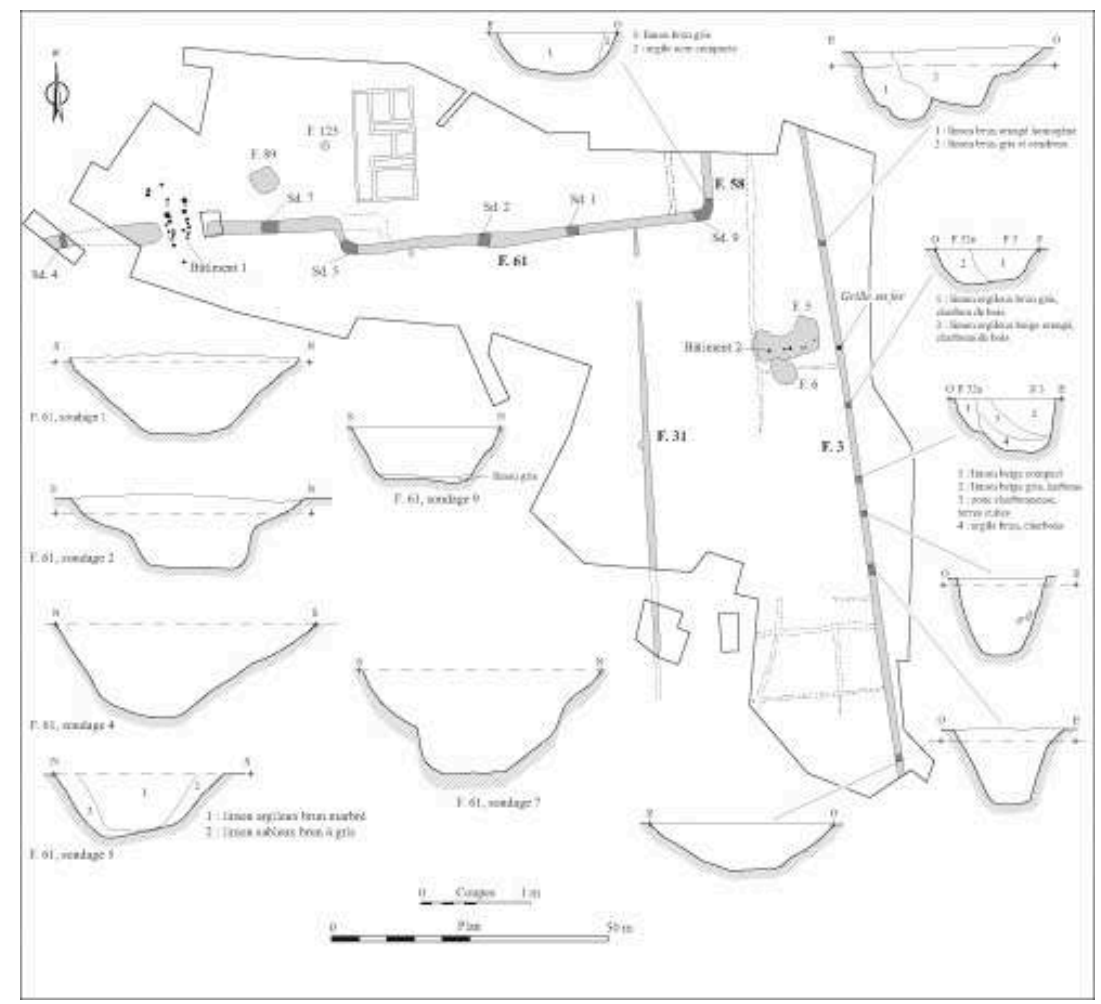

Figure 17 : Troisième phase gallo-romaine : plan des aménagements et coupes des fossés (DAO B. Kerampran / R. Ferrette).

Figure 17: Third Gallo-Roman phase: plan of structures and sections of ditches.

Une seconde construction apparaît à l'emplacement d'une portion comblée du fossé F 98 (bâtiment 1, fig. 18). Les trous de poteaux qui le matérialisent s'organisent selon deux alignements orientés nord-sud et pratiquement parallèles. Ils dessinent un rectangle de $9 \mathrm{~m}$ de long au maximum pour une largeur de $3 \mathrm{~m}$. Le premier axe comprend huit poteaux, répartis de façon assez régulière mais offrant des caractéristiques morphologiques différentes (fig. 18, Tp. 91-92, 97, 102, 106, 110 à 112). Le second alignement comprend neuf emplacements de poteaux qui, à l'instar des précédents, comportent des ouvertures et des profondeurs variables. La proximité de certains creusements et leurs caractéristiques distinctes pourraient témoigner de réfections, voire d'une succession de plusieurs édifices. L'interruption du fossé $\mathrm{F} 61 \mathrm{au}$ niveau du bâtiment 1 amène aussi à envisager une relation étroite et fonctionnelle entre ces deux éléments. L'hypothèse d'un édifice permettant l'accès à la zone sud depuis la villa paraît être une hypothèse recevable. 


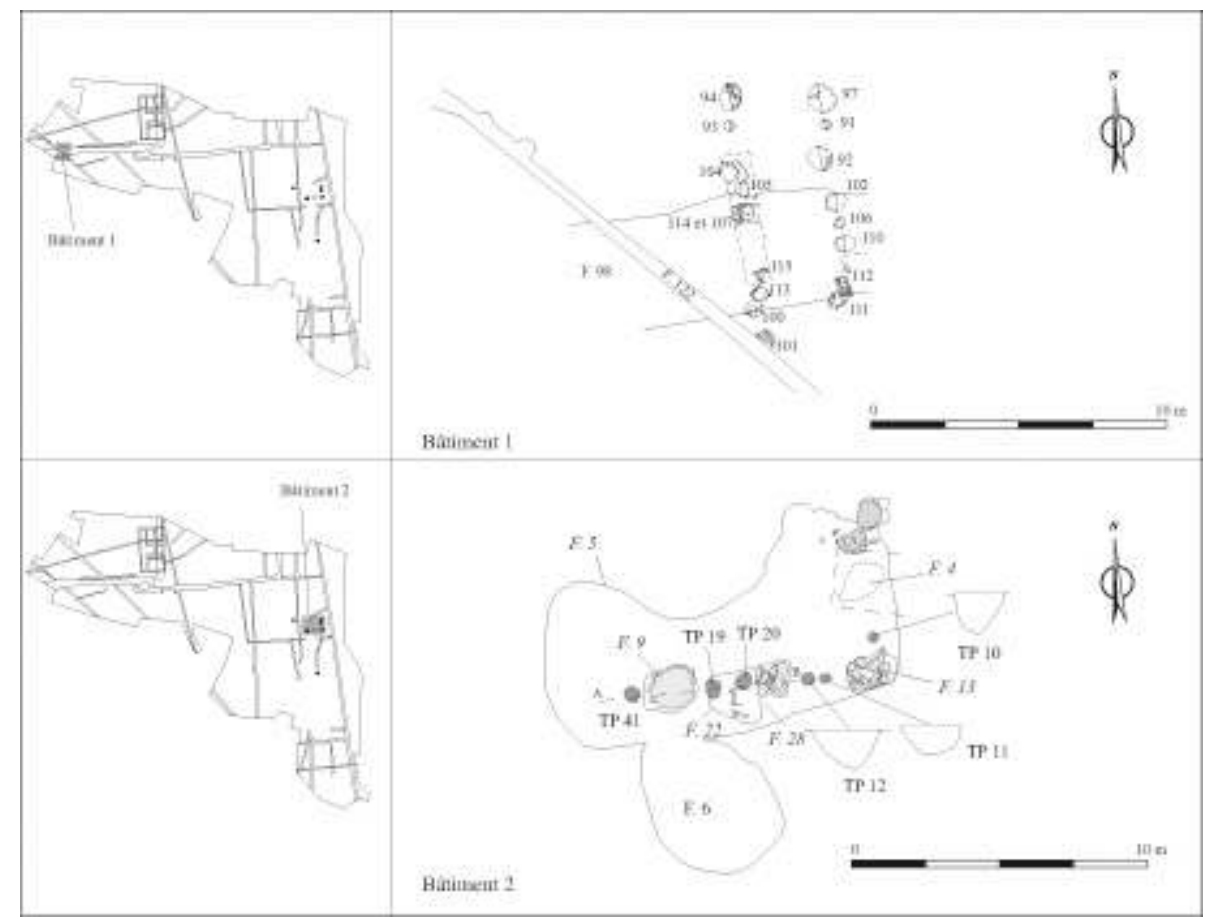

Figure 18: Localisation des bâtiments 1 et 2 sur poteaux plantés (DAO B. Kerampran / R. Ferrette). Figure 18: Location of post buildings 1 and 2 .

\section{La villa et ses aménagements annexes}

Orientée nord-sud et regardant vers l'ouest, elle est construite pour partie à l'emplacement de l'enclos A de la phase 1 . Son mur arrière est en effet installé sur le bord est du fossé F 2046, tandis que les murs 2007 de la salle 8 et 2008 de la salle 5 sont positionnés en limite du bord intérieur de ce même fossé (cf. supra fig. 5). De plan rectangulaire, le bâtiment est long d'une vingtaine de mètres pour une largeur de $11 \mathrm{~m}$ hors oeuvre. Un seul programme architectural a été mis en évidence et son plan témoigne d'une symétrie parfaite (fig. 19). La villa comprend sept pièces précédées d'une galerie de façade (« salle $1 »)$. Un espace non fermé sur son côté ouest (« salle $2 »)$ fait office de transition entre cette galerie portique et les pièces en retrait. Il est bordé de deux couloirs qui conduisent soit vers une grande pièce (salle 6), soit vers deux autres plus modestes et situées sur le pignon nord (salles 7 et 8). Il n'est pas impossible que l'un de ces deux couloirs ait abrité une cage d'escalier menant à un étage. Enfin, une dernière pièce se développe en retrait de l'espace 2 (salle 5). 


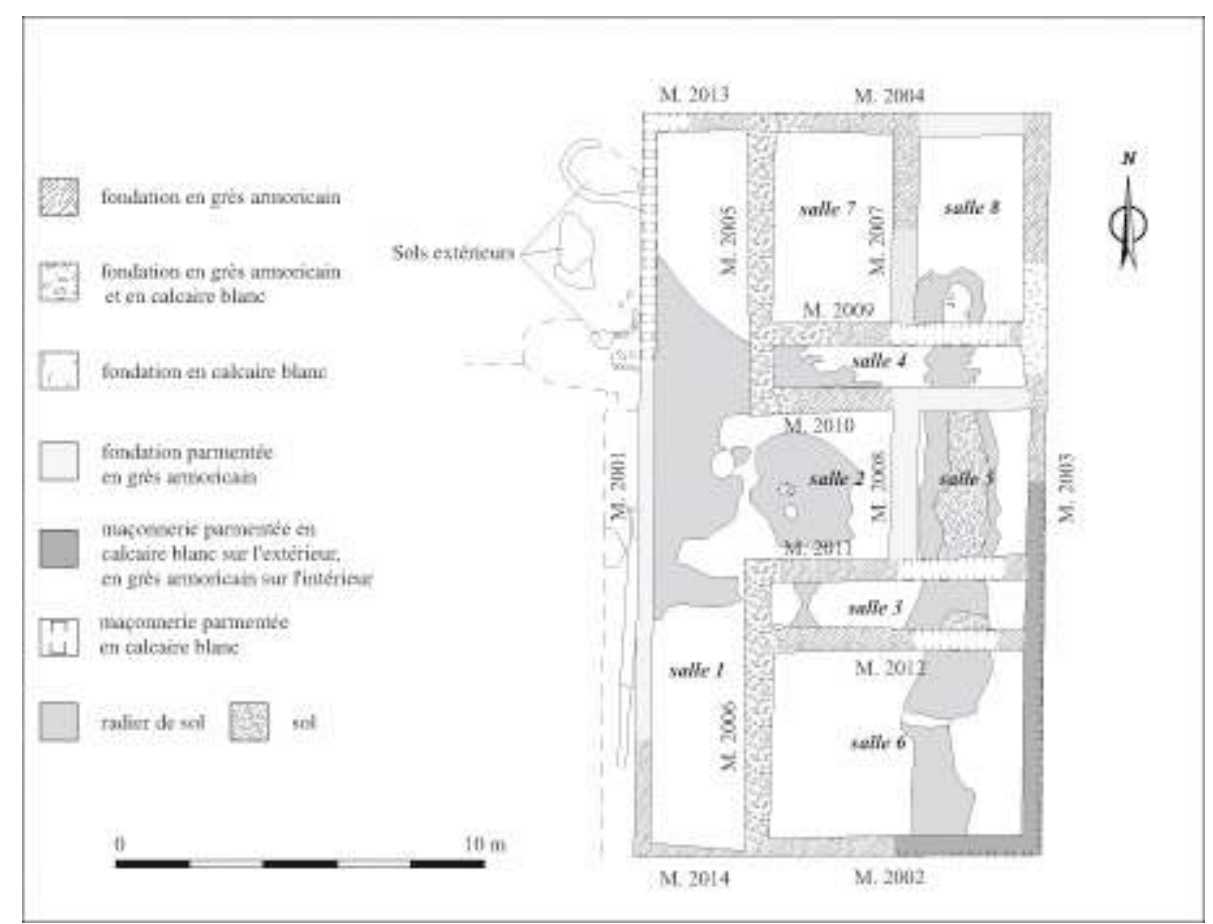

Figure 19 : Plan simplifié de l'édifice résidentiel de la dernière phase gallo-romaine (DAO B. Kerampran / R. Ferrette).

Figure 19: Last Gallo-Roman phase: simplified plan of residential building.

79 L'unicité de la composition se lit dans la méthode de construction. Les ouvriers ont d'abord réalisé un rectangle en débutant par le mur 2003, puis par les pignons 2004 et 2002. Ils ont poursuivi par les maçonneries 2006 et 2005 pour finir par 2010 et 2011, qui s'appuient sur le mur arrière. Les maçonneries internes qui cloisonnent les différents espaces sont les dernières réalisées. Les pignons 2013 et 2014 de la galerie façade s'appuient quant à eux sur le corps de l'édifice. Plutôt que d'y voir un rajout postérieur, il faut certainement mettre ce mode de construction au compte d'une charge moindre à supporter, qui ne nécessitait pas un renfort particulier.

La mise en œuvre des maçonneries est constante. Les radiers sont formés de grès armoricain, associé parfois à des éclats de débitage de calcaire blanc. Ils sont coiffés d'une fondation parementée de blocs gréseux grossièrement équarris. Les élévations utilisent par contre majoritairement des moellons en calcaire blanc et leur blocage est constitué d'éclats de taille.

Cet agencement diffère cependant à l'emplacement du fossé 2046. Les fondations en vrac, largement débordantes, sont alors recouvertes d'une semelle de béton de chaux sur laquelle sont disposées des assises non visibles de moellons en calcaire blanc. Parfois, de gros blocs ont été employés afin de renforcer la cohésion de l'ensemble, à l'image du mur 2002. Ces renforts trahissent une connaissance de l'existence de F 2046, alors que celui-ci était comblé depuis plusieurs décennies. Cette connaissance a pu être empirique et se produire au moment de la construction de l'édifice, mais le respect strict de l'orientation et des bordures du fossé 2046 reste étonnant. Quoi qu'il en soit, les précautions prises n'ont pas évité l'affaissement parfois conséquent des maçonneries au-dessus de l'enclos A (cf. supra fig. 5, F 2046 sondage 6). L'explication réside, certes dans le fait d'un terrain plus meuble, mais aussi dans l'existence probable d'un étage et donc d'une charge plus importante reposant sur les murs. 

particulièrement riches en céramique: 222 fragments, estimés correspondre à un minimum de 33 individus. Ils témoignent d'une formation dans le courant de la deuxième moitié $\mathrm{du} \mathrm{I}^{\mathrm{er}}$ siècle, au moins à partir des années 60 , tout en renfermant quelques éléments caractéristiques des horizons claudiens et parfois même tibériens. Ainsi, ces ensembles présentent-ils plusieurs points de comparaison avec le comblement de F 39, daté du troisième quart du $\mathrm{I}^{\text {er }}$ siècle. Des affinités ont également été notées avec les découvertes de la rue Amesland à Sées (Fichet de Clairfontaine et Gros 1995) ou encore avec le mobilier d'ensembles de la deuxième moitié du $\mathrm{I}^{\mathrm{er}}$ siècle à Guichainville (Adrian, 2001, p. 101-111).

\begin{tabular}{|l|l|l|l|l|}
\hline sols villa & Nb Frag. & \%Nb Frag. & NMI & \%NMI \\
\hline sigillée & 20 & $9,0 \%$ & 11 & $33,3 \%$ \\
\hline
\end{tabular}




\begin{tabular}{|l|l|l|l|l|}
\hline paroi fine engobée & 9 & $4,1 \%$ & 3 & $9,1 \%$ \\
\hline terra nigra & 42 & $18,9 \%$ & 5 & $15,2 \%$ \\
\hline engobe blanc & 11 & $5,0 \%$ & 2 & $6,1 \%$ \\
\hline engobe orange/rouge & 5 & $2,3 \%$ & 3 & $9,1 \%$ \\
\hline cér. commune claire & 71 & $32,0 \%$ & 3 & $9,1 \%$ \\
\hline cér. commune sombre & 54 & $24,3 \%$ & 4 & $12,1 \%$ \\
\hline amphore & 10 & $4,5 \%$ & 2 & $6,1 \%$ \\
\hline TOTAL & 222 & $100,0 \%$ & 33 & $100,0 \%$ \\
\hline
\end{tabular}

Tableau 5 : Dénombrement des céramiques des us 2028, 2029 et 2103.

Table 5: Summary of ceramics from su 2028, 2029 and 2103.

La sigillée est représentée par des fragments du pôle Millau-La Graufesenque, à l'exception d'une pièce, sans attribution de forme, issue des ateliers montanais. Cette vaisselle est à situer, pour l'essentiel, dans une fourchette chronologique couvrant les deuxième et surtout troisième quarts du $\mathrm{I}^{\mathrm{er}}$ siècle, avec, comme occurrence la plus récente, une assiette du service A. (Drag. 36, $\mathrm{n}^{\circ}$ 5). La gamme des assiettes comprend également un Ritt. 1 ( $n^{\circ} 1$ ), deux Drag. $15 / 17$ ( $\left.n^{\circ} 2\right)$, un (voire deux) Drag. 18 ( $\left.n^{\circ} 3\right)$. Trois individus de type Drag. 27 appartiennent à la série des coupelles. Les coupes, quant à elles, correspondent au type à collerette Ritt. 12 et à la forme moulée Drag. 29b (n 4$)$.

La céramique à paroi fine engobée rassemble trois individus provenant d'ateliers du centre de la Gaule. Il s'agit de formes ovoïdes destinées à la boisson, diffusées à partir des années 60 ( $n^{\circ}$ 6-7). Le gobelet de plus grande taille comporte un décor de projection de grains de chamotte $\left(n^{\circ} 7\right)$, tandis qu'on recense encore un fragment de paroi à décor de lunules (non ill.).

La terra nigra comprend des productions réalisées aussi bien dans une pâte fine micacée de type Centre que dans une argile à glauconie. Sont attestées deux formes d'assiette et une forme de coupe, respectivement de type Menez 7/11 ( ${ }^{\circ} 8:$ pâte micacée de teinte gris moyen à surfaces gris foncé), Menez 40 ( $n^{\circ} 9$; pâte glauconieuse brune, surfaces gris foncé) et Menez 103 (trois individus dont le $n^{\circ} 10$ à pâte brune micacée et surfaces noires, le $\mathrm{n}^{\circ} 11$ à pâte glauconieuse gris foncé, franges brunes et surfaces gris moyen ainsi qu'une coupe (non illustrée) avec pâte glauconieuse gris clair et surfaces gris moyen). 


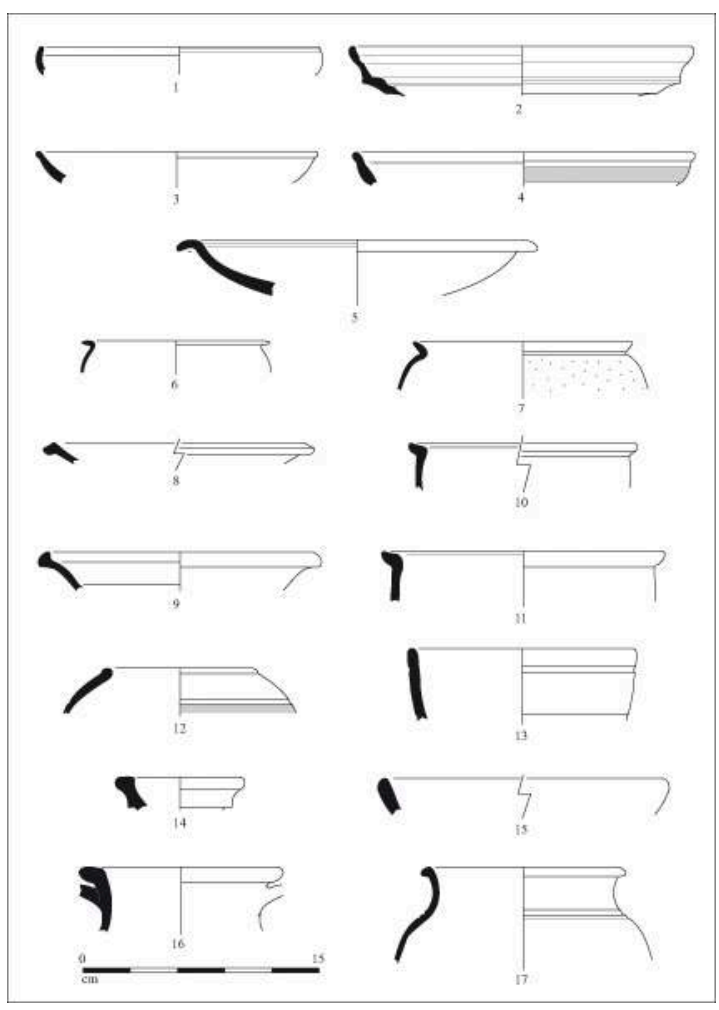

Figure 20 : Mobilier des niveaux de sols (us 2028, 2029, 2103) : 1-5, sigillée ; 6-7, parois fines engobées ; 8-11, terra nigra ; 12-13, céramique à engobe rouge/orangé ; 14, commune claire ; 15 et 17 , commune sombre; 16 , amphore (relevés et DAO L. Simon).

Figure 20: Finds from soil levels (su 2028, 2029, 2103): 1-5, terra sigillata; 6-7, thin-wall slipped ware; 8-17, terra nigra; $12-13$, red/orange slipped ware; 14 , pale domestic ware; 15 \& 17, dark domestic ware; 16, amphora; 18, glass.

La céramique à engobe blanc se limite à quelques fragments de panse de cruche, à pâte beige ou brune, finement micacée.

La céramique à engobe rouge/orangé comprend trois représentants aux caractéristiques techniques et aux formes différentes. Un pot trapu, à petite lèvre ronde et paroi partiellement revêtue d'un décor guilloché, a été réalisé dans une argile rougeâtre très finement sableuse, revêtue d'un engobe rouge foncé $\left(\mathrm{n}^{\circ} 12\right)$. Il correspond à des productions bien cernées dans le quart sud-ouest de l'île-de-France, notamment en territoire carnute, au cours des périodes tibérienne et surtout claudienne (Sellès, 2001, p. 104-105, type 1102.2 ; Barat, 1993, nº 6-7; Barat et Raux, 1994, p. 231, fig. 2, n 17-18). Il est aussi attesté dans la région d'Evreux (Adrian, 2001, fig. $8, n^{\circ} 281-11$ et fig. $12, n^{\circ} 202-28$ et 29 ). L'autre vase est une coupe à lèvre plate soulignée d'une rainure ( $\mathrm{n}^{\circ} 13$; pâte glauconieuse beige à cœur gris, revêtement rouge/ orangé). Elle pourrait s'apparenter au type $601 \mathrm{du}$ faciès de la région de Chartres (Sellès, 2001, p. 64-65), daté du $\mathrm{I}^{\mathrm{er}}$ siècle; elle s'en distingue cependant par ses caractéristiques techniques. Notons encore la présence d'un fragment de panse de cruche à engobe rouge foncé (pâte mi-fine de type Centre).

La céramique commune claire figure dans ces niveaux de sol à un état très fragmentaire. Ainsi, malgré un fort contingent de fragments (71), on n'identifie que trois individus. Parmi eux figure un bord de cruche $\left(n^{\circ} 14\right.$; pâte finement sableuse, rose-orangé à franges et surfaces beiges) qui trouve de nouveau des équivalents formels à Chartres, où le type est produit au cours de la seconde moitié du $\mathrm{I}^{\mathrm{er}}$ siècle. (Sellès, 
2001, p. 182-183, n²803). Les autres fragments de ce lot sont à pâte soit calcaire mifine, soit siliceuse (finement sableuse), soit à grains de glauconie.

La céramique commune sombre comprend une écuelle à bord simple $\left(n^{\circ} 15\right.$, à pâte rugueuse gris moyen) et trois pots, dont un exemplaire à pâte finement sableuse $\left(n^{\circ} 17\right.$, de teinte noire) qui n'est pas sans évoquer les productions de type 150 du répertoire de la céramique NPR commune. Des fragments de vases à pâte glauconieuse doivent également être mentionnés.

94 Les amphores sont au nombre de deux : un individu lié au transport d'huile d'olive du sud de l'Espagne (Dressel 20) et un autre de production "régionale ", à pâte dure, finement sableuse, de couleur rouge $\left(n^{\circ} 16\right)$.

95 Dans ces niveaux de circulation a encore été recueilli un fragment de verre, lié au type Isings 10/AR 124 (fig. $27 \mathrm{n}^{\circ}$ 8). Sa forme correspond à un flacon sphérique, à usage cosmétique. Il a été soufflé dans une matière de teinte "naturelle » bleu-vert et est agrémenté d'un filet de verre blanc opaque enroulé en spirale. De tels flacons sont en usage dans le courant du $\mathrm{I}^{\mathrm{er}}$ siècle, à partir de la période tibérienne. Des exemplaires comparables sont recensés par exemple en Haute-Normandie (Sennequier, 1985, p. 200-201, n 310-311).

\section{La fin de l'établissement gallo-romain}

\section{Un abandon antérieur à la fin du III ${ }^{\mathrm{e}}$ siècle?}

La disparition de l'établissement du Petit Parc semble se produire bien avant le dernier tiers du $\mathrm{III}^{\mathrm{e}}$ siècle. Aucun numéraire de cette période ne figure dans les assemblages les plus récents, alors que les frappes à l'effigie de Tetricus sont nombreuses, par exemple dans le secteur résidentiel de l'établissement du Grand-Herbage à Sées (Leclerc, 2007b, p. 153).

Le bâtiment 2 est détruit par un incendie, comme en témoigne une couche cendreuse à son emplacement. Cette destruction interviendrait vers la fin $\mathrm{du} \mathrm{II}^{\mathrm{e}}$ siècle ou dans le premier tiers du suivant, d'après des tessons de sigillées, de métallescentes ou de céramiques de type «La Bosse » recueillis dans ce niveau de démolition (cf. infra - Les éléments de datation). C'est durant ce même intervalle chronologique que le réseau fossoyé semble condamné. Quelques productions de type «La Bosse » et une amphore régionale Gauloise 12 ont été retrouvées dans le fossé F 61. Des tessons de type « La Bosse " figurent aussi dans les remplissages de F 3 et de F 31.

98 Aucun élément matériel n'autorise en fait à situer dans le temps la destruction de la villa. Les seuls indices à notre disposition résident dans le mobilier découvert dans la probable citerne F 89 (deuxième moitié $\mathrm{II}^{\mathrm{e}}$ siècle), dont le comblement peut cependant être bien antérieur à l'abandon de l'édifice résidentiel (cf. infra Les éléments de datation). Quant à la cause de cet abandon, on peut envisager que le tassement des maçonneries au-dessus du fossé F 2046 ait fragilisé l'ossature de l'édifice qui a fini par devenir inhabitable. D'autres hypothèses, comme par exemple une restructuration foncière, sont aussi plausibles. Par la suite, aucune trace d'une réappropriation des lieux, à l'inverse de l'exemple du Grand-Herbage (Leclerc, 2007a), n'a été mise en évidence sur l'emprise fouillée. 


\section{Les éléments de datation}

\section{Le matériel de la fosse 89 (tabl. 6 ; fig. 21)}

Trois des niveaux de remplissage de cette structure ont livré du mobilier archéologique (us 7, 9 et 13), totalisant 119 fragments de céramique répartis en 22 individus. Leur présentation commune est justifiée par une datation identique, à situer au cours de la deuxième moitié du IIe s. Les marqueurs chronologiques les plus déterminants sont liés aux sigillées et aux céramiques communes sombres.

100 La sigillée comprend trois représentants du centre de la Gaule, dont une assiette au rebord orné de feuilles d'eau (service A2), datée du deuxième quart du $\mathrm{II}^{\mathrm{e}}$ siècle $\left(\mathrm{n}^{\circ} 1\right)$. Les autres éléments présentent les caractéristiques techniques des productions des années 140/190 (deux fragments de bol moulé Drag. 37 et un fragment de forme indéterminée).

\begin{tabular}{|l|l|l|l|l|}
\hline F89 & Nb Frag. & \%Nb Frag. & NMI & \%NMI \\
\hline sigillée & 4 & $3,4 \%$ & 3 & $13,6 \%$ \\
\hline type Beuvray & 1 & $0,8 \%$ & 1 & $4,5 \%$ \\
\hline terra nigra & 1 & $0,8 \%$ & 1 & $4,5 \%$ \\
\hline cér. grise mi-fine & 6 & $5,0 \%$ & 2 & $9,1 \%$ \\
\hline engobe blanc & 4 & $3,4 \%$ & 1 & $4,5 \%$ \\
\hline cér. commune claire & 54 & $45,4 \%$ & 3 & $13,6 \%$ \\
\hline cér. commune sombre & 45 & $37,8 \%$ & 9 & $40,9 \%$ \\
\hline amphore & 4 & $3,4 \%$ & 2 & $9,1 \%$ \\
\hline TOTAL & 119 & $100,0 \%$ & 22 & $100,0 \%$ \\
\hline
\end{tabular}

Tableau 6 : Dénombrement des céramiques de la fosse F 89

Table 6: Summary of ceramics from pit $F 89$. 


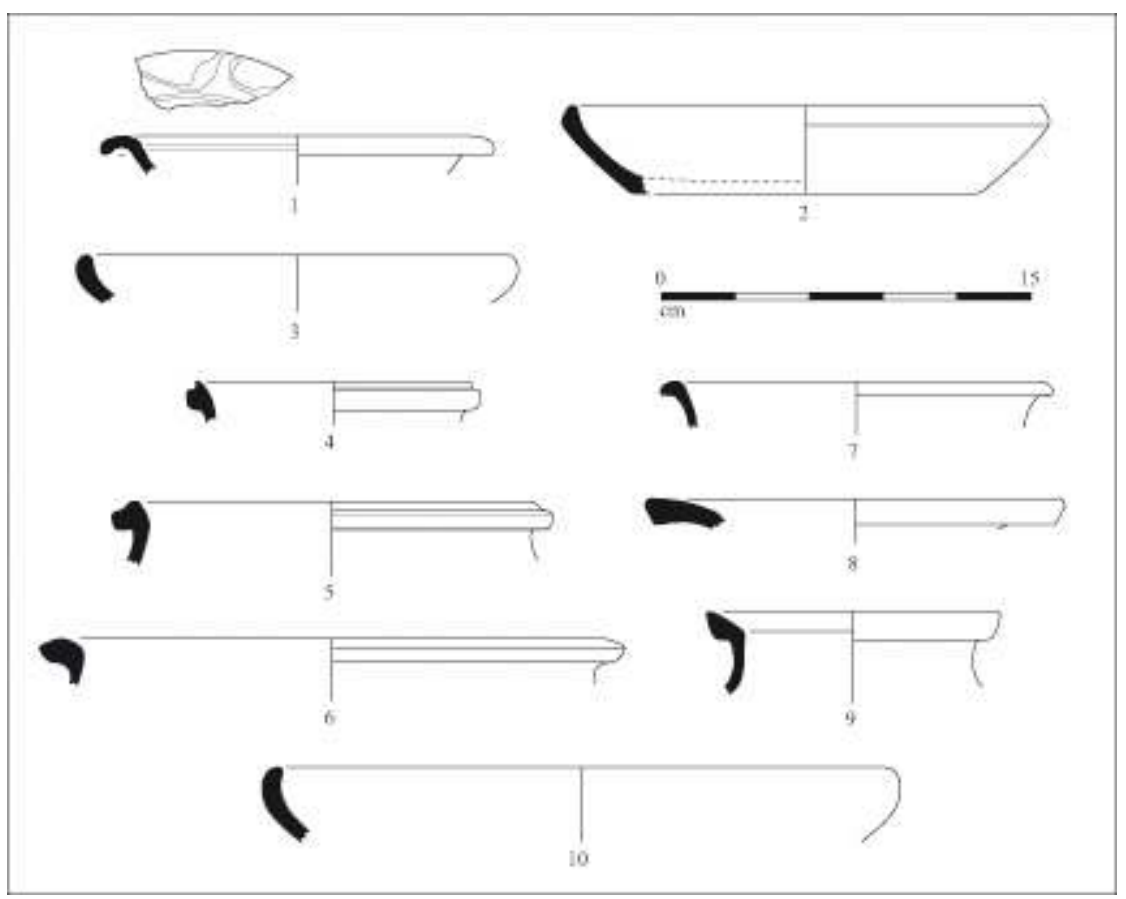

101 Figure 21: Mobilier de la fosse 89: 1, sigillée; 2, céramique grise mi-fine; 3-10, commune sombre tournée (relevés et DAO L. Simon).

Figure 21: Finds from pit 89: 1, terra sigillata; 2, medium grade grey ware; 3-10, wheel-turned dark domestic ware.

Un fond de vase ovoïde de type Beuvray est résiduel, de même qu'un fragment de terra nigra.

La céramique grise mi-fine figure notamment, dans cet ensemble, par le biais d'une assiette apode à bord légèrement rentrant et fond plat $\left(\mathrm{n}^{\circ} 2\right)$. Sa pâte est gris moyen à surfaces gris foncé.

La céramique à engobe blanc est représentée par des fragments de cruche, à pâte glauconieuse ou à quartz fin, dont une anse à un sillon.

La céramique commune à pâte claire est la catégorie la plus riche en fragments, qui ne correspondent cependant qu'à trois individus. Elle comprend pour l'essentiel des fragments de cruche à pâte soit calcaire soit sableuse, ou encore confectionnée dans une argile à glauconie.

106 La céramique commune sombre est également bien attestée avec 45 fragments se répartissant en 9 vases. Ils présentent majoritairement une pâte à quartz. C'est le cas d'une écuelle à bord rentrant ( $\mathrm{n}^{\circ} 3$; pâte grise à surfaces brun-gris), de pots à lèvre en gouttière $\left(n^{\circ} 4\right.$, de teinte gris moyen; $n^{\circ} 5$ à pâte gris foncé, franges brunes et surfaces grises, contenant quelques grosses inclusions de feldspath) ou à lèvre épaissie ( $n^{\circ} 6$; cœur brun, surfaces noires) ou encore à petite lèvre rabattue $\left(\mathrm{n}^{\circ} 7\right.$; pâte brun-gris à surfaces gris clair, très cuite). Notons encore un individu à pâte glauconieuse $\left(\mathrm{n}^{\circ} 8\right.$; cœur gris, franges oranges, surfaces brun-gris). Par ailleurs, au sein de la céramique commune sombre s'individualise nettement un groupe de tessons caractéristiques des productions de type «La Bosse » (Sarthe) ou assimilées, datées de la deuxième moitié du II $^{\mathrm{e}}$ siècle à la deuxième moitié du suivant (Guillier, 1997 ; Bazin et Delage, 2005, p. 652). Les rares éléments morphologiques se rapportent à un pot à bord en « bec 
d'aigle " $\left(\mathrm{n}^{\circ} 9\right)$, dans sa variante classique de la deuxième moitié du II ${ }^{\mathrm{e}}$ siècle, à une coupe à bord rentrant LB 201 ( $\left.\mathrm{n}^{\circ} 10\right)$, ainsi qu'à un marli de coupe LB 203.

La catégorie des amphores est illustrée par trois tessons caractéristiques des Dressel 20, et par un fragment indéterminé.

\section{Le mobilier des fosses $F 5$ et $F \quad 6$ (tabl. 7 ; fig. 22)}

Ces deux lots proviennent d'une couche cendreuse incluant divers matériaux de construction, qui illustre la démolition du bâtiment 2. Ce niveau scelle en effet l'emplacement de l'édifice (F 5) ainsi que la fosse F 6, contemporaine de son fonctionnement. Ils ont livré un total de 126 tessons de céramique, correspondant à un minimum de 24 individus. Il s'agit de l'un des lots les plus récents du site, datable de la fin du $\mathrm{II}^{\mathrm{e}}$ siècle au premier tiers du $\mathrm{III}^{\mathrm{e}}$ siècle. Certains fragments ont été altérés, parfois fortement, sous l'action de la chaleur.

La sigillée comprend six fragments, provenant tous du centre de la Gaule. Les plus récents sont typiques des productions du dernier tiers du II $^{\mathrm{e}}$ siècle au premier tiers du III ${ }^{\mathrm{e}}$ siècle : il s'agit de deux fonds de bols moulés Drag. 37. Notons encore une coupelle L044 $\left(n^{\circ} 1\right)$ présentant les caractéristiques du milieu du $I^{e}$ siècle, ainsi que deux assiettes, l'une de forme Drag. 18 (non datée en raison d'un passage au feu) et l'autre de forme indéterminée (milieu/deuxième moitié $\mathrm{du} \mathrm{II}^{\mathrm{e}}$ siècle). De la même aire de production est issu un gobelet en céramique métallescente, dont le type ne peut être précisé (fin $\mathrm{II}^{\mathrm{e}}$-milieu $\mathrm{III}^{\mathrm{e}}$ siècle). Ce lot comporte également un individu résiduel à pâte brune revêtue d'un engobe micacé, caractérisé par une lèvre oblique épaisse portant une double incision. La céramique à engobe blanc est elle aussi anecdotique, avec un fragment de panse de cruche à pâte rougeâtre.

\begin{tabular}{|l|l|l|l|l|}
\hline F5-F6 & Nb Frag. & \%Nb Frag. & NMI & \%NMI \\
\hline sigillée & 6 & $4,8 \%$ & 5 & $20,8 \%$ \\
\hline métallescente & 1 & $0,8 \%$ & 1 & $4,2 \%$ \\
\hline engobe micacé & 3 & $2,4 \%$ & 1 & $4,2 \%$ \\
\hline engobe blanc & 1 & $0,8 \%$ & 1 & $4,2 \%$ \\
\hline cér. commune claire & 17 & $13,5 \%$ & 3 & $12,5 \%$ \\
\hline cér. commune sombre & 34 & $27,0 \%$ & 8 & $33,3 \%$ \\
\hline amphore & 64 & $50,8 \%$ & 5 & $20,8 \%$ \\
\hline TOTAL & 126 & $100,0 \%$ & 24 & $100,0 \%$ \\
\hline
\end{tabular}

Tableau 7 : Dénombrement des céramiques des fosses $F 5$ et $F$.

Table 7: Summary of ceramics from pits $F 5$ and $F 6$.

110 Mieux représentée, avec 17 fragments, la céramique commune claire est également liée à des récipients de type cruche, majoritairement à pâte calcaire. Se distingue tout particulièrement un exemplaire à goulot étroit et lèvre arrondie, doté de deux anses à section en $\mathrm{D}$, comportant deux fines rainures superficielles $\left(\mathrm{n}^{\circ} 2\right)$. 
La céramique commune sombre comprend 34 tessons, qui équivalent à un minimum de 8 individus liés à deux groupes techniques très différents. Au premier, caractérisé par une pâte à quartz de teinte gris moyen à gris foncé, souvent micacée, appartiennent cinq des vases : une écuelle à bord rentrant, une coupe à collerette et bord rentrant, des pots à lèvre épaissie et inclinée $\left(n^{\circ} 3\right)$, rabattue $\left(n^{\circ} 4\right)$ ou bien encore en gouttière $\left(n^{\circ} 5\right)$. Le second groupe rassemble des vases caractéristiques des productions à pâte kaolinitique de type «La Bosse » ou assimilés : une cruche à large goulot LB $439\left(\mathrm{n}^{\circ} 6\right)$, ainsi que des pots LB 609/610 $\left(n^{\circ} 7\right)$ et LB $607\left(n^{\circ} 8\right)$, ce dernier trouvant des parallèles à Sées à la même époque (Blaszkiewicz et Churin, 1991). À ce second groupe de vases à pâte sombre appartient également un fond de récipient indéterminé, à pied formé par un double anneau.

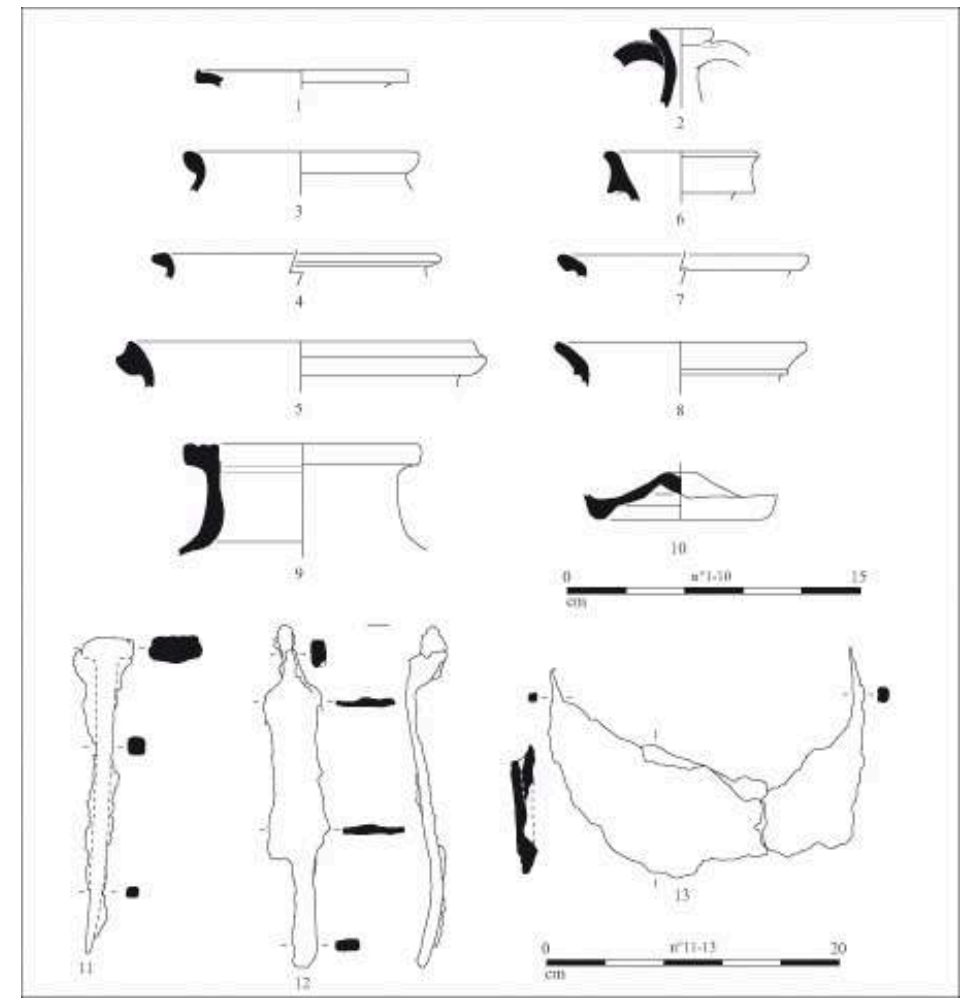

Figure 22 : Mobilier des fosses 5 et $6: 1$, sigillée ; 2, commune claire ; 3-8, commune sombre tournée ; 9-10, amphore ; 11-13, fer (relevés et DAO L. Simon).

Figure 22: Finds from pits 5 \& 6: 1, terra sigillata; 2, pale domestic ware; 3-8, wheel-turned dark domestic ware; 9-10, amphorae; 17-13, iron

112 La catégorie des amphores rassemble la moitié des 64 fragments de ce lot. Elle regroupe seulement cinq individus qui correspondent à trois aires de production bien distinctes. Du sud de la péninsule ibérique provient un conteneur de type Dressel 20, utilisé pour acheminer de l'huile, tandis qu'on recense un fragment d'amphore italique, dont le type ne peut être précisé (Dressel 2/4 ?). L'essentiel des éléments relève en fait d'une production «régionale » à pâte calcaire, en particulier de Gauloise 12, type présumé utilisé pour le transport du vin $\left(n^{\circ} 9\right.$ à pâte orangée, $n^{\circ} 10$, rose foncé). Enfin, un fragment d'amphore présente les caractéristiques des productions du Val de Loire (pâte brune finement micacée, cœur noir et couverte blanchâtre).

Parmi les récipients, signalons encore la présence d'un fragment de verre, sous la forme d'un goulot de vase soufflé en verre naturel bleu-vert. 
114 Quelques objets en fer figuraient également dans ce comblement: un grand clou d'assemblage ( $\left.n^{\circ} 11\right)$, un objet indéterminé ( $n^{\circ} 12$, élément de scellement ?), ainsi qu'une ferrure de pelle/bêche $\left(n^{\circ} 13\right)$.

\section{Les témoins postérieurs à l'occupation gallo-romaine}

Les seules traces d'une occupation postérieure à l'Antiquité sont constituées par les fossés F 122 et 2093, dont l'orientation n'obéit plus au parcellaire antique (fig. 23). Leur tracé rectiligne et parallèle nous amène à penser qu'ils constituent les vestiges d'un ancien chemin dont ne subsisteraient que les fossés bordiers, distants d'une quinzaine de mètres. Cette hypothèse semble confortée par leur direction semblable à celle du CR 28 , ce dernier pouvant en représenter l'ultime évolution. L'unique tesson retrouvé dans le remplissage de F 2093 appartient une céramique à glaçure verte qui n'est pas antérieure au XII ${ }^{\mathrm{e}}$ siècle.

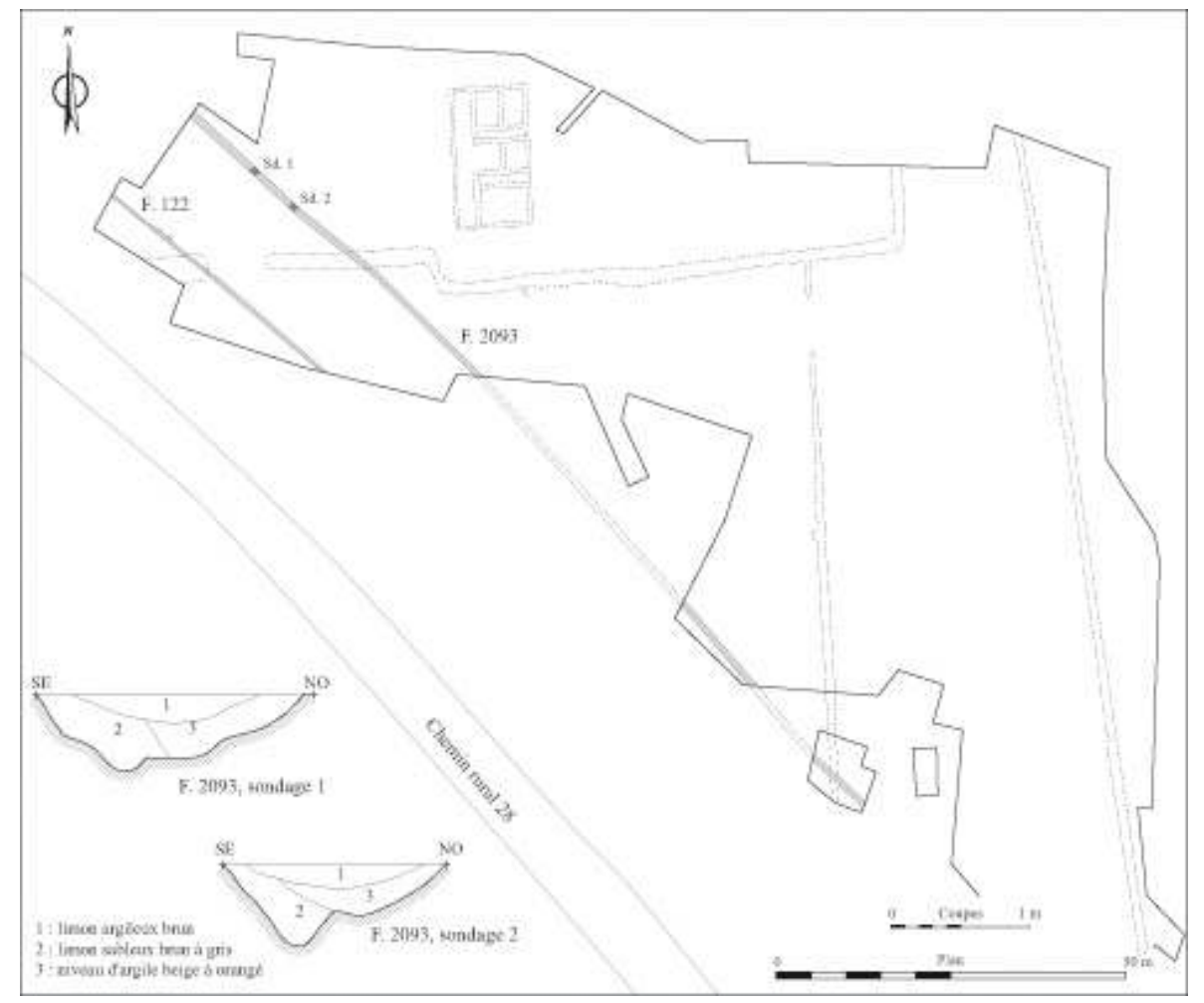

Figure 23 : Plan et coupes des vestiges postérieurs à la période gallo-romaine (DAO B. Kerampran/R. Ferrette).

Figure 23: Plan and sections of post Gallo-Roman features.

\section{Mobilier en fer, verrerie et amphores}

\section{Le mobilier en fer}

\section{Données générales}

116 Quelques objets en fer méritent une attention particulière. Ils constituent soit des pièces liées au cadre de vie des occupants de la villa, soit des outils répondant aux différentes activités du domaine, soit encore des éléments d'attelage. 
117 Parmi les premiers se trouvent une possible grille de fenêtre (fig. 24), un lot de clous forgés de taille moyenne, mais aussi un exemplaire de grand module (fig. 22, $\mathrm{n}^{\circ} 11$ ), utilisés au sein des bâtiments de la villa. S'y ajoute un hypothétique élément de scellement (fig. 22, $\mathrm{n}^{\circ} 12$ ).

118 Les outils sont représentés essentiellement semble-t-il par des instruments à usage agricole: une pelle/bêche attestée par la ferrure renforçant son extrémité (fig. 22, $n^{\circ} 13$ ), une serpe à ébrancher (fig. 26, $n^{\circ} 3$ ), ainsi qu'un manche d'instrument indéterminé (fig. 25, $\mathrm{n}^{\circ} 1$ ), ayant pu avoir un usage pour le travail du bois (?).

119 À la troisième série appartiennent des objets évoquant au moins un véhicule: une clavette de moyeu (fig. 26, $\mathrm{n}^{\circ}$ 6), ainsi qu'une longue barre pouvant avoir fait office de renfort ou de soutien de caisse (fig. $25, n^{\circ} 2$ ).

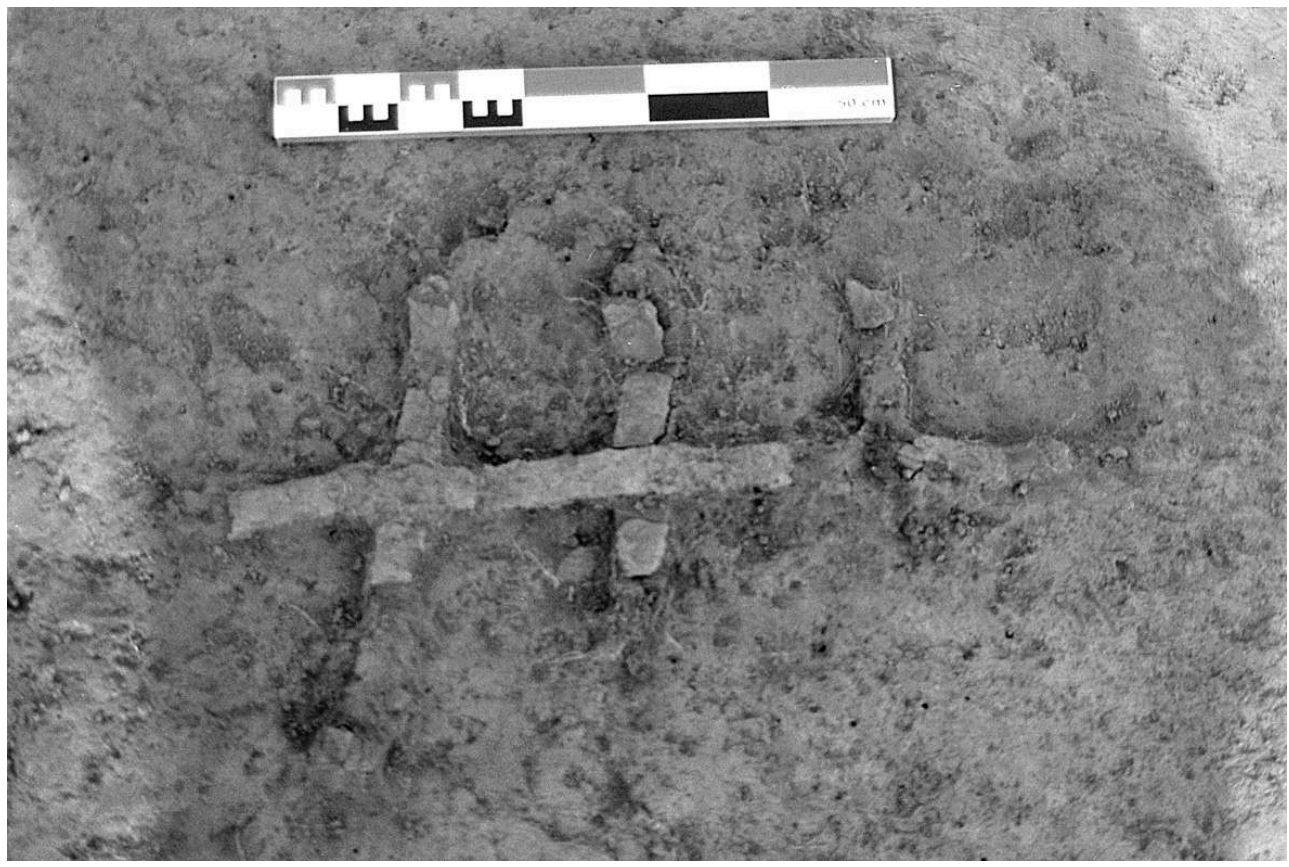

Figure 24 : Grille de fenêtre (ou renfort de coffre ?) découvert lors du décapage du fossé F 3 (cliché V. Chaigne - INRAP).

Figure 24: Window bars (or chest reinforcment?) uncovered during preliminary scraping of ditch $F 3$ 


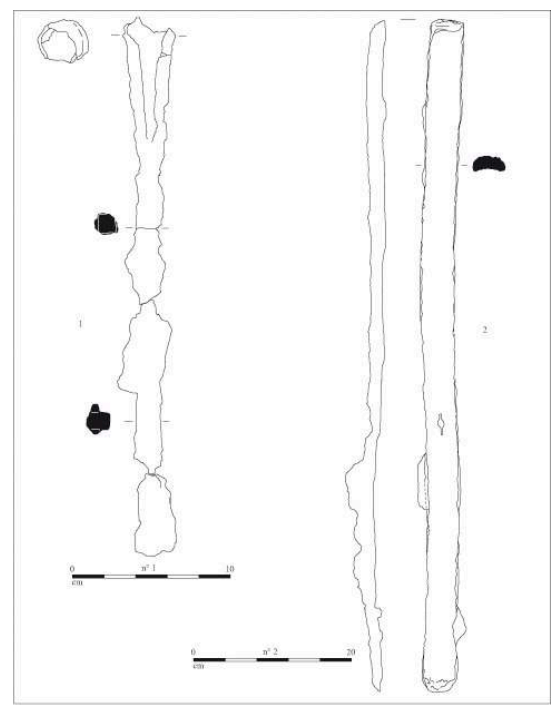

Figure 25 : Mobilier en fer découvert dans le fossé F 3 (relevés et DAO L. Simon).

Figure 25: Iron finds from ditch $F 3$.

Enfin, deux objets de même type restent indéterminés (fig. 26, $\mathrm{n}^{\circ} 4-5$ : fourches? houes?).

\section{Catalogue}

\section{Grille de fenêtre (ou renfort de coffre? - fig. 24).}

121 Fragments de trois barres plates de taille similaire, croisant à angle droit une autre barre de même largeur (largeur des fragments de 34 à $37 \mathrm{~mm}$, avec quelques uns plus faibles, autour de $31 \mathrm{~mm}$ ). D'après les observations recueillies lors de la fouille, les extrémités de chacune des trois barres amorcent un retour perpendiculaire.

Provenance : Fossé F 3, décapage, proximité du bâtiment 2.

Datation du contexte ${ }^{6}: \mathrm{III}^{\mathrm{e}}$ siècle

Comparaisons $^{7}$ pour les grilles de fenêtre : Halbout et al. 1987, 62, n 48 (Rouen/SeineMaritime, III ${ }^{e}$ siècle; grille avec croisillons pointus placés à chaque intersection, obstruant ainsi les carreaux formés par les barres) ; Manning, 1985, 128, pl. 60, R17-18 (Hinton St Mary, Grande-Bretagne, fin $\mathrm{III}^{\mathrm{e}}$ ou IV ${ }^{\mathrm{e}}$ siècle et Margate, Grande-Bretagne, grilles avec croisillons pointus); Adam, 2005, 331, fig. 701 (Herculanum, Italie, $\mathrm{I}^{\mathrm{er}}$ siècle.) 


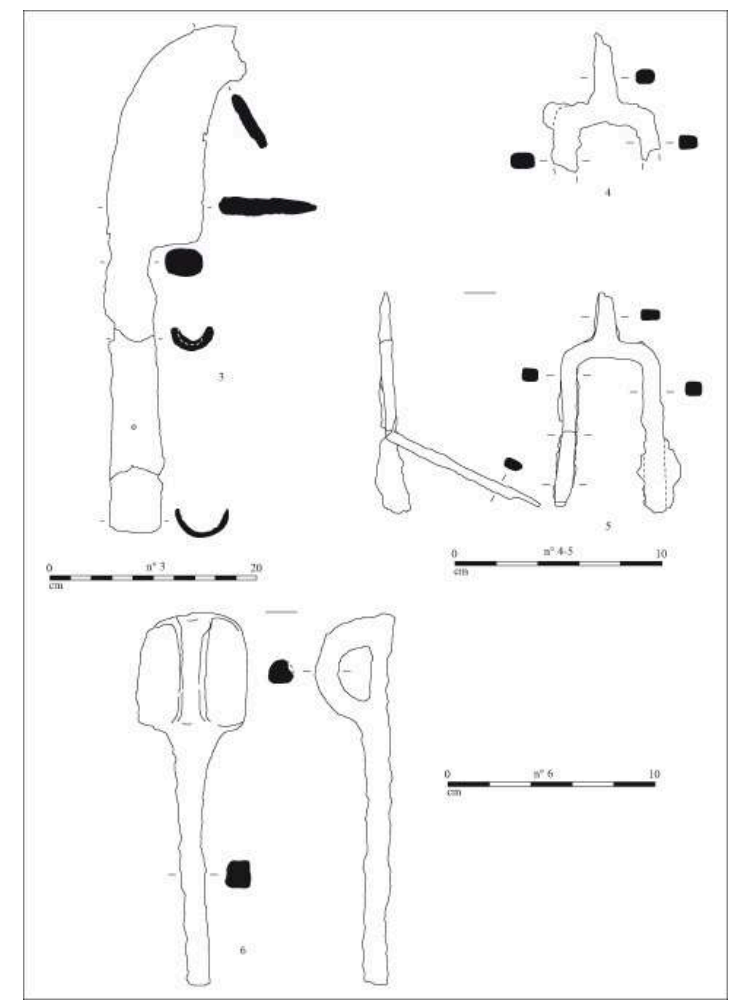

Figure 26 : Mobilier en fer, provenances diverses (relevés et DAO L. Simon).

Figure 26: Iron finds, various provenances.

\section{Grand clou d'assemblage (fig. 22, $\left.n^{\circ} 11\right)$.}

Clou à longue tige de section carrée, à tête en forme de T.

- Provenance : F 6, fosse.

- Datation du contexte $:$ fin du $\mathrm{II}^{\mathrm{e}}$ siècle à premier tiers du $\mathrm{III}^{\mathrm{e}}$ siècle.

- Comparaison : Manning, 1985, 134-136, pl. 63, R99 (Borough Hill, Grande-Bretagne).

\section{Élément de scellement ? (fig. 22, $\left.n^{\circ} 12\right)$.}

- Provenance : F 5, fosse.

- Datation du contexte $:$ fin du $\mathrm{II}^{\mathrm{e}}$ siècle à premier tiers du $\mathrm{III}^{\mathrm{e}}$ siècle.

- Comparaison : Feugère et al., 1992, 44, n 89 (Saintes, Charente-Maritime, 30/50 à 150/170 ; piton de scellement).

Ferrure de pelle/bêche : outil pour retourner la terre (fig. $\left.22, n^{\circ} 13\right)$.

- Provenance : F 6, fosse.

- Datation du contexte $:$ fin du IIe siècle à premier tiers du III $^{\mathrm{e}}$ siècle.

- Comparaisons : Hofmann, 1985, 14, pl. V, n 5-6 (Compiègne, Oise) ; Manning, 1985, 44, type 2.

Serpe : outil à ébrancher (fig. 26, $\left.n^{\circ} 3\right)$.

Lame à tranchant concave, dont l'extrémité est manquante.

Long manche, sous forme de tige massive et pleine du côté de la lame, se prolongeant par une douille semi-couvrante pour l'emmanchement (fixation latérale). Dans le corps 
de la douille subsiste une perforation destinée à accueillir un clou de fixation. Le manche est conservé sur toute sa longueur.

- Provenance : F 67, fosse.

- Datation du contexte : à partir du milieu du i ${ }^{\mathrm{er}}$ siècle.

- Comparaisons : Halbout et al., 1987, n 151-152 (Rouen, Seine-Maritime, deuxième moitié du $\mathrm{II}^{\mathrm{e}}$ siècle et Planches, Orne); Feugère et al., 1992, 74-75, n 143-145 (types différents); Manning, 1985, 56, pl. 23, F41 (Hod Hill, Grande-Bretagne, fin de l'âge du Fer ou milieu du $\mathrm{I}^{\mathrm{er}}$ siècle).

Outil à emmanchement à douille (la douille semble ouverte); tige pleine de section carrée : ciseau plat ? (fig. $25, n^{\circ} 1$ ).

- Provenance : Fossé F 3, décapage.

- Datation du contexte : III $^{\mathrm{e}}$ siècle.

- Comparaisons: Duvauchelle, 2005, 47-51, pl.19-22, n 101-106, 119 (Avenches, Suisse, contextes datés de la période tibérienne à la fin $\mathrm{du} \mathrm{II}^{\mathrm{e}} / \mathrm{III}^{\mathrm{e}}$ siècle; ciseaux à bois, bédane, gouge, ciseau droit) ; Halbout et al., 1987, n 161 (Planches, Orne ; gouge).

Longue barre aplatie, de profil légèrement bombé, présentant une perforation au tiers de sa longueur : barre de renfort ou de soutien de la caisse d'un chariot ? (fig. $\left.25, n^{\circ} 2\right)$.

- Provenance : Fossé F 3, décapage, proximité du bâtiment 2.

- Datation du contexte : III ${ }^{\mathrm{e}}$ siècle.

- Comparaisons : Bouchette et al., 1998, 94, 96, n 227 (Saintes, Charente-Maritime, milieu à troisième quart du $\mathrm{I}^{\mathrm{er}}$ siècle) ; Manning, 1985, 142, pl. 67, S107 (Coldham Common, GrandeBretagne).

Clavette de moyeu (roue de chariot) : élément assurant le maintien du moyeu de la roue sur son axe; variante à anneau (type $2 b$ de Manning) (fig. $26, n^{\circ} 6$ ).

- Provenance : diagnostic (MT2161-1-3).

- Comparaisons : Feugère et al., 1992, 90-96, n 185 (Saintes, Charente-Maritime, premier quart du $\mathrm{I}^{\mathrm{er}}$ siècle); Halbout et al., 1987, $\mathrm{n}^{\circ} 213$ (Rouen, Seine-Maritime, milieu du II siècle); Manning, 1985, 72-74, pl. 31, H41-42 (Great Wakering, Grande-Bretagne et sans provenance).

Petites fourches? Petites houes à dents? (infra, fig. 26, $n^{\circ} 4-5$ ).

Les deux pointes formant un $U$ et la pointe opposée sont de section carrée, voire rectangulaire. L'objet le plus complet présente, dans son état de conservation actuel, une pointe partiellement relevée à l'oblique.

- Provenance : sol 2023, sol extérieur de la villa.

- Datation du contexte : après 60.

- Comparaisons: Eneau, 2002, 28, 75, pl.11, n 194 (Gué de Sciaux, Vienne, remblai haut Moyen Âge ; lame d'outil) ; Noël, 1983, 34, pl. XV, n 3.10 (Viville, Belgique, sépulture rurale du milieu du $\mathrm{I}^{\mathrm{er}}$ siècle; fourchette); Vilvorder, 1990, 74, fig. 32, $\mathrm{n}^{\circ} 12$ (Braives, Belgique ; fourchette). 


\section{Le mobilier en verre}

127 Un lot restreint de verre antique ${ }^{8}$, composé de trente fragments pour un minimum de dix individus, a été découvert lors du diagnostic et de la fouille. Ils sont caractéristiques de la verrerie du Haut-Empire (fig. 27). Le répertoire comporte de la vaisselle de table $\left(n^{\circ} 1-4\right)$, des vases pouvant avoir été utilisés tant pour le service que pour le stockage de liquides $\left(n^{\circ} 6-7\right)$, des récipients destinés à la toilette $\left(n^{\circ} 8-9\right)$, mais aussi du verre à vitre $\left(n^{\circ} 10\right)$. Il est ainsi le reflet de domaines variés de la vie quotidienne au sein de cet établissement rural antique.

Les récipients ont tous été obtenus par soufflage, à l'exception d'un individu moulé, une coupe côtelée Is. 3/AR $2\left(n^{\circ} 1\right)$. Les seuls décors recensés consistent en filets appliqués et refondus à la surface des objets. Ils sont de teinte blanc opaque, sur une matière bleu-vert. Ils sont attestés sur deux individus du Ier s. : une petite coupe à boire Is. 17/ AR $28\left(n^{\circ} 2\right)$ et un flacon sphérique à parfum de type Is. 10/AR $124\left(n^{\circ} 8\right)$, pour lesquels ces applications sont habituelles. Le spectre des couleurs comprend quelques individus artificiellement colorés (brun, ambre, bleu cobalt), côtoyant des pièces de teinte «naturelle » bleu-vert, jaune-vert ou vert, ainsi que deux fragments d'un individu décoloré (incolore).

L'unique fragment de vitre recensé est de teinte bleu-vert $\left(n^{\circ} 10\right)$ et résulte de la technique du coulage. Cet élément implique à l'évidence qu'une partie des ouvertures de la villa était pourvue de vitres.

130 Ce modeste corpus n'appelant pas plus de commentaire, les données typologiques, techniques et chronologiques sont résumées dans le tableau 8, par contexte de découverte.

\section{Les amphores}

\section{Présentation}

131 Le corpus du site, diagnostic et fouille confondus, se compose de 304 fragments. Ils correspondent à un effectif réduit puisque l'estimation effectuée à l'échelle du site, c'est-à-dire en faisant abstraction du phasage, fournit un minimum de 17 individus, chiffre particulièrement faible pour une occupation longue de plus de deux siècles. 


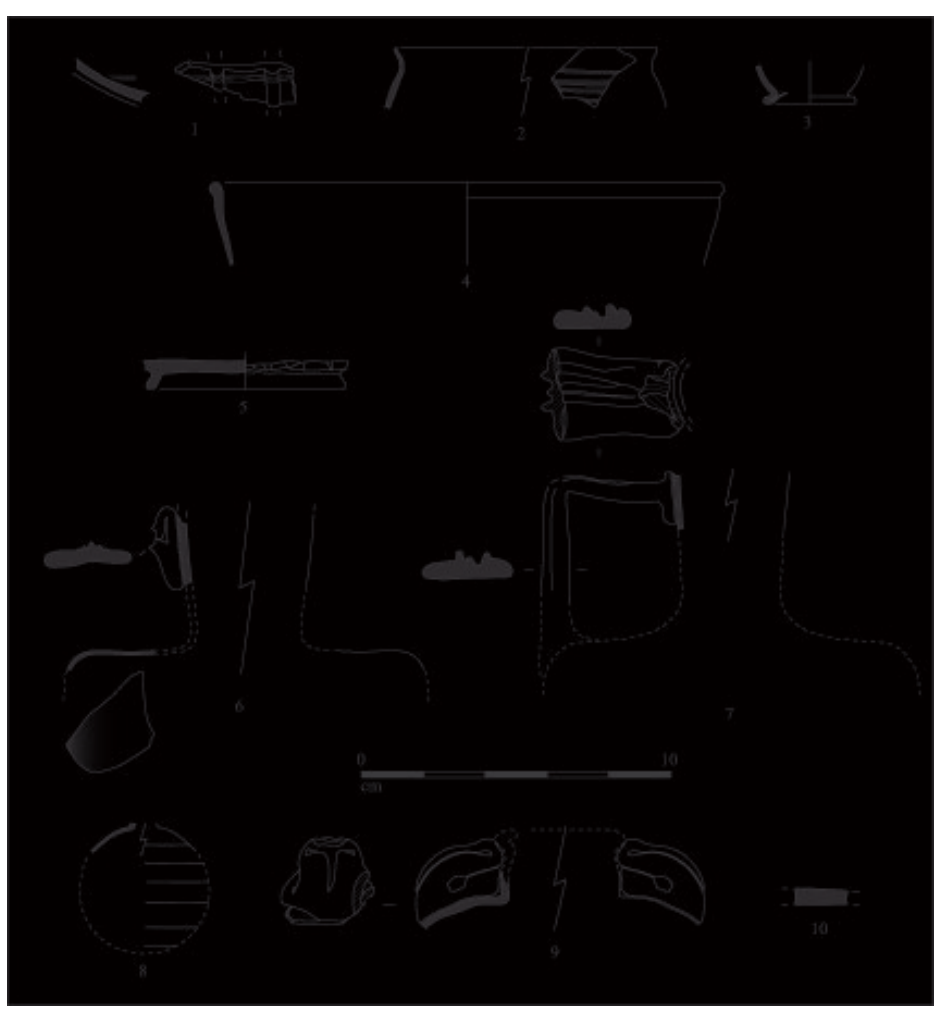

Figure 27 : Mobilier en verre (relevés et DAO L. Simon).

Figure 27: Glass finds.

Les types identifiés sont au nombre de treize (tab. 9, fig. 28) : Dressel $1 b\left(n^{\circ} 1\right)$, Dressel $2 / 4$ de fabrication italique $\left(\mathrm{n}^{\circ} 2\right)$, Dressel $2 / 4$ de fabrication gauloise $\left(\mathrm{OCG}^{9}\right)$, Dressel $2 / 4$ de provenance indéterminée, Pascual. 1 de Tarraconaise ( $\left.{ }^{\circ}{ }^{3}-4\right)$ et Pascual 1 de fabrication gauloise ( $«$ famille» $O C G, n^{\circ}$ 5), Dressel. 7/11, Dressel 20, Gauloise 3/5, Gauloise 12 ( $\left.\mathrm{n}^{\circ} 6-10\right)$, ainsi que trois individus, de fabrication gauloise là encore, mais non répertoriés dans les typologies traditionnelles ( $\left.n^{\circ} 11-13\right)$.

L'analyse des provenances met en évidence trois grands pôles d'origine : l'Italie (2 individus), la péninsule ibérique (4) et la Gaule (9). Enfin, quelques fragments restent indéterminés (1 individu).

\begin{tabular}{|l|l|l|l|l|l|l|l|l|l|}
\hline Fait & Sond. & $\begin{array}{l}\text { Datation } \\
\text { contexte }\end{array}$ & Illus. & Catégorie & Forme & $\begin{array}{l}\text { Réf. } \\
\text { typo. }\end{array}$ & Teinte & $\begin{array}{l}\text { Datation } \\
\text { verre }\end{array}$ & Observations \\
\hline 39 & & $\begin{array}{l}\text { v. 50/60 à } \\
70\end{array}$ & $n^{\circ} 3$ & récipient & gobelet & indét. & vert & Ier-IIe s. & Is. 34/AR 37? \\
\hline
\end{tabular}




\begin{tabular}{|c|c|c|c|c|c|c|c|c|c|}
\hline 39 & & $\begin{array}{lll}\text { v. } 50 / 60 & \text { à } \\
70 & & \end{array}$ & $\mathrm{n}^{\circ} 6$ & récipient & bouteille & indét. & brun & Ier s.-IIIe s. & $\begin{array}{l}\text { fragment de } \\
\text { goulot avec } \\
\text { attache } \\
\text { supérieure } \\
\text { d'anse; } \\
\text { fragment } \\
\text { d'épaulement: } \\
\text { bouteille carrée } \\
\text { (Is. 50/AR 156), } \\
\text { voire } \\
\text { rectangulaire } \\
\text { (Is. 90/AR 157) }\end{array}$ \\
\hline 39 & & $\begin{array}{lll}\text { v. } 50 / 60 & \text { à } \\
70 & & \end{array}$ & & récipient & indét. & indét. & ambre & Ier s. & épaisseur fine \\
\hline 61 & sd 6 surf. & v. 40 à 80 & $\mathrm{n}^{\circ} 2$ & récipient & coupe & $\begin{array}{l}\text { Is. } \\
17 / \\
\text { AR } 28\end{array}$ & $\begin{array}{l}\text { bleu- } \\
\text { vert }\end{array}$ & $10 / 20$ à 70 & \\
\hline 2028 & & $2 / 2$ du Ier s. & $\mathrm{n}^{\circ} 8$ & récipient & flacon & $\begin{array}{l}\text { Is. } \\
10 / \\
\text { AR } \\
124\end{array}$ & $\begin{array}{l}\text { bleu- } \\
\text { vert }\end{array}$ & 20 à $100 / 120$ & \\
\hline 2026 & & v. 60 à 100 & & récipient & indét. & indét. & $\begin{array}{l}\text { bleu- } \\
\text { vert }\end{array}$ & & \\
\hline 5,6 & sd méca. & $\begin{array}{l}\text { fin IIe-1/3 } \\
\text { IIIe s. }\end{array}$ & & récipient & indét. & indét. & $\begin{array}{l}\text { bleu- } \\
\text { vert }\end{array}$ & & $\begin{array}{l}\text { fragment de } \\
\text { goulot }\end{array}$ \\
\hline 2006 & arase mur & n.d. & & récipient & indét. & indét. & cobalt & Ier s.? & épaisseur fine \\
\hline diag. & VR2141-20-1 & $\begin{array}{l}\text { secteur } \\
\text { villa }\end{array}$ & $\mathrm{n}^{\circ} 1$ & récipient & coupe & $\begin{array}{l}\text { Is. 3/ } \\
\text { AR } 2\end{array}$ & ambre & \begin{tabular}{|lr} 
fin & Ier \\
$B C-2 / 2$ & Ier $s$. \\
$A D$ &
\end{tabular} & $\begin{array}{l}\text { zone médiane } \\
\text { interne gravée } \\
\text { superficiellement }\end{array}$ \\
\hline diag. & VR2141-20-1 & $\begin{array}{l}\text { secteur } \\
\text { villa }\end{array}$ & & récipient & indét. & indét. & brun & Ier s.? & \\
\hline diag. & VR2141-21-2 & $\begin{array}{l}\text { secteur } \\
\text { villa }\end{array}$ & & récipient & indét. & indét. & $\begin{array}{l}\text { bleu- } \\
\text { vert }\end{array}$ & & \\
\hline diag. & $\begin{array}{l}\text { VR2143 } \\
\text { bis-1-1 }\end{array}$ & F61? F98? & $\mathrm{n}^{\circ} 7$ & récipient & bouteille & indét. & $\begin{array}{l}\text { bleu- } \\
\text { vert }\end{array}$ & Ier-IIIe s. & $\begin{array}{ll} & \text { partie } \\
\text { supérieure } \\
\text { d'une anse } \\
\text { coudée } \\
\text { nervurée; } \\
\text { traînéeset } \\
\text { points de } \\
\text { particules } \\
\text { métalliques } \\
\text { dans la matière }\end{array}$ \\
\hline
\end{tabular}




\begin{tabular}{|c|c|c|c|c|c|c|c|c|c|}
\hline diag. & $\begin{array}{l}\text { VR2143 } \\
\text { bis-1-1 }\end{array}$ & F61? F98? & $n^{\circ} 10$ & vitrage & vitre & & $\begin{array}{l}\text { bleu- } \\
\text { vert }\end{array}$ & Ier-IIIe s. & $\begin{array}{l}\text { vitre coulée }(1 \\
\text { côté lisse, } 1 \text { côté } \\
\text { rugueux); } \\
\text { épaisseur } 5 \mathrm{~mm}\end{array}$ \\
\hline diag. & $\begin{array}{l}\text { VR2143 } \\
\text { bis-1-2 }\end{array}$ & F61? F98? & $n^{\circ} 9$ & récipient & aryballe & $\begin{array}{l}\text { Is. } \\
61 / \\
\text { AR } \\
151\end{array}$ & $\begin{array}{l}\text { bleu- } \\
\text { vert }\end{array}$ & $\begin{array}{l}\text { milieu Ier- } \\
\text { IIIe s. }\end{array}$ & $\begin{array}{l}\text { traînée d'oxyde } \\
\text { verdâtre dans le } \\
\text { repli de l'anse; } \\
\text { anse inversée } \\
\text { (AV V 125.1); } \\
\text { grand module }\end{array}$ \\
\hline diag. & $\begin{array}{l}\text { VR2143 } \\
\text { bis-1-3 }\end{array}$ & F61? F98? & $n^{\circ} 5$ & récipient & indét. & indét. & $\begin{array}{l}\text { jaune- } \\
\text { vert }\end{array}$ & & 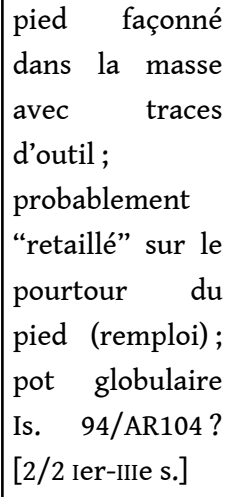 \\
\hline diag. & $\begin{array}{l}\text { VR2162 } \\
\text { bis-1-1 }\end{array}$ & F3? & $n^{\circ} 4$ & récipient & plat & $\begin{array}{l}\text { Is. } 47 \\
\text { var/ } \\
\text { AR } \\
88.1\end{array}$ & $\begin{array}{l}\text { bleu- } \\
\text { vert }\end{array}$ & 2/2 Ier-IIIe s. & \\
\hline diag. & $\begin{array}{l}\text { VR2162- } \\
\text { HS-1 }\end{array}$ & indét. & & indét. & indét. & indét. & incolore & $\begin{array}{l}\text { à partir fin } \\
\text { Ier } s .\end{array}$ & \\
\hline
\end{tabular}

Tableau 8 : Corpus du mobilier en verre du Petit Parc.

Table 8: Corpus of Petit Parc glass finds.

Le pôle italien est attesté avec deux types: Dressel $1 \mathrm{~b}$ et Dressel 2/4. La péninsule ibérique est représentée par trois types, de Tarraconaise (Pascual 1) et de Bétique (Dressel 7/11 et Dressel 20). La Gaule est majoritaire, avec sept types. Ils proviennent pour l'essentiel de l'Ouest et du Centre-Ouest (Pascual 1 voire Dressel 2/4 OCG ; Gauloise 12, type à double inflexion, type à bord plat et type à bord rond) mais aussi, plus ponctuellement, de Narbonnaise (Gauloise 3/5).

Les denrées initialement véhiculées sont majoritairement du vin (11 individus). Ce transport est attesté par les types Dressel 1 et Dressel 2/4 d'Italie (2 individus), Pascual 1 d'Espagne (2) ou par la Gauloise 3/5 de Narbonnaise (1). On le présume pour les conteneurs de Gaule de l'ouest et du centre-ouest : Gauloise 12 (NMI : 3), Pascual 1 OCG (1), une possible Dressel 2/4 OCG et une Dressel 2/4 de provenance indéterminée. L'hypothèse $d u$ transport $d u$ vin dans les quatre autres amphores de fabrication « régionale » peut être éventuellement posée, mais manque d'arguments étayés.

Les autres produits, en provenance exclusive du sud de la péninsule ibérique, sont représentés à titre anecdotique par un individu chacun : de l'huile avec le type Dressel 20, des saumures liées au type Dressel 7/11 (ou du vin d'après certaines hypothèses récentes : Silvino et Poux, 2005). 


\begin{tabular}{|c|c|c|c|c|c|c|}
\hline Origine & type & lèvre & anse & fond & total tessons & NMI / site \\
\hline \multicolumn{7}{|l|}{ Italie } \\
\hline & D1B & 1 & 2 & & 40 & 1 \\
\hline & D2/4 & & 1 & & 2 & 1 \\
\hline & D1 ou D2/4 & & & & 9 & 0 \\
\hline \multicolumn{7}{|l|}{ Pén. Ibér. } \\
\hline \multirow[t]{2}{*}{ Tarrac. } & Pasc. 1 & 2 & 2 & & 1 & 2 \\
\hline & Tarrac. & & & & 43 & 0 \\
\hline \multirow[t]{2}{*}{ Bétique } & D7/11 & & & & 4 & 1 \\
\hline & D20 & & & & 36 & 1 \\
\hline \multicolumn{7}{|l|}{ Gaule } \\
\hline Narb. & G3/5 & & 2 & 1 & 50 & 1 \\
\hline \multirow[t]{3}{*}{ Lyonnaise OCG } & Pasc. 1 & 1 & & & 1 & 1 \\
\hline & D2/4? & & & & 1 & 1 \\
\hline & OCG & & & 1 & 1 & 0 \\
\hline \multirow[t]{6}{*}{ Lyonnaise Ouest } & G12 & 3 & & 1 & 34 & 3 \\
\hline & double inflexion & 1 & & & 1 & 1 \\
\hline & bord plat & 1 & & & 1 & 1 \\
\hline & bord rond & 1 & & & 3 & 1 \\
\hline & Val de Loire & & & & 1 & 1 \\
\hline & Indét. & & & & 66 & 0 \\
\hline \multicolumn{7}{|l|}{ Indét. } \\
\hline & D2/4 & 1 & & & 1 & 1 \\
\hline & Indét. & & & & 9 & 0 \\
\hline & TOTAL & 11 & 7 & 3 & 304 & 17 \\
\hline
\end{tabular}

Tableau 9 : Corpus des amphores du Petit Parc.

Table 9: Corpus of Petit Parc amphorae.

\section{Remarques concernant les productions de Gaule de l'ouest}

1) Les amphores Gauloise 12 (3 individus, 34 fragments, $n^{\circ} 6-10$ ) ont une pâte calcaire, orangée à beige foncé ; un exemplaire présente une pâte rose violacé, teinte due peutêtre à une surcuisson ( $n^{\circ} 9-10$; décor ondé, fond ombiliqué). Ces caractéristiques techniques sont celles que l'on rencontre majoritairement pour les cruches du site 
même. Ce sont également celles des amphores et cruches du site de Macé, localisé à une douzaine de kilomètres (Simon, 2004a), mais aussi d'occupations gallo-romaines de la région de Caen par exemple (Dufournier et Marin, 1987 ; Simon, 2009 ; travaux inédits menés à Vieux et Touffréville). Rappelons que des travaux antérieurs ont permis de poser l'hypothèse de productions bas-normandes d'amphores Gauloise 12 dans le Calvados et l'Orne, en particulier à Sées (Dufournier et Marin, 1987; Misonne et al., 1998; Blaszkiewicz et Churin, 1991, fig. 5, $\mathrm{n}^{\circ} 1$ et 3). Notons que le même type est également produit dans des départements voisins mais aussi au-delà : l'Eure ${ }^{10}$, l'Eureet-Loir (Misonne et al., 1998 ; Sellès, 2001) et la Sarthe (Misonne et al., 1998), mais avec des caractéristiques techniques différentes.

À ce groupe de production peuvent être associés 66 fragments de panse de gros récipients à paroi épaisse, présentant les mêmes caractéristiques techniques. Ces productions régionales sont issues de contextes datés à partir du II ${ }^{\mathrm{e}}$ siècle.

2) Les productions de Gaule Lyonnaise occidentale comprennent également un bord d'amphore à double inflexion $\left(\mathrm{n}^{\circ} 11\right)$, de large diamètre $(22 \mathrm{~cm})$ et présentant une pâte finement sableuse, beige jaunâtre (niveau daté du milieu du i ${ }^{\text {er }}$ siècle apr. J.-C.; F 14). Cet emballage est à rapprocher de deux cruches ou amphorettes en céramique commune claire (similitudes techniques et parentés morphologiques) découvertes sur ce site (dont l'une dans le même contexte) et datées entre le milieu et la fin du Ier s. apr. J.-C. Des productions de forme et pâte similaires à cet individu sont connues notamment à Chartres (Eure-et-Loir), où elles ont été réalisées dans deux ateliers, actifs de la période claudienne à la seconde moitié $d u{ }^{\mathrm{er}}$ siècle (Sellès, 2001, p. 160-161, réf. 1543). Notons que des petits modules de même type et autres amphorettes morphologiquement proches sont également fabriqués dans la même ville à cette période.

140 3) Une autre amphore $\left(n^{\circ} 12\right)$, d'aspect technique similaire (pâte dure, finement sableuse), mais de couleur rouge cette fois, est également rattachée à la même grande aire de production (région de Chartres - Dourdan): diamètre $13 \mathrm{~cm}$, départ d'anse plate; contexte de découverte daté des années 60 à la fin du Ier s. avec mobilier résiduel de la période claudienne.

141 4) C'est encore le cas d'une amphore à bord arrondi, à pâte beige finement sableuse contenant une très grosse inclusion de silex $\left(n^{\circ} 13\right)$. Cet individu a été recueilli au moment du diagnostic (CE-2143bis-1-7). Il peut être comparé au type 1506.3 défini pour la région de Chartres (Sellès, 2001, p. 143).

\section{Conclusion}

De ce modeste corpus, on retiendra la prépondérance des productions du grand quart nord-ouest de la Gaule (notamment Gauloise 12), vraisemblablement pour véhiculer du vin, le principal produit de consommation importé en amphores sur ce site. Parallèlement, on soulignera les quantités limitées ainsi que la faible variété des importations lointaines. 


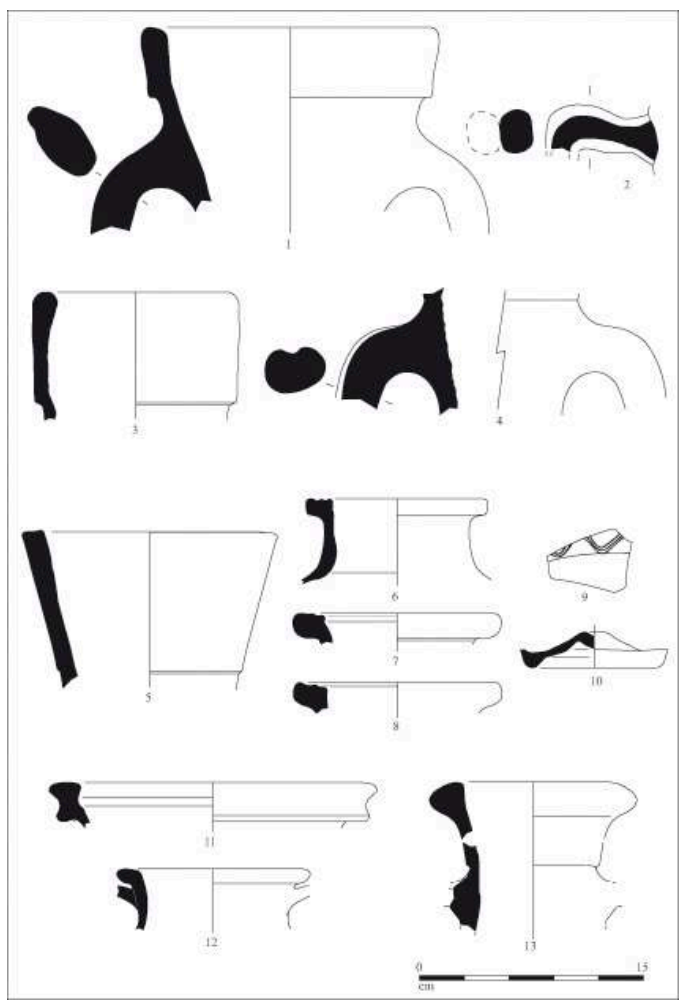

Figure 28 : Les principaux fragments d'amphores du Petit Parc (relevés et DAO L. Simon).

Figure 28: Selected amphorae fragments.

\section{L'établissement rural du Petit Parc}

La fouille du Petit Parc a permis d'explorer un site à vocation agricole aux confins du territoire des Esuviens/Sagiens, dans un secteur géographique où, avant le développement des opérations d'archéologie préventives liées aux autoroutes A 28 Nord et A 88, les connaissances sur le milieu rural reposaient principalement sur les prospections, en particulier sur les travaux initiés par G. Leclerc (2006) ou J. Desloges (2000).

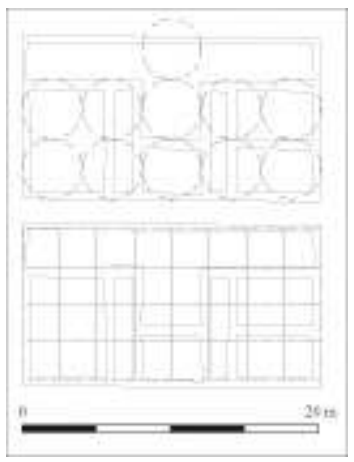

Figure 29 : Proportions et proposition de tracé régulateur pour la villa du Petit Parc (DAO R. Ferrette). Figure 29: Proportions and proposal regulating layout for Petit Parc villa.

L'emprise de la fouille n'autorise aucunement une appréciation spatiale globale de l'ensemble mis au jour et restreint de fait la portée des conclusions et interprétations que l'on peut avancer. La poursuite du site au-delà des limites de l'intervention est 
manifeste, tant à l'ouest qu'au sud, et il ne fait guère de doute que bon nombre de réponses aux questions que soulèvent cette occupation sont à rechercher dans les terrains adjacents. Malgré tout, les informations rassemblées sont suffisamment pertinentes pour venir enrichir le débat sur l'occupation du sol dans cette partie du département de l'Orne.

\section{Évolution chronologique et structurelle}

145 Abstraction faite de la période néolithique, l'implantation humaine apparaît relativement ancienne et remonte certainement à la Protohistoire. Toutefois, les quelques témoins laténiens retrouvés, structures et mobilier, ne permettent nullement de discerner une continuité de l'occupation depuis La Tène moyenne jusqu'à l'époque gallo-romaine incluse. L'orientation des fossés les plus anciens conforte même la probabilité d'un hiatus.

146 Une continuité de l'occupation ne devient perceptible qu'à partir de la création de l'enclos A (supra fig. 5). Ce dernier, ainsi que l'enclos B, vont déterminer l'organisation structurelle du paysage puisque certaines de leurs limites perdureront durant toute l'occupation gallo-romaine et que les orientations qu'ils adoptent seront respectées.

L'établissement rural du Petit Parc semble puiser son origine dans une ferme à enclos fossoyé et bâtiments légers, apparue dans le courant de la seconde moitié du i ${ }^{\text {er }}$ siècle avant notre ère et dont les ressources seraient issues à la fois de l'élevage et de l'agriculture. Doté à l'origine d'un talus interne et de larges fossés, l'enclos A devait ceinturer un habitat rassemblant un ou plusieurs édifices de terre et bois. À l'exception de la fosse F 103 dont la fonction n'est pas connue, l'absence tangible de traces d'occupation à l'intérieur de cet espace principal peut se justifier par leur érosion totale ou par la localisation de celles-ci en dehors de l'emprise concernée par les travaux autoroutiers. Sur le site gaulois de La Houssaye à Buré, l'habitat occupe ainsi le centre de l'enclos (Hincker, 2007). Quoi qu'il en soit, le tracé rectiligne et l'unique angle dégagé de l'enclos A évoquent bien les fermes que R. Agache qualifiait « d'indigènes » (Agache, 1978, p. 130).

Les dimensions et les limites modestes de l'enclos B plaident en revanche pour une fonction très différente. L'existence de courts fossés au niveau de son entrée accrédite l'hypothèse d'une aire de pacage pour le bétail. Ce système d'entonnoir, avec fossés et talus surmonté d'une haie, autorisait en effet le guidage des animaux (Audouze et Buschsenschutz, 1989, p. 209; Menez, 1996, p. 206). Les seuls indices tangibles d'une pratique culturale résideraient alors dans les fosses 60 et 87, interprétées comme des silos pour stocker des céréales à long terme. L'utilisation de ce mode de conservation tend à se raréfier durant La Tène finale dans certaines régions, notamment en Picardie ou dans la vallée de l'Aisne (Gransar, 2000 ; Pion et al., 1996, p. 97-100). Pour l'Orne, les exemples de Neuville-Près-Sées ou de la ferme gauloise de La Houssaye sur la commune de Buré montrent que la conservation des graines était assurée dans des greniers aériens (Besnard-Vauterin, 2007 ; Hincker, 2007), mais sur un laps de temps assez court dans ce cas.

Après le changement d'ère, l'exploitation du Petit Parc connaît des évolutions qui dévoilent deux aspects majeurs (cf. supra fig. 9). Le premier témoigne d'une succession rapide des limites parcellaires. C'est du moins ce que tend à établir l'intervalle chronologique restreint constaté entre le comblement partiel de l'enclos A et celui du 
fossé $\mathrm{F} 98$, qui est de l'ordre d'une génération. Même si, dans la partie sud-est de l'intervention, l'absence d'une vision fine de ce processus évolutif engendre des difficultés de compréhension, la multiplicité des creusements prouve que le paysage est rapidement modifié. Le second point pourrait correspondre à une extension de l'exploitation, illustrée justement par le développement de ces structures linéaires. Il semble en effet témoigner d'un essor des activités agro-pastorales, dont la nature exacte est toutefois difficilement restituable même si l'existence de fossés se croisant à angle droit va dans le sens d'une pratique axée principalement sur la céréaliculture. Un corollaire de ce développement spatial peut résider dans le déplacement de l'habitat. Le mobilier recueilli dans le fossé $\mathrm{F} 98$ montre bien, par sa diversité et sa quantité, que la zone d'habitat du début de notre ère ne devait pas être très éloignée du noyau d'origine supposé être enserré par l'enclos A. En revanche, à la fin du Ier siècle, au moins un bâtiment est pressenti dans la partie sud-est de l'intervention grâce aux découvertes mobilières et à l'aménagement de passages. Sa nature n'est toutefois pas connue (habitat ou simple bâtiment d'exploitation?) et l'on peut aussi s'interroger sur la présence ou non de plusieurs cellules familiales sur l'établissement.

La dernière grande étape, qui débute sans doute à la fin du premier siècle ou au début du suivant, marque la construction de la villa, au sens d'exploitation agricole et résidentielle disposant au moins de soubassements en dur (Ferdière, 1988, p. 157-158; cf. supra fig. 17). L'ensemble dégagé appartient à la famille des villae à galerie de façade, largement répandue en Gaule septentrionale (Agache, 1978, p. 286-292 ; Gros, 2001, p. 324-326 ; Galliou, 2005, p. 133-134 ; Brunet-Gaston et Gaston, 2003-2004 ; Maligorne, 2006, p. 82-87) et dans les provinces voisines. Sa superficie au sol, environ $220 \mathrm{~m}^{2}$, classe l'ensemble de Menil-Froger parmi les constructions les plus petites de sa catégorie dans l'ouest de la Gaule (Maligorne, 2006, p. 82 et note 40). Malgré tout, le portique et la symétrie témoignent d'une recherche de monumentalité, comme pour beaucoup d'édifices de ce type (Gros, 2001, p. 326). La construction s'organise en effet autour des deux espaces centraux qui s'inscrivent intérieurement dans un cercle proche de $4 \mathrm{~m}$ de diamètre, mesure qui se retrouve dans les salles latérales. L'analyse montre en outre l'utilisation d'un carré de référence de 8,5 pieds de $0,296 \mathrm{~m}$ lors de la réalisation du bâtiment. L'ensemble est compris dans un rectangle de 8 modules sur 4 , qui exclut le stylobate et le mur arrière, soit un rapport de 1 sur 2 entre la longueur et la largeur de l'édifice (fig. 29). On retrouve dans cet exemple deux principes exposés par Vitruve, la symétrie et la proportion, qui contribuent à l'harmonie et à l'ordonnance rationnelle d'un édifice.

La création de la villa s'accompagne d'une simplification du réseau parcellaire, constitué désormais de grands tracés rectilignes bordant l'habitat et qui peuvent participer à la mise en valeur de son architecture. L'organisation de l'espace, pressentie dès la phase initiale, se retrouve en outre pleinement puisque le fossé $F \quad 61$ et son retour F 58 semblent constituer une séparation physique entre une zone résidentielle et une autre à vocation agricole. La première occupe l'emplacement de l'ancien enclos $\mathrm{A}$ et comprend une cour en avant de la villa, mais il faut certainement étendre cet espace particulier aux terrains situés immédiatement à l'est de l'édifice, jusqu'à la hauteur du fossé 58 , car aucune installation n'a été décelée dans ce périmètre. Il est d'ailleurs possible que F. 61 et F. 58 désignent une partie d'un enclos; on aurait alors une aire résidentielle entièrement ceinturée par une limite fossoyée, système connu sur d'autres établissements ruraux (Ferdière 1988, p. 186 ; Naas, 2008, p. 82-83). Un point qui reste 
non résolus est l'emplacement exact qu'occupe la villa à l'intérieur de ce secteur privilégié, car elle apparaît relativement proche du fossé 61 .

À l'inverse, le secteur au sud et à l'est des limites fossoyées précédentes apparaît plutôt dévolu aux activités agricoles. Depuis la villa, l'accès à ce que l'on peut qualifier de champs s'opère grâce au passage aménagé à la hauteur du fossé $\mathrm{F} 61$, tandis qu'un second passage, au niveau de $\mathrm{F} 31$, permet certainement de gagner le bâtiment 2 situé à proximité du fossé F 3 . Il manque bien évidement toutes les installations que l'on s'attendrait à trouver dans une exploitation agricole : granges, greniers, étables... Les données concernant le bâtiment 2 sont trop lacunaires pour lui attribuer une fonction particulière. On ne peut non plus exclure la disparition de leurs fondations en raison de l'érosion ou l'existence d'édifices au-delà des limites de l'emprise décapée.

La fouille du Petit Parc renvoie donc l'image d'une exploitation agricole qui, d'une ferme à enclos fossoyé apparue après la Conquête, va se transformer un siècle et demi plus tard en un établissement plus élaboré avec à sa tête une villa, même si celle-ci reste modeste au regard de certains édifices de l'est ou du nord de la Gaule (Collart, 1996). L'organisation de cette exploitation lors de la dernière phase laisse aussi entrevoir, contrairement à d'autres établissements du quart nord-ouest de la Gaule (Courbot, 2000 , p. 470), qu'il n'y a jamais eu de réel déplacement de l'habitat et que l'organisation initiale, centrée autour de l'enclos A, subsistera pendant trois siècles, en respectant les orientations de la trame fossoyée primitive.

\section{Le site du Petit Parc dans le cadre régional}

Malgré l'essor de l'archéologie préventive dans l'Orne grâce à la réalisation des autoroutes A 28 Nord et A 88, les points de comparaisons disponibles restent encore rares. Très peu d'établissements ruraux disposant d'un bâtiment d'habitation en dur ont fait l'objet d'une étude complète et une part importante de l'information est issue de fouilles pratiquées au XIX siècle (Fichet de Clairfontaine, 1999, p.62-63). Les quelques plans qui nous sont parvenus concernent souvent des ensembles construits beaucoup plus importants que la villa de Ménil-Froger (fig. 30) : Mauves-sur-Huisnes, Ceton (Bernouïs, 1999, p. 96-97 et 153-154) ou des espaces particuliers comme les balnéaires de Chandai ou de Villiers-sous-Mortagne (ibid., p. 101-104 et 215-217). Dans d'autres exemples étudiés plus récemment, une partie seulement de la cour a été abordée, à l'image des sites de Valframbert (ibid. p. 211-212) ou de Colombiers (ibid., p. 108-110). Ces établissements, avec porches d'entrée monumentaux et longs murs de clôture, correspondent à de grandes exploitations qui semblent s'être principalement développées en marge de la plaine de Sées, sur des terres de qualité inégale (Fichet de Clairfontaine et Leclerc, 2007, p.103). C'est sans doute également à ce type d'exploitation que se rattache la villa de La Chasnière à Marcéi fouillée récemment (fig. 30 ; Le Gaillard, 2004 ; 2007). Le site du Grand-Herbage à Sées appartient par contre au contingent d'exploitations rurales de taille modeste qui semblent jalonner les plaines de Sées et d'Alençon (Fichet de Clairfontaine et Leclerc, 2007, p. 106). On n'y retrouve toutefois pas l'organisation pressentie lors la dernière phase du Petit Parc (fig. 30). Les installations du Haut-Empire se déploient en effet à l'intérieur d'une cour ceinturée d'un mur, comprenant à l'origine un porche d'entrée (Leclerc, 2007b). Le bâtiment résidentiel offre un plan rectangulaire simple, sans galerie de façade, et plusieurs édifices sur poteaux plantés laissent penser qu'une partie des travaux 
agricoles se déroulait dans la cour. G. Leclerc identifie ainsi plusieurs greniers aériens, une aire de battage et une construction rectangulaire pouvant évoquer une étable ou une grange (Leclerc, 2007a, p. 145-146 ; 2007b, p. 104). Il n'existe donc pas de séparation claire entre un secteur résidentiel et une zone d'activités liées à la production de l'établissement. En revanche, un élément de confort, absent au Petit Parc, réside dans la création, lors d'une extension de l'habitat du Haut-Empire, d'une salle sur hypocauste aux murs ornés d'enduits peints (Leclerc, 2007a, p. 142).

Même si les données sont hétérogènes, aucun des établissements précédemment cités ne semble avoir connu une occupation antérieure au changement d'ère. La fondation de la ferme du Grand-Herbage se produit vers les années 70-80 de notre ère (Leclerc, 2007b) ; les premières installations de Valframbert remontent au milieu ou au cours de la seconde moitié du $\mathrm{I}^{\text {er }}$ siècle apr. J.-C., tandis que celles de Colombiers demeurent mal datées, mais aucun indice d'une occupation de la transition époque gauloise/époque gallo-romaine n'y est attesté. Par contre, des fermes apparues au cours de l'époque laténienne ou vers le milieu du Ier s. av. J.-C. sont abandonnées avant le changement d'ère, comme celles des Ruisseaux à Neuville-Près-Sées (Besnard-Vauterin, 2005 ; 2007) ou de La Houssaye à Buré (Hincker, 2007). D'autres, à l'image de l'exploitation agricole de La Sarthe, toujours à Buré (Hincker, 2007), connaissent encore une occupation durant une partie de l'époque gallo-romaine, différente cependant de celle du Petit Parc.

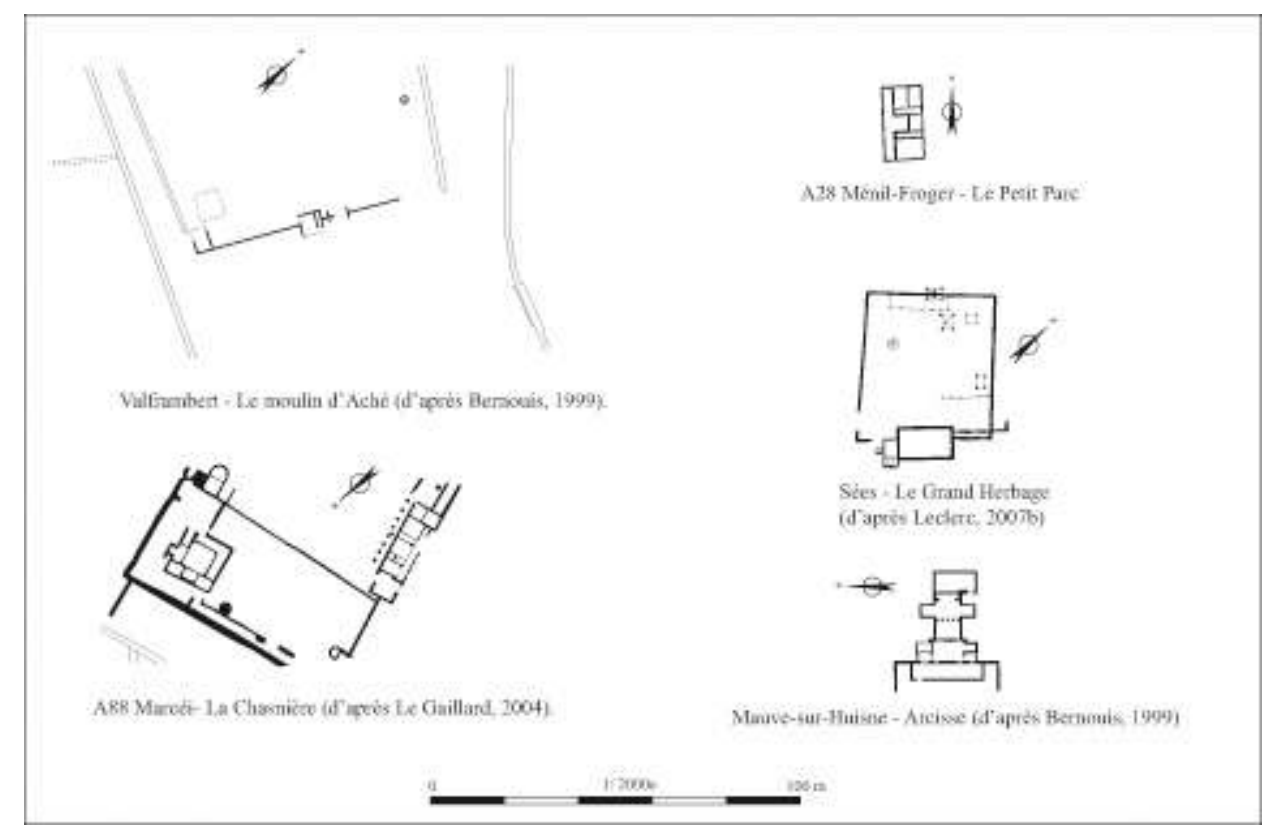

Figure 30 : Quelques exemples d'établissements ruraux gallo-romains du département de l'Orne (DAO R. Ferrette).

Figure 30: Some examples of Gallo-Roman farmsteads from dept. Orne.

En l'état actuel des connaissances, le site du Petit Parc, ainsi que son évolution, apparaissent sans véritable point de comparaison dans le département de l'Orne. Cependant, il entretient de nombreuses similitudes avec ce que l'on connaît dans le nord-ouest (Collart, 1996) ou dans le centre de la Gaule (Gandini, 2008, p. 394-396) : développement de fermes à enclos fossoyé au cours du premier siècle avant notre ère qui, au fil des transformations, aboutiront à la création de bâtiments en dur. Toutefois, à la différence d'exemples picards, la villa du Petit-Parc n'a pas donné lieu à une 
composition imposante, à l'image de nombreux établissements à galerie de façade de l'ouest de la Gaule (Maligorne, 2006, p. 82). L'édifice du Petit Parc reste modeste, tant par sa superficie que par l'absence d'équipements de confort ou de prestige (bains...), même si la possibilité d'un balnéaire séparé de l'habitat ne doit pas être exclue.

Quoi qu'il en soit, l'établissement du Petit Parc est inséré dans un réseau commercial organisé dès son origine. Si les témoins antérieurs au changement d'ère apparaissent ténus (amphore Dressel $1 \mathrm{~b}$ notamment), ils sont beaucoup plus nombreux à partir de l'époque augustéenne puisque l'exploitation reçoit dès lors des céramiques du GrandOuest, mais aussi du sud et du centre de la Gaule (vaisselle fine), ainsi que des denrées transportées en amphores depuis les péninsules ibérique et italique (vin, huile). Tous ces éléments, auxquels se mélangent des productions locales, confèrent sa richesse au répertoire, tout en témoignant du dynamisme de l'économie locale. On peut penser que l'exploitation et la transformation du minerai de fer dès la période gauloise, et surtout à l'époque romaine comme l'illustre l'atelier paléométallurgique de Saint-Evroult-deMonfort (Langlois, 2003 ; Quévillon, 2007) ont contribué pour partie au dynamisme et à la richesse de la région, en outre bien desservie par les axes routiers. Un autre point non négligeable pour la compréhension de l'essor propre de l'établissement du Petit Parc tient certainement à la proximité de l'éperon d'Exmes, pour lequel une opération récente a confirmé une occupation importante à la fin de l'époque gauloise (Gallouin et al., 2007; Marcigny et al. 2007). Il est dès lors tentant de voir dans le site de MénilFroger une ferme dont une grande partie de la production était à l'origine destinée à alimenter ce site de hauteur, et qui a ensuite bénéficié du développement de la ville de Sées dont l'essor avait dû générer de nouveaux besoins.

Les auteurs tiennent particulièrement à remercier Bruno Bazin, Anne-Françoise Cherel, Mélanie Demarest, Philip Kenrick, Laure Dédouit, Sophie Quévillon, Lucien Rivet, Hervé Sellès.

\section{BIBLIOGRAPHIE}

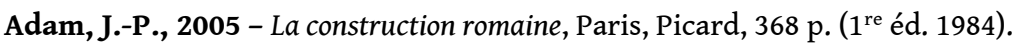

Adrian, Y.-M., 2001 - La céramique du Haut-Empire dans la région d'Evreux (Eure) : première approche du répertoire et de ses approvisionnements, Revue archéologique de l'Ouest, 18, p. 95-143.

Agache, R., 1978 - La Somme pré-romaine et romaine, Amiens, Société des Antiquaires de Picardie, $512 \mathrm{p}$.

Audouze, F. et Buchsenschutz, O., 1989 - Villes, villages et campagne de l'Europe celtique, Paris, Hachette, 362 p.

Barat, Y., 1993 - La céramique rouge à surface lustrée du Haut-Empire, in DUFÄ̈, B. (dir.), Trésors de terre. Céramiques et potiers dans l'île-de-France gallo-romaine (catalogue d'exposition), Versailles, Conseil général des Yvelines, p. 167-170. 
Barat, Y. et Raux, S., 1994 - Brève synthèse des productions franciliennes du $\mathrm{I}^{\mathrm{er}}$ au $\mathrm{III}^{\mathrm{e}}$ siècle, in TUFFREAU-LIBRE, M. et JACQUES, A. (dir.), La céramique du Haut-Empire en Gaule Belgique et dans les régions voisines : faciès régionaux et courants commerciaux (Actes de la table ronde d'Arras, 12-14 octobre 1993), Berck-sur-Mer, Centre de Recherches archéologiques et de Diffusion culturelle, (Nord-Ouest Archéologie, 6), p. 229-252.

Bazin, B. et Delage, R., 2005 - Un lot de céramiques de la fin du Haut-Empire à Allonnes (Sarthe), Marseille, Société française pour l'étude de la Céramique antique en Gaule, Actes du Congrès de Blois, p. 649-653.

Blaszkiewicz, P. et Churin, T., 1991 - Découverte d'un four de potier à Sées (Orne), Revue archéologique de l'Ouest, 8, p. 117-122.

Bernouis, P., 1999 - L'Orne - 61, Paris, Académie des Inscriptions et Belles-Lettres (Carte archéologique de la Gaule), 249 p.

Besnard-Vauterin, C.-C., 2005 - Une ferme de la fin de l'époque gauloise à Neuville-près-Sées « les Ruisseaux » (Orne), Revue archéologique de l'Ouest, 22, p. 181-198.

Besnard-Vauterin, C.-C., 2007 - Une ferme de la fin de l'époque gauloise à Neuville-près-Sées, «Les Ruisseaux », in DELRIEU, F. et DESLOGES, J. (dir.), ArchéOrne, 250 ans d'archéologie dans l'Orne, Cabourg, Cahiers du Temps, p. 74-75.

Bonnet-Borel, F., 1997 - Le verre d'époque romaine à Avenches-Aventicum. Typologie générale, Avenches, Association Pro Aventico (Documents du Musée romain d'Avenches, 3), 98 p.

Bouchette, A., Boulestin, B., Bourhis, J.-R., Buisson, J.-F., Duffault, C., Gomez de Soto, J., Lemoine, S., Tournepiche, J.-F., Vernou, C. et Vieau, M., 1998 - Le char romain du Musée archéologique de Saintes, Saintes, Musée municipal, 130 p.

Brunet-Gaston, V. et Gaston, C., 2003-2004 - Typologie et décor des villae : modèle de diffusion aux confins de la Lyonnaise septentrionale, in BEDON, R. (dir.), Rvs amoenvm, les agréments de la vie rurale en Gaule Romaine et dans les régions voisines, Limoges, Pulim (Caesarodunum XXXVIIXXXVIII), p. 78-88.

Chambon, M.-P., 2001 - évolution de la céramique du début de la période romaine au début du IIe siècle de notre ère à Orléans/Cenabum, Marseille, Société française pour l'étude de la Céramique antique en Gaule, Actes du Congrès de Lille-Bavay, p. 355-364.

Collart, J.-L., 1996 - La naissance de la villa en Picardie : la ferme gallo-romaine précoce, in BAYARD, D. et COLLART, J.-L., De la ferme indigène à la villa romaine (Actes du $2^{\mathrm{e}}$ colloque de l'association AGER, Amiens, septembre 1993), Revue archéologique de Picardie, $\mathrm{n}^{\circ}$ spécial 11, p. 121-156.

Corrocher, J., 1983 - La céramique à glaçure plombifère de Vichy (Allier). Revue archéologique du Centre de la France, 22, p. 15-40.

Courbot, C., 2000 - Evolutions des établissements ruraux à la période de transition ( $\mathrm{I}^{\mathrm{er}}$ siècle av.$\mathrm{I}^{\mathrm{er}}$ siècle apr.) dans le quart nord-ouest de la France, in MARION, S. et BLANCQUAERT, G. (dir.), Les installations agricoles de l'âge du Fer en France septentrionale, Paris, Presses de l'école normale supérieure (études d'Histoire et d'Archéologie, $\mathrm{n}^{\circ}$ 6), p. 463-474.

Cousyn, P., 2003 - Ménil-Froger (61) Le Petit Parc (Rapport d'évaluation), Caen, SRA de BasseNormandie. 
Couvin, F., 2005 - Premier aperçu de la céramique du Val de Loire au $\mathrm{i}^{\mathrm{er}}$ siècle de notre ère, au regard des fouilles récentes des secteurs d'Orléans, Blois et Tours, Marseille, Société française pour l'étude de la Céramique antique en Gaule, Actes du Congrès de Blois, p. 99-138.

Delrieu, F. et Desloges, J. (dir.), 2007 - ArchéOrne, 250 ans d'archéologie dans l'Orne, Cabourg, Cahiers du Temps, $143 \mathrm{p}$.

Desloges, J., 2000 - Chemins et paysages de la Plaine de Caen, Prospection aérienne, Caen, Bilan Scientifique de la région Basse-Normandie, p. 99-101.

DuFAü, B., BARAT, Y. et RAUX, S., 1997 - Fabriquer de la vaisselle à l'époque romaine. Archéologie d'un centre de production céramique en Gaule: La Boissière-École, $I^{\mathrm{er}}$ et III ${ }^{\mathrm{e}}$ siècle après J.-C., Versailles, Service archéologique départemental des Yvelines, $256 \mathrm{p}$.

Dufournier, D. et Marin, J.-Y., 1987 - Une production d'amphores du $\mathrm{II}^{\mathrm{e}}$ siècle dans le Calvados, Marseille, Société française pour l'étude de la céramique antique en Gaule, Actes du Congrès de Caen, p. 23-27.

Duvauchelle, A., 2005 - Les outils en fer du Musée Romain d'Avenches, Avenches, Association Pro Aventico (Documents du Musée romain d'Avenches, 11), 232 p., 54 pl.

Eneau, T., 2002 - Les objets en fer du sanctuaire gallo-romain du Gué-de-Sciaux (Antigny, Vienne), Chauvigny, Association des Publications chauvinoises (Mémoire XXI), 120 p.

Ferdière, A., 1988 - Les campagnes en Gaule romaine, les hommes et l'environnement en Gaule rurale, Paris, Errance, tome 1, 284 p.

Ferrette, R., 2003 - La céramique gallo-romaine du site de Monterfil II à Corseul (Côtes-d'Armor). étude d'ensembles de l'époque augustéenne au début du IV siècle, Montagnac, éditions Monique Mergoil, 224 p., 69 pl.

Ferrette, R. et Cherel, A.-F., 2004 - Coulmer «La Corvée » (DFS de fouille préventive), Caen, SRA de Basse-Normandie.

Feugère, M., Thauré, M. et Vienne, G., 1992 - Les objets en fer dans les collections du Musée archéologique de Saintes ( $\mathrm{I}^{\mathrm{er}}-\mathrm{XV} \mathrm{e}^{\mathrm{e}}$ siècles), Saintes, Musée municipal, $115 \mathrm{p}$.

Fichet de Clairfontaine, F., 1992 - Les débuts de la romanisation dans le département de l'Orne. Céramiques d'époques augustéenne et tibérienne de l'oppidum d'Exmes Archéologie dans l'Orne 1987-1992, Société historique et archéologique de l'Orne, 106 (n²-3-4), p. 78-101.

Fichet de Clairfontaine, F., 1999 - L'occupation humaine à l'époque romaine, in BERNOUïs, P., L'Orne - 61, Paris, Académie des Inscriptions et Belles-Lettres (Carte archéologique de la Gaule), p. 60-68.

Fichet de Clairfontaine, F. et Gros, H., 1995 - Sées (Orne). Le mobilier céramique des années 50-80 après J.- C. étude d'un ensemble clos du site de la rue Amesland, Marseille, Société française pour l'étude de la Céramique antique en Gaule, Actes du Congrès de Rouen, p. 25-38.

Fichet de Clairfontaine, F. et Leclerc, G., 2007 - Antiquité - L'Orne gallo-romaine, in DELRIEU, F. et DESLOGES, J. (dir.), ArchéOrne, 250 ans d'archéologie dans l'Orne, Cabourg, Cahiers du Temps, p. 95-114.

Galliou, P., 2005 - L'Armorique romaine, Brest, éditions Armeline, 415 p.

Gallouin, E., Ghesquière, E. et Marcigny, C., 2007 - Exmes : cité gauloise ?, in Delrieu, F. et Desloges, J. (dir.), ArchéOrne, 250 ans d'archéologie dans l'Orne, Cabourg, Cahiers du Temps, p. 77. 
Gandini, C., 2008 - Des campagnes gauloises aux campagnes de l'Antiquité tardive : la dynamique de l'habitat rural dans la cité des Bituriges Cubi (II siècle av. J.-C.-VII ${ }^{\mathrm{e}}$ siècle apr. J.-C.), Tours, FERACF (Revue archéologique du Centre de la France, supplément 33), 511 p. + CDrom.

Génin, M., Hoffmann, B. et Vernhet, A., 2002 - Les productions anciennes de La Graufesenque, in GENIN, M. et VERNHET, A. (dir.), Céramiques de La Graufesenque et autres productions d'époque romaine, nouvelles recherches. Hommages à Bettina Hoffmann, Montagnac, éditions Monique Mergoil, p. 45-104.

Gransar, F., 2000 - Le stockage alimentaire sur les établissements ruraux de l'âge du Fer en France septentrionale : compléments des structures et tendances évolutives, in MARION, S. et BLANCQUAERT, G. (dir.), Les installations agricoles de l'âge du Fer en France septentrionale, Paris, Presses de l'école normale supérieure, (études d'Histoire et d'Archéologie n 6), p. 277-297.

Gros, P., 2001 - L'architecture romaine du début du III ${ }^{\mathrm{e}}$ siècle av. J.-C. à la fin du Haut-Empire, t. 2, Maisons, palais, villas et tombeaux, Paris, Picard, $527 \mathrm{p}$.

Guillier, G., 1997 - La production céramique du Haut-Empire de l'officine rurale de La Bosse (Sarthe), Marseille, Société française pour l'étude de la Céramique antique en Gaule, Actes du Congrès du Mans, p. 239-254.

Guitton, D., 2001 - Importation des sigillées italiques et de tradition italique à Rezé (LoireAtlantique) à travers l'étude des marques de potiers, Marseille, Société française pour l'étude de la Céramique antique en Gaule, Actes du Congrès de Lille-Bavay, p. 319-330.

Guitton, D. et Thebaud, S., 2001 - Les ensembles céramiques précoces de Rezé (LoireAtlantique), Marseille, Société française pour l'étude de la Céramique antique en Gaule, Actes du Congrès de Lille-Bavay, p. 283-318.

Guyard, L., 1998 - Les céramiques antiques précoces découvertes à l'emplacement du cardo, rue Saint-Martin (Paris, IVème), in TUFFREAU-LIBRE, M. et JACQUES, A. (dir.), La céramique précoce en Gaule Belgique et dans les régions voisines : de la poterie gauloise à la céramique gallo-romaine (Actes de la table ronde d'Arras, 14-17 octobre 1996), Berck-sur-Mer, Centre de Recherches archéologiques et de Diffusion culturelle (Nord-Ouest Archéologie, 9), p. 305-316.

Halbout, P., Pilet, C. et Vaudour, C., 1987 - Corpus des objets domestiques et des armes en fer de Normandie : $d u \mathrm{I}^{\mathrm{er}}$ au XV $v^{\mathrm{e}}$ siècle, Caen, Cahiers des Annales de Normandie (20), $255 \mathrm{p}$.

Hincker, V., 2007 - Les fermes protohistoriques et antiques de Buré, in DELRIEU, F. et DESLOGES, J. (dir.), ArchéOrne, 250 ans d'archéologie dans l'Orne, Cabourg, Cahiers du Temps, p. 76.

Hofmann, B., 1985 - Inventaire de quincaillerie antique, Guiry-en-Vexin, Centre de Recherches archéologiques du Vexin Français (Cahier Archéologique n 5), 100 p.

Isings, C., 1957 - Roman Glass from Dated Finds, Groningen-Djakarta, J.-B. Wolters, 185 p.

Jigan, C., 1988 - Les vases à glaçure plombifère trouvés en Normandie : état de la question, Marseille, Société française pour l'étude de la Céramique antique en Gaule, Actes du Congrès d'Orange, p. 189-207.

Jobelot, N. et Vermeersch, D., 1991 - La céramique noire à pâte rougeâtre (NPR) : une première approche, Marseille, Société française pour l'étude de la céramique antique en Gaule, Actes du Congrès de Cognac, p. 291-302.

Jobelot, N. et Vermeersch, D., 1993 - La céramique « noire à pâte rougeâtre », esquisse d'une typologie, Trésors de terre, Céramiques et potiers dans l'île de France gallo-romaine, Versailles, Conseil général des Yvelines, p. 158-166. 
Jobelot, N., 2000 - À propos de la céramique noire, pâte rougeâtre (NPR), Marseille, Société française pour l'étude de la Céramique antique en Gaule, Actes du Congrès de Libourne, p. 263-264.

Lallemand, D. et Tuffreau-Libre, M. 2005 - La céramique « type Besançon » en Gaule centrale, Marseille, Société française pour l'étude de la Céramique antique en Gaule, Actes du Congrès de Blois, p. 63-81.

Langlois, J.-Y., 2003 - Saint-Evroult-de-Montfort - Le Buisson (A 28 Rouen-Alençon), Caen, Bilan scientifique de la région Basse-Normandie, p. 102-103.

Laubenheimer, F., Cantin, N. et Schmitt, A. et coll., 2005 - Vin et vignoble du Centre-Ouest de la Gaule au $\mathrm{I}^{\mathrm{er}}$ siècle. Le témoignage des amphores Pascual 1 et Dressel 2/4 blanches à pâte orangée et cœur gris, Marseille, Société française pour l'étude de la céramique antique en Gaule, Actes du Congrès de Blois, p. 377-382.

Leclerc, G., 2006 - Les apports de la prospection aérienne à la connaissance du peuplement antique de l'Orne, in JUHEL, V. (dir.), Archéologie et prospection en Basse-Normandie, Caen, Société des Antiquaires de Normandie (Mémoire XXXVIII), p. 179-186.

Leclerc, G., 2007a - La ferme antique du Grand-Herbage à Sées, in Delrieu, F. et Desloges, J. (dir.), ArchéOrne, 250 ans d'archéologie dans l'Orne, Cabourg, Cahiers du Temps, p. 104-105.

Leclerc, G., 2007b - L'établissement rural antique du Grand-Herbage à Sées (Orne), Revue archéologique de l'Ouest, 24, p. 139-167.

Le Gaillard, L., 2004 - A 88 - Marcéi, Caen, Bilan scientifique de la région Basse-Normandie, p. 95-96.

Le Gaillard, L., 2007 - La villa gallo-romaine de Marcéi : premier aperçu par les travaux autoroutiers, Bulletin de la Société historique et archéologique de l'Orne, 126 (n³-4), p. 147-157.

Maligorne, Y., 2006 - L'architecture romaine dans l'ouest de la Gaule, Rennes, Presses universitaires de Rennes, 229 p.

Manning, W. H. 1985 - Catalogue of the Romano-British Iron Tools, Fittings and Weapons in the British Museum, London, British Museum Publications, 306 p., 85 pl.

Marcigny, C., Ghesquière, E. et Lepaumier, H., 2006 -Un exemple de prospection thématique : l'inventaire des mégalithes de Basse-Normandie. L'exemple d'un polissoir inédit à Saint-Germainde-Clairefeuille (Orne), in JUHEL, V. (dir.), Archéologie et prospection en Basse-Normandie, Caen, Société des Antiquaires de Normandie (Mémoire XXXVIII), p. 113-116.

Marcigny, C., Ghesquière, E., Gallouin, E. et Vipard, L., 2007 - Archéologie d'un site de hauteur de l'Orne, l'éperon d'Exmes, Bulletin de la Société historique et archéologique de l'Orne, 126 $\left(n^{\circ} 3-4\right)$, p. 65-78

Menez, Y., 1985 - Les céramiques fumigées de l'ouest de la Gaule, Quimper, Cahiers de Quimper antique (2), $125 \mathrm{p} ., 44 \mathrm{pl}$.

Menez, Y., 1989 - Les céramiques fumigées ("Terra Nigra ») du Bourbonnais. étude des collections de Néris-les-Bains et Châteaumeillant. Revue archéologique du Centre de la France, 28 (fasc. 2), p. 117-178.

Menez, Y., 1996 - Une ferme de l'Armorique gauloise, Le Boisanne à Plouër-sur-Rance (Côtes-d'Armor), Paris, MSH (Documents d'Archéologie française, 58), $272 \mathrm{p}$.

Misonne, B., Bocquet, A., Laduron, D., et Laubenheimer, F., 1998 - Les amphores Gauloise 12 du bassin de la Seine, caractérisation minéralogique, pétrographique et chimique, in 
LAUBENHEIMER, F. (dir.), Les amphores en Gaule, II, Besançon, Presses universitaires Franc-Comtoises, p. 145-158.

Naas, P., 2008 - Les enclos d'époque romaine en Armorique péninsulaire et dans les régions limitrophes, Aremorica, 2, p. 67-85.

Noël, J., 1983 - Habitat et nécropole d'époque romaine à Viville (près d'Arlon), Namur, Vie Archéologique (Suppl. 11), 65 p.

Oxe, A., Comfort, H. et Kenrick, P., 2000 - Corpus Vasorum Arretinorum : a catalogue of the signatures, shapes and chronology of Italian Sigillata, Bonn, Halbert, $554 \mathrm{p} \mathrm{(2} 2^{\text {nd }}$ ed.).

Pion, P., Gransar, F. et Auxiette, G., 1996 - Les établissements ruraux dans la vallée de l'Aisne, de la fin du second âge du Fer au début du Haut-Empire romain (II siècle av. J.-C./I ${ }^{\text {er }}$ siècle apr. J.C.) : bilan provisoire des données et esquisses de synthèse, in BAYARD, D. et COLLART, J.-L., De la ferme indigène à la villa romaine (Actes du $2^{\mathrm{e}}$ colloque de l'association AGER, Amiens, septembre 1993), Revue archéologique de Picardie, $\mathrm{n}^{\circ}$ spécial 11, p. 55-107.

Polak, M., 2000 - South gaulish terra sigillata with potter's stamps from Vechten. Nimègues, Rei Cretarice Romance Fautorum Acta, Suppl. 9, 440 p.

Quevillon, S., 2007 - Un atelier paléométallurgique à Saint-Evrout-de-Monfort, in DELRIEU, F. et DESLOGES, J. (dir.), ArchéOrne, 250 ans d'archéologie dans l'Orne, Cabourg, Cahiers du Temps, p. 115.

Rivet, L., 2005 - Estampilles sur sigillées italiques du site dit « nord-est cathédrale » à Fréjus (Var), Marseille, Société française pour l'étude de la Céramique antique en Gaule, Actes du Congrès de Blois, p. 713-719.

Rütti, B., 1991 - Die römischen Gläser aus Augst und Kaiseraugst, Augst, Römermuseum (Forschungen in Augst, 13), 2 vol., $370+432$ p., 221 pl.

Seguier, J.-M. et Mallet, F., 2005 - Le faciès augustéen de la Plaine de France d'après le mobilier des établissements de Charny et de Compans (Seine-et-Marne), Marseille, Société française pour l'étude de la Céramique antique en Gaule, Actes du Congrès de Blois, p. 529-560.

Sellès, H., 1992 - Premières caractérisations des productions de terra nigra et de terra rubra à Chartres au Ier siècle, Marseille, Société française pour l'étude de la Céramique antique en Gaule, Actes du Congrès de Tournai, p. 163-180.

Sellès, H., 1998 - La céramique gallo-romaine précoce à Chartres, in TUFFREAU-LIBRE, M. et JACQUES, A. (dir.), La céramique précoce en Gaule Belgique et dans les régions voisines : de la poterie gauloise à la céramique gallo-romaine (Actes de la table ronde d'Arras, 14-17 octobre 1996), Berck-sur-Mer, Centre de Recherches archéologiques et de Diffusion culturelle (Nord-Ouest Archéologie, 9), p. 317-334.

Sellès, H., 2001 - Céramiques gallo-romaines à Chartres et en Pays carnute. Catalogue typologique, Revue archéologique du Centre de la France, Suppl. 16 - études sur Chartres, 1, 254 p.

Sennequier, G., 1985 - Verrerie d'époque romaine, Collections des Musées Départementaux de SeineMaritime, Rouen, Musées Départementaux de Seine-Maritime, 209 p.

Silvino, T., Poux, M. et Garnier, N. (coll.), 2005 - Où est passé le vin de Bétique ? Nouvelles données sur le contenu des amphores dites « à sauces de poisson et à saumures » de types Dressel 7/11, Pompéi VII, Beltran II ( $\mathrm{I}^{\mathrm{er}}$ siècle avant J.-C.-II ${ }^{\mathrm{e}}$ siècle après J.-C.), Marseille, Société française pour l'étude de la Céramique antique en Gaule, Actes du Congrès de Blois, p. 501-514. 
Simon, L., 2004a - Un ensemble céramique du milieu du II ${ }^{\mathrm{e}}$ siècle dans la cité des Sagiens : le site de Boue à Macé (Orne), Marseille, Société française pour l'étude de la céramique antique en Gaule, Actes du Congrès de Vallauris, p. 483-487.

Simon, L., 2004b - Le mobilier gallo-romain, in LE GAILLARD (L.), Creully - Le Clos de l'Epinette (DFS de diagnostic archéologique), Caen, SRA Basse-Normandie, p. 25-35, fig. 20-30.

Simon, L., 2007 - Le mobilier céramique de la zone d'habitat (zone 1), in FERRETTE, R. (dir.), Canchy (14), RN 13-RD 204, RFO de fouille, Caen, SRA Basse-Normandie, p. 103-148.

Simon, L., 2009 - La céramique, in BESNARD-VAUTERIN, C.-C. (dir.), En Plaine de Caen, Une campagne gauloise et antique : L'occupation du site de l'Étoile à Mondeville, Rennes, PUR, p. 183-195, fig. 162-211.

Simon, L., Jardel, K. et Mortreau, M., 2002 - Première approche des horizons céramiques de la Plaine de Caen (Calvados), de la Conquête à l'époque claudienne, Marseille, Société française pour l'étude de la Céramique antique en Gaule, Actes du Congrès de Bayeux, p. 11-50.

Vilvorder, F., 1990 - Les objets en fer, in BRULET, R. (dir.), Braives gallo-romain IV. La zone centreouest, Louvain-la-Neuve, Publications d'Histoire de l'Art et d'Archéologie de l'Université catholique de Louvain-la-Neuve (LXXVI), p. 72-74.

Watté, J.-P., 1990 - Le Néolithique en Seine-Maritime (Supplément. au Bulletin trimestriel de la Société géologique de Normandie et des Amis du Muséum du Havre), 3 vol., 797 p., 443 fig.

\section{NOTES}

1. . L'intersection F 2 et $\mathrm{F} 34$ a été détruite par un fossé médiéval (F 2093). Le croisement F 38/F 2 se situait sous les installations techniques liées à la fouille. Il n'a donc pu être mis en évidence.

2. Sa localisation se situerait à la hauteur de l'accès à la fouille.

3. . La typologie employée est celle de Y. Menez (1985), excepté pour les nº 19-21, relatifs à une forme caractéristique de la région Centre (Menez, 1989).

4. . Un sondage réalisé lors du diagnostic a détruit son côté est. Rappelons que c'est grâce à l'interruption du fossé F 61, qu'il a été possible de déduire que le F 98 de la phase 2 se prolongeait vers l'ouest.

5. . L'hypothèse d'une circulation à terme sur certains de ces radiers est à envisager. Elle suppose simplement un défaut d'entretien des sols du bâtiment. Un cas similaire existe par exemple sur la villa des Alleux à Taden (Côtes-d'Armor).

6. . Établie, à chaque fois, d'après le mobilier céramique.

7. . La datation des exemplaires de comparaison est donnée lorsqu'elle est mentionnée dans les publications citées.

8. . Les références typologiques employées renvoient à Isings, 1957 (typologie Is.) ; Rütti, 1991 (typologie AR); Bonnet Borel, 1997 (typologie AV V).

9. . Précisons que l'appellation OCG qualifie des productions à pâte orangée, rouge foncé ou brun et cœur gris, portant souvent un revêtement blanchâtre, la pâte étant riche en inclusions. Ces caractéristiques techniques se retrouvent principalement sur des amphores de type Pascual 1 et Dressel 2/4, plus rarement Gauloise 4. Elles ont été fabriquées sur le territoire de la Gaule, notamment à Crouzilles-Mougon (Indre-etLoire : Laubenheimer et al., 2005). Bien qu'attestées en faible quantité, elles ne sont pas 
absentes de la région Basse-Normandie, comme le montrent par exemple des découvertes du Calvados: Creully (Simon, 2004b; fragments de panse), Vieux (fragments), Touffréville (type Dressel 2/4) et Canchy (Simon, 2007 ; types Pascual 1 et Dressel 2/4). Les informations concernant Vieux et Touffréville sont issues de travaux inédits menés par F. Laubenheimer, K. Jardel et F. di Napoli; je les remercie de m'autoriser à les mentionner.

10. . Notamment sur le site des Ventes, au cours de la première moitié du $\mathrm{II}^{\mathrm{e}}$ siècle (information aimablement transmise par Y.-M. Adrian, qui en assure l'étude).

\title{
RÉSUMÉS
}

Une fouille préventive effectuée sur la commune de Ménil-Froger, non loin de la ville de Sées, a permis d'étudier un site dont l'occupation la plus ancienne remonterait au Néolithique moyen. L'essentiel des structures découvertes concerne cependant la période gallo-romaine. Elles appartiennent pour partie à un établissement agricole à enclos fossoyé, apparu après la Conquête. Cette exploitation évolue ensuite rapidement et son apogée est marqué au second siècle par la construction d'une villa qui semble abandonnée durant les premières décennies du siècle suivant. L'étude de ce site apporte un éclairage supplémentaire sur l'occupation du département de l'Orne durant l'époque gallo-romaine.

A preventive excavation at Ménil-Froger, near Sées, provided the opportunity to study a site whose first occupation goes back to Middle Neolithic. Nevertheless, most of the excavated features are of the Gallo-Roman period. They partly belong to a ditch-enclosed farmstead dating from after the Conquest. This develops rapidly and its peak is marked, in the 2nd century, by the building of a villa which seems to have been abandonned during the first decades of the following century. Study of this site throws a complementary light on the human occupation of the Orne during the Gallo-Roman period.

\section{INDEX}

Mots-clés : Orne, Néolithique, gallo-romain, ferme, enclos, villa, parcellaire

Keywords : Orne, Neolithic, Gallo-Roman, farmstead, enclosure, villa, field system

\author{
AUTEURS \\ ROMUALD FERRETTE \\ Inrap Grand-Ouest - 37 rue du Bignon, 35577 Cesson-Sévigné \\ LAURE SIMON
}

Inrap Grand-Ouest - 37 rue du Bignon, 35577 Cesson-Sévigné 